A UNITED STATES DEPARTMENT OF COMMERGE PUBLIGATION
National Bureaú of Standard’s Library, E-01 Admin. Bldg. DEC 221969

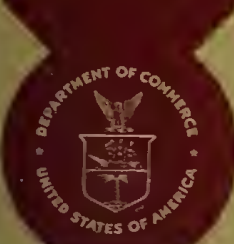

\title{
Activities of the \\ NBS Spectrochemical Analysis Section \\ July 1968 to June 1969
}




\section{NATIONAL BUREAU OF STANDARDS}

The National Burcau of Standards ' was cstablished by an act of Congress March 3, 1901. Today, in addition to scrving as the Nation's central measurement laboratory, the Bureau is a principal focal point in the Federal Government for assuring maximum application of the physical and cngineering sciences to the advancement of technology in industry and commerce. To this end the Bureau conducts rescarch and provides central national services in four broad program areas. These are: (1) basic mcasurements and standards, (2) materials measurements and standards, (3) technological measurements and standards, and (4) transfer of tcchnology.

The Bureau comprises the Institute for Basic Standards, the Institute for Materials Research, the Institute for Applied Technology, the Center for Radiation Research, the Center for Computer Sciences and Technology, and the Office for Information Programs.

THE INSTITUTE FOR BASIC STANDARDS provides the central basis within the United States of a complete and consistent system of physical measurement; coordinates that system with measurement systems of other nations; and furnishes essential services leading to accurate and uniform physical measurements throughout the Nation's scientific community, industry, and commerce. The Institute consists of an Office of Measurement Services and the following technical divisions:

Applied Mathematics-Electricity-Metrology-Mechanics-Heat-Atomic and Molecular Physics-Radio Physics "-Radio Engineering "-Time and Frequency"-Astrophysics "-Cryogenics."

THE INSTITUTE FOR MATERIALS RESEARCH conducts materials research leading to improved methods of measurement standards, and data on the properties of well-characterized materials needed by industry, commerce, educational institutions, and Government; develops, produces, and distributes standard reference materials; relates the physical and chemical properties of materials to their behavior and their interaction with their environments; and provides advisory and research services to other Government agencies. The Institute consists of an Office of Standard Reference Materials and the following divisions:

Analytical Chemistry_Polymers_Metallurgy_Inorganic Materials_Physical Chemistry. THE INSTITUTE FOR APPLIED TECHNOLOGY provides technical services to promote the use of available technology and to facilitate technological innovation in industry and Government; cooperates with public and private organizations in the development of technological standards, and test methodologies; and provides advisory and research services for Federal, state, and local government agencies. The Institute consists of the following technical divisions and offices:

Engineering Standards-Weights and Measures - Invention and Innovation - Vehicle Systems Research-Product Evaluation-Building Research-Instrument Shops-Measurement Engineering-Electronic Technology-Technical Analysis.

THE CENTER FOR RADIATION RESEARCH engages in research, measurement, and application of radiation to the solution of Bureau mission problems and the problems of other agencies and institutions. The Center consists of the following divisions:

Reactor Radiation-Linac Radiation-Nuclear Radiation-Applied Radiation.

THE CENTER FOR COMPUTER SCIENCES AND TECHNOLOGY conducts research and provides technical services designed to aid Government agencies in the selection, acquisition, and effective use of automatic data processing equipment; and serves as the principal focus for the development of Federal standards for automatic data processing equipment, techniques, and computer languages. The Center consists of the following offices and divisions:

Information Processing Standards-Computer Information - Computer Services — Systems Development-Information Processing Technology.

THE OFFICE FOR INFORMATION PROGRAMS promotes optimum dissemination and accessibility of scientific information generated within NBS and other agencies of the Federal government; promotes the development of the National Standard Reference Data System and a system of information analysis centers dealing with the broader aspects of the National Measurement System, and provides appropriate services to ensure that the NBS staff has optimum accessibility to the scientific information of the world. The Office consists of the following organizational units:

Office of Standard Reference Data-Clearinghouse for Federal Scientific and Technical Information "-Office of Technical Information and Publications-Library-Office of Public Information-Office of International Relations.

\footnotetext{
Headquarters and Laboratories at Gaithersburg. Maryland, unless otherwise noted; mailing address Washington, D.C. 20234.

${ }^{3}$ Located at 5285 Port Royal Road, Springfield, Virginia 22151.
} 


\title{
NBS TECHNICAL NOTE 502
}

ISSUED DECEMBER 1969

Nat. Bur. Stand. (U.S.), Tech. Note 502,108 pages (Dec. 1969) CODEN: NBTNA

\section{Activities of the NBS Spectrochemical Analysis Section July 1968 to June 1969}

\author{
Edited by Bourdon F. Scribner \\ Spectrochemical Analysis Section \\ Analytical Chemistry Division \\ Institute for Materials Research \\ National Bureau of Standards \\ Washington, D.C. 20234
}

\begin{abstract}
NBS Technical Notes are designed to supplement the Bureau's regular publications program. They provide a means for making available scientific data that are of transient or limited interest. Technical Notes may be listed or referred to in the open literature.
\end{abstract}

For sale by the Superintendent of Documents, U.S. Government Printing Office, Washington, D.C., 20402 (Order by SD Catalog No. C13.46:502), Price $\$ 1.00$ 


\section{FOREWORD}

The Analytical Chemistry Division was established as a separate division at the National Bureau of Standards on September 1, 1963, and became part of the Institute for Materials Research in the February 1, 1964, reorganization. It consists at present of nine Sections and about 100 technical personnel encompassing some 45 different analytical competences from activation analysis and atomic absorption to vacuum fusion and $x$-ray spectroscopy. These competences, and in turn the Sections which they comprise, are charged with research at the forefront of analysis as well as awareness of the practical sample, be it standard reference material or service analysis. In addition it is their responsibility to inform others of their efforts.

Formal publication in scientific periodicals is a highly important output of our laboratories. In addition, however, it has been our experience that informal, annual summaries of progress describing efforts of the past year can be very valuable in disseminating information about our programs. A word is perhaps in order about the philosophy of these yearly progress reports. In any research program a large amount of information is obtained and techniques developed which never find their way into the literature. This includes the "negative results" which are so disappointing and unspectacular but which can often save others considerable work. Of importance also are the numerous small items which are often explored in a few days and which are not important enough to warrant publication -- yet can be of great interest and use to specialists in a given area. Finally there are the experimental techniques and procedures, the designs and modifications of equipment, etc., which often require months to perfect and yet all too often must be covered in only a line or two of a journal article. 
Thus our progress reports endeavor to present this information which we have struggled to obtain and which we feel might be of some help to others. Certain areas which it appears will not be treated fully in regular publications are considered in some detail here. Other results which are being written up for publication in the journal literature are covered in a much more abbreviated form.

At the National Bureau of Standards publications such as these fit logically into the category of a Technical Note. In 1969 we plan to issue these summaries for all of our sections. The following is the fifth annual report on progress of the Spectrochemical Analysis Section.

W. Wayne Meinke, Chief Analytical Chemistry Division 


\section{PREFACE}

This is the fifth in a series of annual progress reports of the Spectrochemical Analysis Section of the Analytical Chemistry Division. The Section is concerned with instrumental elemental analysis, especially for those spectioscopic techniques that are capable of multi-element determinations. These include optical, $x$-ray, and mass spectroscopy

Chemical elements are uniquely identified by the characteristic frequency of emitted spectra, and amounts present can be determined by measurement of the intensity of emitted radiation. However, many factors enter into successful spectral analysis and must be carefully controlled. These include, in optical and $x$-ray spectrometry, the production of radiant energy by excitation, the dispersion of radiant energy into a spectrum, and the measurement of spectral wavelengths and intensities. In a similar way, spark source mass spectrometry involves ion formation, dispersion into a mass spectrum, and measurement of intensities for recorded masses. In general these are methods of comparative analysis in which calibration by synthesized or analyzed standards is required.

The research program of the Section is directed largely toward a better understanding of the phenomena involved in producing and measuring optical and x-ray emitted energy and mass spectra, and the improvement of spectrochemical methods, instruments, and calibration procedures. Included in the work of the Section are the development of appropriate standard reference materials, analyses of materials to assist other research projects, and literature surveys such as bibliographies and critical reviews. 
The purpose of this report is to review the program, facilities, and accomplishments of the section for the past year.

In order to specify procedures adequately, it has been necessary occasionally to identify commercial materials and equipment in this report. In no case does such identification imply recommendation or endorsement by the National Bureau of Standards, nor does it imply that the material or equipment identified is necessarily the best available for the purpose.

Bourdon F. Scribner, Chief Spectrochemical Analysis Section 
1. INTRODUCTION ........... 1

A. Facilities . . . . . . . . . . . . . I

B. Activities . . . . . . . . . . . . . 2

2. OPTICAL SPECTROMETRY . . . . . . . . . . . . . 7

A. High-aperture Spectrograph . . . . . . . . 8

B. Microanalysis in the DC Arc . . . . . . . . . 14

C. Computer Programs . . . . . . . . . . . . 16

D. Future Computer Applications . . . . . . . 18

E. Applications to Analysis . . . . . . . . . . 23

1. Standard Reference Materials . . . . . . 23

2. Other Analyses.......... . . 26

3. ELECTRON PROBE MICROANALYSIS . . . . . . . . 30

A. Quantitative Analysis . . . . . . . . 30

B. Standard Reference Materials . . . . . . . . 31

C. Non-diffractive Techniques of Qualitative and

Semi-quantitative Analysis . . . . . . . . . 34

ע. New Technique and Instrumentation for Target Current Scanning. . . . . . . . . . 38

E. Further Improvements in Target Current

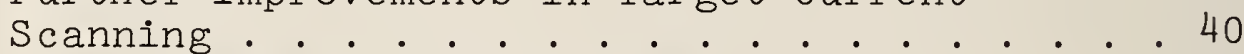

F. Color Composite X-ray Scans . . . . . . . . 44

G. Applications to Analysis . . . . . . . . . 45

H. Literature Research . . . . . . . . . . 46

4. X-RAY FLUORES CENCE SPECTROMETRY . . . . . . . . 47

A. Research Activities . . . . . . . . . 47

B. Applications . . . . . . . . . . . . . 49

C. Contributions of NBS Personnel . . . . . . . 51

5. SPARK SOURCE MASS SPECTROMETRY . . . . . . . . 52

A. Instrument Modifications . . . . . . . . 52

l. Source Pump . . . . . . . . . . . . 52

2. New Pump for Plate Prepump Section . . . 53 
B. Use of 100-mesh Grids to Remove Matrix

C. Plate Development : . . . . . . . . . . . : . . . . . 55

D. Homogeneity Testing of Iron in High Purity Gold SRM 685...............59

E. Analysis of High Purity Materials . . . . . .60

F. Survey Analysis of a Steel Sample . . . . . .61

G. Trace Characterization of Spark Source Ion Samples of SRM Platinum 681 . . . . . . 64 1. Introduction . . . . . . . . . . . 64 2. Results .............. . 64 3. Discussion . . . . . . . . . . 68

6. PRECONCENTRATION TECHNIQUES . . . . . . . . 70

A. High Purity Metals . . . . . . . . . . 70

B. Ingot Iron and Steels . . . . . . . . . 71

C. Simulated Lunar Glasses . . . . . . . . . . 72

D. Ultra-Pure Liquid Reagents . . . . . . . 73

7. PERSONNEL AND ACTIVITIES . . . . . . . . . . 74

A. Personnel Listing . . . . . . . . . . 74

B. Publications . . . . . . . . . . . . 75

C. Talks Given . . . . . . . . . . . . 77

D. Committee Activities . . . . . . . . . 80

8. ACKNOWLEDGMENTS . . . . . . . . . . . 82

9. LIST OF REFERENCES . . . . . . . . . . . . 83

APPENDIX: Typical certificates for NBS Standard

Reference Materials.......... 85

A. SRM 682 High-Purity Zinc . . . . . . . . 85

B. SRM 683 Zinc Metal. . . . . . . . . . 87

C. SRM 685 High-Purity Gold... . . . . . 89

D. SRM 481 Gold-Silver Wires for Microprobe Analysis . . . . . . . . . . . . . . .91

E. SRM 1051b Barium Cyclohexanebutyrate. . . . 95

F. SRM 1159, 1160 Electronic and Magnetic Alloy Standards . . . . . . . . . . . . 97

G. SRM 1800 Microstandard Ion-Exchange Beads . 99 


\section{LIST OF FIGURES}

FIGURE NO.

PAGE

1. Microphotometer tracings of $3100 \AA$ region of spectra of NBS SRM II6I . . . . . . . . . . 9

2. Diagram of circuit for observation of timeresolved and time-integrated spectral intensities . . . . . . . . . . . . . . . . Il

3. Emission intensity vs time for the $\mathrm{Cu} 3247 \AA$ line with laser-plus-spark excitation . . . 13

4. Emission intensity vs time for the $\mathrm{Cu} 3247 \AA$ line excited by the laser without spark. . I Is

5. Analytical functions fitted by two operators using the program CFIT2 . . . . . . . . . 17

6. Drop of anomalous water, approximately $l \mu g \cdot \cdot 28$

7. Same sample of anomalous water after sampling with the laser probe .......... 28

8. Integral measurements of intensities of $\mathrm{Ca} \mathrm{K} \alpha$ and $\mathrm{S} K \alpha$ from ion exchange resin beads loaded with $\mathrm{Ca}$. . . . . . . . . . . . . .

9. Non-diffractive spectra obtained at $20 \mathrm{keV}$ and $2 \times 10^{-8} \mathrm{~A}$, in 4 minutes ........

10. Spectrum of a $\mathrm{Cu}-\mathrm{Au}$ alloy obtained with the silicon detector, and reconstructed on the

11. Schematic diagram of the target current amplifier with linear and derivative component.

12. Target current signal . . . . . . . . . 40

13. Target current scans of titanium boride contaminated with iron

14. Scanning target, current image of human tooth............. 42

15. Target current of metal grids . . . . . . . 43

16. Scanning electron micrograph of a partially recrystallized lamp filament 
17. Determination of $\mathrm{Ni}$ in $\mathrm{Ni}-\mathrm{Fe}-\mathrm{Cr}-\mathrm{Co}$ alloy by x-ray fluorescence........ 50

18. Rebuilt source pumping system . . . . . . . 54

19. New pumping system for photographic plates . . 55

20. Exposures of Pt SRM 681 with and without a 100-mesh Au grid ......... . 56

21. Mass spectrum of Pt SRM 681 without grid, using

Cavard's developer . . . . . . . . . 57

22. Mass spectrum of Pt SRM 681 with grid, using D-19 developer .......... . 58

23. Mass spectrum of Pt SRM 681 with grid, using Cavard's developer ......... 58

24. Normalized ion beam measurements of trace elements in spark source ion sample Pt $\mathrm{SRM}$. . . . . . . . . . . . . 65

\section{LIST OF TABLES}

TABLE NO.

1. Standard reference materials of interest for spectrometric applications . . . . . . 5

2. Detection limits by the semi-micro arc method ( $0.5 \mathrm{mg}$ sample) and the copper spark .. . 15

3. Proposed low alloy steel SRM . . . . . . 24

4. Analyses of copper-gold alloys by nondispersive detection and pulse height analysis... . 38

5. X-ray absorptiometric analysis of metal foil synthetic standards........... . 48

6. Homogeneity tests for iron in gold SRM 685 . 59

7. Analysis of high-purity tin SRM 741 . . . . 61

8. Mass spectrometric survey analysis of steel using a standard . . . . . . . . . . 62 
9. Mass spectrometric survey analysis of steel using estimated sensitivity factors . . . . .63

10. Interdependence of trace element fluctuations in spark source ion sample of Platinum SRM

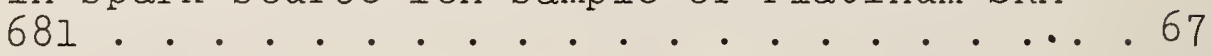

11. Analysis of spark source ion samples Platinum

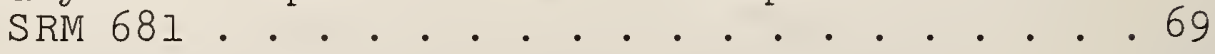


ACTIVITIES OF THE NBS SPECTROCHEMICAL ANALYSIS SECTION

July 1968 through June 1969

Edited by Bourdon F. Scribner

ABSTRACT

Spectrochemical research activities, improvements in equipment, and applications are summarized. In optical emission spectrometry micro methods were investigated and computer programs were completed for fitting analytical curves. In electron probe microanalysis studies of corrections for quantitative analysis and new gains in non-diffractive analysis and target current scanning were made. X-ray absorptiometry was applied to the analysis of thin metal foils and computer programs were improved for correction of $x$-ray fluorescence analysis. Chemical pre-concentration of impurities combined with isotope dilution spark source mass spectrometry found increased application in accurate trace analysis. Resolution of the mass spectrometer was improved and the behavior of ion samples was studied. Extensive involvement in the standard reference materials program contributed to certification of several SRM's including high purity $\mathrm{Zn}$ and $\mathrm{Au}$, two sets of wires, $\mathrm{Au}-\mathrm{Ag}$ and $\mathrm{Au}-\mathrm{Cu}$, for microprobe analysis, and electronic and magnetic alloys. Listings are given of 21 publications and 29 talks by members of the section during the year.

Key words:

Analytical curve functions, color composite, computer programs, electron probe, gold analysis, isotope dilution method, laser probe, metal foil analysis, microanalysis, nondiffractive x-ray spectra, optical spectrometry, platinum analysis, preconcentration techniques, spark source mass 
spectrometry, spectrochemical analysis, spectrograph, standard reference materials, steel analysis, target current scanning, trace analysis, $x$-ray absorptiometry, $x$-ray fluorescence analysis, $x$-ray scans. 


\section{INTRODUCTION}

In the four preceding annual reports in this series $[1,2,3,4]$ we have described the facilities and program of the Section in some detail and references to the past reports will be found in several places in the current report. Copies of the earlier reports are available on request. In each report, the research activities and the output in terms of publications, talks given, and analytical work have been recorded. This report follows the same format to present a description of our efforts and accomplishments for the past year. In the introduction we will summarize the major activities of the Section.

\section{A. Facilities}

The major equipment of the Section includes the following.

3-meter Eagle mounting grating spectrograph

3.4-meter Ebert mounting grating spectrograph

21-foot Wadsworth mounting grating spectrograph

2-meter multi-channel optical spectrometer

3-meter multi-channel optical spectrometer

1.5-meter multi-channel vacuum optical spectrometer

0.75-meter Ebert mounting, scanning spectrometer

0.75-meter Czerny-Turner mounting spectrograph/spectrometer Multi-channel x-ray fluorescence spectrometer

Single-channel vacuum $x$-ray fluorescence spectrometer Electron probe microanalyzer with 3 x-ray spectrometers Spark source mass spectrograph

Accessory equipment includes microphotometers, sample preparation devices, microscopes, teletypewriter readout devices, etc. One facility that we continue to find highly useful to our work is a teletypewriter terminal located in our laboratory and connected by wire to a remote time-sharing computer service. The NBS computer facility is available for 
large batch-loading jobs such as calculations on studies of homogeneity of standard reference materials.

During the past year no major equipment accessions were made although certain spectrometric equipment, such as the multi-channel x-ray spectrometer, should be considered for replacement in the near future. Improvements in existing equipment were made to obtain better speed, resolution, or new applications. These include an efficient illuminating system for the high-speed Czerny-Turner mounting spectrograph, use of non-diffractive detector system and improved target current scanning in electron microprobe analysis, and improved pumping systems for the spark source mass spectrometer.

\section{B. Activities}

The laboratory is organized into four major groups with the personnel listed in section 7 of this report. The groups are optical spectrometry, $x$-ray spectrometry, spark source mass spectrometry, and enrichment techniques. In addition to 15 full-time employees, there are usually 3 to 4 summer assistants who have contributed effectively to the program. Two persons were supported by outside agencies: Dr. Jean Hénoc, guest worker, from the Centre National d'Etudes des Telécommunications, France, and Barry L. Hammond, research associate, from the Naval Ship Research and Development Center, Annapolis, Md.

This year a research contract on Counterpart Funds was monitored by our Section. The contract work, located at the Atomic Energy Commission, Soreq, Israel, under Mrs. Sima Held, was applied to trace analysis problems relating to standard reference materials.

The activity of the Section is divided approximately equally between ( 1 ) general research and development and (2) service activities involving spectrometric analyses for 
certification of standard reference materials, analyses for other projects at NBS, and development and analyses for other Government laboratories. Research activities are directed toward improvements in spectrometric instrumentation and methods of analysis leading to increased sensitivity, precision, and accuracy. This involves the study of sources of error and the development of models and devices for correction of measurements to arrive at more accurate results. Because of complexities in calibration and corrections, considerable reliance is placed on high speed computer operations.

In optical spectrometry a high-aperture spectrograph was applied to microanalysis by laser initiated spark discharges, and microanalysis in the dc arc was improved by a special technique for handling small samples, less than $1 \mathrm{mg}$. Because of the importance of automated operations in emission spectroscopy, considerable attention was given to completing work on two computer programs, one for computations in calibration of photographic emulsions and the other for computations for fitting analytical functions, the mathematical equivalent of analytical curves. Following this work a critical survey of future computer applications was made and is discussed in this report.

The effort in electron probe microanalysis continued with strong emphasis on the study of corrections for quantitative analysis; this resulted in an extensive FORTRAN sub-program for determining the effect of fluorescent radiation excited by the continuum. Another program was developed for computations involved in multi-point homogeneity tests on a micro scale. The latter was applied in the characterization of two sets of wires for microprobe standard reference materials. Other studies included non-diffractive techniques for rapid qualitative and semi-quantitative analysis by the microprobe and a new technique for target current scanning. Finally, improvements were made in color composite $x$-ray scanning images by including topographic information. 
$\mathrm{X}$-ray spectrometry was extended to the area of $\mathrm{x}$-ray absorptiometry which proved to be applicable to simultaneous determination of the composition and mass per unit area of thin metal foils. Improvement was made in the program for calibration and correction for interelement interferences in $\mathrm{x}$-ray fluorescence analysis.

The resolution and sensitivity of spark source mass spectrometry were improved for cases where weak lines appear close to strong lines of the major constituent. The gain in resolution is well illustrated in a series of tracings. Analyses of high-purity materials with respect to the performance of the mass spectrograph were studied, especially for the analysis of platinum, gold, and tin.

Methods for the preconcentration of impurities combined with isotope dilution and spark source mass spectrometry have proved highly effective for the analysis of high-purity materials. These methods involve deposition of the concentrated impurities on gold wires which serve as electrodes in the mass spectrograph. The methods were applied to the analysis of platinum, zinc, and gold. The methods were extended to the determination of trace elements in ingot iron and are being investigated for application to the analysis of glass and chemical reagents.

The effort in standard reference material characterization has been especially effective this year. The analysis of standards often poses severe problems which generatie research and development in the section. It will be of interest to summarize the status of work on numerous standards on which we are engaged.

The Section contributed a major effort to the certification of 21 standard reference materials issued during the year. These standards, of special utility in spectrometric analysis, are listed in Table 1 . 
Table 1. Standard reference materials of interest for spectrometric applications

SRM NO.

Title

Date Issued

High purity metals:

$\begin{array}{ll}\text { 682* } & \text { High Purity Zinc } \\ 683^{*} & \text { Zinc Metal } \\ 728 & \text { Intermediate Purity Zinc } \\ 685^{*} & \text { High Purity Gold }\end{array}$

July 1968

July 1968

July 1968

September 1968

Microprobe standards:

$\begin{array}{ll}480 & \text { Tungsten-20\% Mo alloy } \\ 481 * & \text { Gold-Silver Wires } \\ 482 & \text { Gold-Copper Wires }\end{array}$

November 1968 February 1969

June 1969

Organo-metallic for oil analysis

105lb* Barium Cyclohexanebutyrate

$1055 \mathrm{~b}$

Cobalt Cyclohexanebutyrate

$1057 \mathrm{~b}$

Dibutyltin Bis(2-ethylhexanonate)

1069b Sodium Cyclohexanebutyrate

1079b Tris (1-phenyl-1, 3-butanediono) iron (III)

1080a Bis (1-phenyl-1, 3-butane-

$1066 a$ octaphenylcyclotetrasiloxane

Biomedical standards:
912
913
Urea
Uric acid
Creatinine
914
Calcium Carbonate
915

July 1968

July 1968

August 1968

February 1969

February 1969

February 1969 April 1969

Metal alloys:

1159,1160* Electronic and Magnetic Alloy Standards

February 1969

Microstandard:

$1800 *$

Ion-Exchange Beads

Calcium Loaded

September 1968

September 1968

September 1968

March 1969

March 1969

* Certificate reproduced in Appendix 
Selected typical certificates have been reproduced in the Appendix to this report, as indicated in the footnote to Table 1. The contributions of analysts to the certification work are acknowledged on the certificates.

Other SRM's of interest for calibration in spectrometric analysis are in course of preparation and certification. Included are a set of five special steels to replace the earlier NBS low-alloy steels, two soda lime glasses in plate form, glasses for impurity elements, three high temperature alloys, and several biomedical and metallo-organic standards.

Analyses made by the groups in the section during the 12-month period June 1, 1968 through May 31, 1969 are as follows.

Method

Optical emission

Electron microprobe $\mathrm{X}$-ray fluorescence

Spark source mass

Total
Samples

691

42

91

$\underline{27}$

851
Determinations

11,607

6,202

601

799

19,209
Reports

117

21

22

12

172

These analyses include both service work and characterization of standard reference materials. Descriptions of some especially interesting analyses are given at appropriate places in the report.

B. F. Scribner 


\section{OPTICAL SPECTROMETRY}

During this year, work has been completed on the testing of computer programs for calibrating photographic emulsions and for fitting analytical curves. The development and testing of these programs has given new insight into the problems. As a result of this work, two manuscripts have been prepared which describe both the methods of computation and other scientific results of the study.

Looking ahead to future developments, a study has been made of potential benefits of more elaborate computations in spectrochemical analysis, since modern computers make it possible to carry out such computations in a short time and at a very reasonable cost. It was concluded that it will be desirable to develop instrumentation which will permit the scientist to obtain very much more data from an emission spectrum than is possible with existing equipment. A reasonable extrapolation of earlier work here and in other laboratories indicates that further automation can greatly improve the speed and accuracy of spectrochemical analysis while reducing the human effort.

Installation of a new spectrometer/spectrograph for use with the laser probe source, and also with other weak light sources, is essentially complete, and studies of its capabilities are underway. The new instrumentation has already made it possible to detect seven elements in a speck of dust, about $20 \mu \mathrm{m}$ on a side and estimated to weigh about $0.1 \mu \mathrm{g}$.

A dc arc method has been developed for samples weighing a few tenths of a milligram. This method is needed for samples which are too small for normal arc analysis, requiring several milligrams, yet are larger than the microgram samples normally analyzed by the electron microprobe or the laser probe. The semi-micro method has detection limits comparable to those obtained with copper spark excitation, but has the advantage that solid samples can be analyzed conveniently. 
Determination of the accuracy and precision of the semi-micro method are not complete, but preliminary results are encouraging.

Approximately 50 percent of the effort in optical spectrometry has been devoted to the characterization of standard reference materials and to service analyses for other projects at NBS.

A. High-aperture Spectrograph

The last publication in this series [4] showed an $\mathrm{f} / 6.3$ spectrograph which had just been installed, primarily for use with the laser probe but also for work with other lowintensity light sources. The auxiliary components of this spectrograph have now been received, except for an achromatic lens, and installed. The achromatic lens, which is being fabricated in the NBS optical shop, will be needed when uniform slit illumination is required for quantitative analysis.

The auxiliary components which have been installed include the Cassegrain collimator for efficient illumination of the spectrograph and electronic circuitry permitting time-resolved spectroscopy of the laser plume and/or the spark. An arc/spark stand has also been purchased for use with other light sources. It has been specially modified so that it can be used with the Cassegrain collimator.

Figure 1 gives a direct comparison of spectra recorded on the $\mathrm{f} / 6.3$ Czerny-Turner spectrograph (lower trace) and the 2l-ft. Wadsworth spectrograph previously used with the laser probe. The spectra were taken nearly five years apart, but every effort was made to duplicate the excitation conditions. The sample was NBS Standard Reference Material 461, a low-alloy steel containing $1.73 \%$ nickel. The spectral region scanned on the plates includes the $3100 \AA$ iron triplet, which was a weak feature in these spectra because the spark was operated at maximum capacitance and voltage and minimum inductance and 


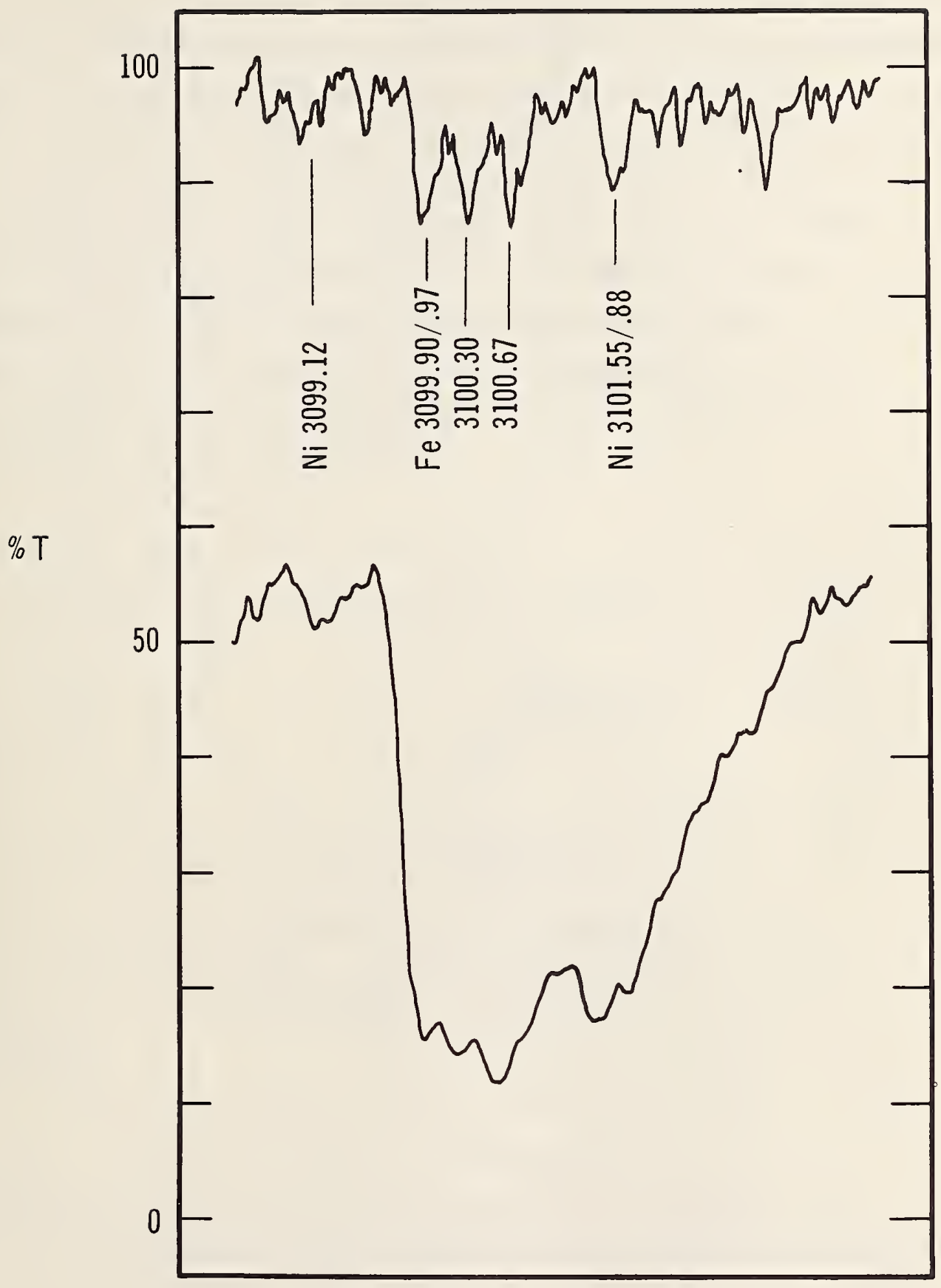

Figure 1. Microphotometer tracings of $3100 \AA$ region of spectra of NBS SRM 1161. Spectra were photographed on a 2I-ft. Wadsworth-mount spectrograph (upper curve) and a 0.75-m CzernyTurner-mount spectrograph (lower curve). 
resistance, thus favoring lines of the ionized atoms. The scanning speed of the microphotometer was twice as fast for the Wadsworth spectrograph as for the Czerny-Turner spectrograph, in order to compensate for the difference in linear reciprocal dispersions of the two instruments ( 5 vs $10 \AA / \mathrm{mm}$ ).

The triplet could just barely be seen by eye on the plate taken on the Wadsworth spectrograph. This is confirmed by the upper tracing in Figure 1 , where the peak heights are only two to three times the noise level of the photographic plate (103-0). The background in the exposure is not detectably different from the clear, unexposed portion of the plate. In contrast, the lower trace, of the plate taken on the new spectrograph, shows the triplet as a prominent group of lines on a background having a transmittance near 50\%, which is approximately the optimum background level for detection of a weak line [5].

Two nickel lines appear on the lower trace, while on the upper trace one of these lines is absent and the other appears only slightly above the noise level. To the right of the 3101 \& nickel line on the upper trace, there appears another apparent line of equal intensity. This line does not show up on the lower trace, and no line could be found in the standard wavelength tables which would be expected to show up in this position under the exposure conditions used. In fact, this apparent line is probably noise.

Figure 1 also shows the loss in resolution that can be expected with the spectrograph of lower dispersion. Because of the high light-gathering power of the new spectrograph, the exposures could have been made with a narrower slit, thus improving the resolution. In this case, the use of a narrower slit would not have helped very much, since the resolution is largely controlled by the granularity of the fast emulsion used to photograph the spectra (103-0 plate). With a stable light source and photoelectric recording, or with a finegrained emulsion such as SA-1, the spectrograph is capable 
of clearly resolving the iron triplet.

The electronic circuitry for time-resolved spectroscopy was designed and built by Mr. Walter Brenner of the Electronic Instrument Section of NBS. Figure 2 shows a schematic diagram of the circuit. The low-level signal from the photomultiplier goes first to a preamplifier which is contained within the photomultiplier housing; this avoids problems which might have been encountered if the low-level signal were carried out to an amplifier, due to pickup of noise from the flashlamp or the spark. The signal from the preamplifier is amplified further and sent to both the Y-axis input of the oscilloscope and to an integrator.

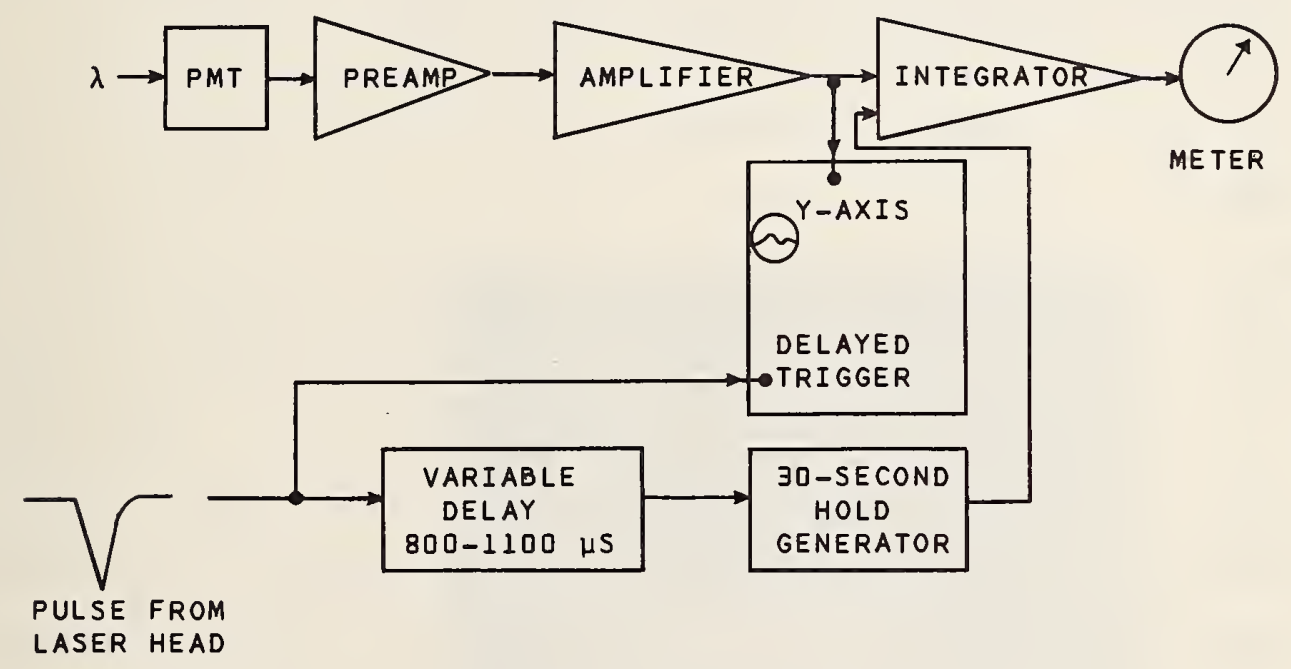

Figure 2. Diagram of circuit for observation of time-resolved and time-integrated spectral intensities. 
The oscilloscope sweep and the integrator are both controlled by an electrical pulse from the laser head. This pulse triggers the flashlamp, and it thus comes at a fixed time before lasing. The pulse from the laser head goes directly to the sweep trigger of the oscilloscope; the oscilloscope has an adjustable delayed sweep. The pulse also goes through a 800- to 1100- $\mathrm{s}$ delay and to a 30-s hold generator. This results in a signal to the integrator which is delayed relative to the pulse from the laser head and lasts for $1 / 2$ minute.

In the absence of this control signal, the integrator operates. However, the small dark-current signal from the photomultiplier bleeds off as fast as it arrives, and no net integrated signal is indicated. The arrival of a larger signal from the photomultiplier causes the meter to show the accumulated signal. On arrival of the control pulse, the meter locks on the signal and holds it until the control signal ends 30 s later.

Figures 3 and 4 illustrate the performance of the circuit in time-resolved spectroscopy. They are tracings of the course of intensity with time for the Cu 3247 \& line with a sample of copper metal in the laser probe source. Because of the high intensity of this line, much of the light signal was deliberately wasted (by removing the Cassegrain collimator) and the amplifier was operated at a low gain. Figure 3 shows a tracing, at a sweep rate of $10 \mu \mathrm{s} /$ large division, of the intensity when the laser is operated with spark cross-excitation. Figure 4 shows the course of intensity with time, at the same sweep rate, for the laser plume without cross excitation.

The time resolution achieved with this circuit is about $0.3 \mu \mathrm{s}$, as gauged by viewing the dark-current noise pulses on the oscilloscope. Even at the most sensitive amplifier settings, no pickup of noise could be seen on the oscilloscope trace or the integrator when the laser and spark were 


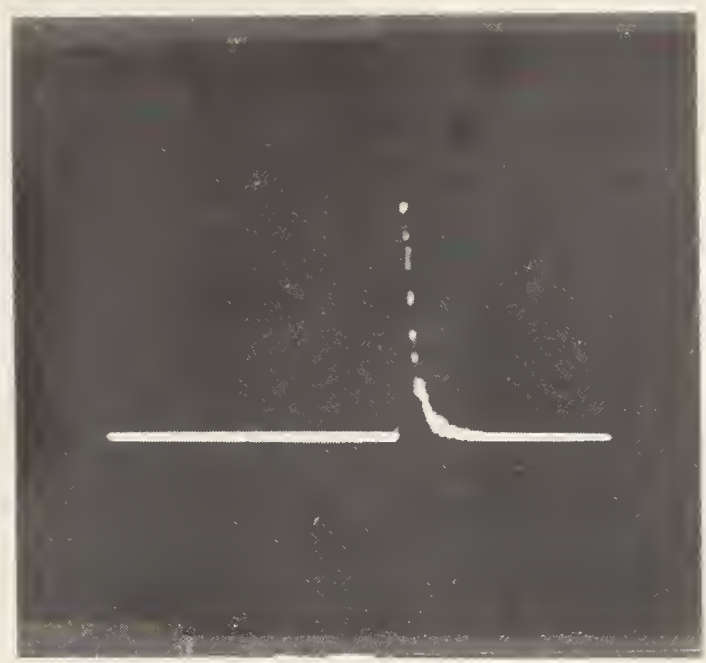

Figure 3. Emission intensity vs time for the $\mathrm{Cu} 3247 \AA$ line with laser-plus-spark excitation. Sweep rate was $10 \mathrm{~ms}$ for the trace width.

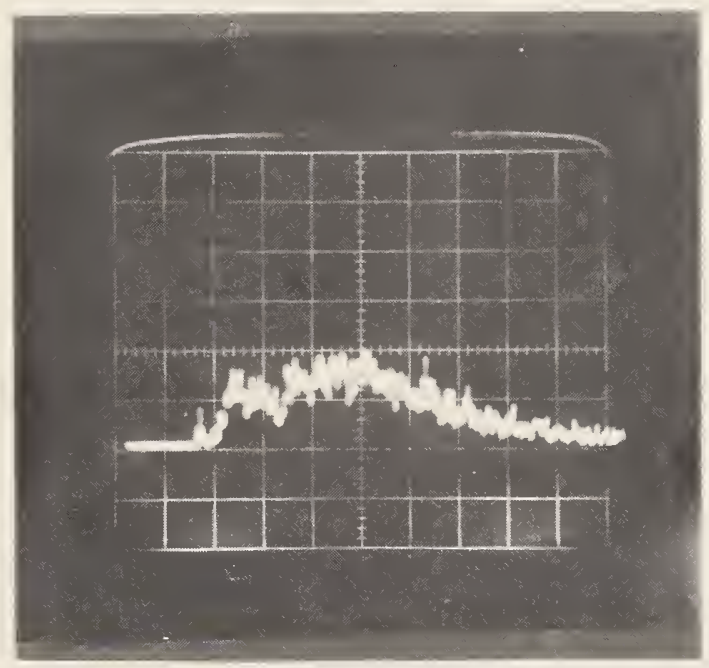

Figure 4. Emission intensity vs time for the $\mathrm{Cu} 3247 \AA$ line excited by the laser without spark. Sweep rate same as in Figure 3 . 
fired but the slit of the spectrograph was closed.

Successful operation of this circuitry will allow us to study in detail the course of events in the laser plume, with and without spark cross-excitation. The information thus obtained should be helpful in improving the efficiency of excitation. Data published by Piepmeier and Malmstadt [6] suggest that the spark may be triggered by arrival at the electrodes of a cloud of electrons moving ahead of the atoms and ions from the sample. If this tentative finding is confirmed by further studies, it appears that it will be necessary to arrange for a new way of triggering the spark so that the discharge is held off until the arrival of the sample cloud.

B. Microanalysis in the DC Arc

Frequent need arises in this laboratory for the semiquantitative analysis of microscopic samples, weighing considerably less than the 5 to $25 \mathrm{mg}$ normally needed for a spectroscopic analysis. Some are materials which are inherently difficult to prepare, such as an isotopically-enriched lead which we have recently analyzed. Another type of sample recently analyzed was the very small amount of ash obtained by dry ashing a 40-g sample of pure polymer.

We have for some time been using a semi-quantitative method of analysis based on dilution of the sample with gallium oxide. This has been successful with larger samples, but with smaller samples the detection limits were not always satisfactory. Modification of the method has allowed us to obtain improved detection limits for these small samples.

The material to be analyzed, up to $1 \mathrm{mg}$, is placed in a polytetrafluorethylene (Teflon) capillary tube, $2 \mathrm{~mm}$ long, with the bottom sealed by a small piece of wax film. Up to $1.5 \mathrm{mg}$ of gallium oxide, depending on the sample weight, is added, and the tube is placed in the crater of a $1 / 8-i n$. 
electrode. The sample is arced at $5 \mathrm{~A}$ for $5 \mathrm{~s}$ and $15 \mathrm{~A}$ for $15 \mathrm{~s}$ in an atmosphere of $70 \% \mathrm{O}_{2}-30 \% \mathrm{Ar}$. The spectra are recorded photographically on a 3.4-m Ebert-mount spectrograph.

Typical detection limits for a $0.5 \mathrm{mg}$ sample with this method are listed in Table 2. They are given in nanograms of the elements, for direct comparison with the data of Nachtrieb [7] for the copper spark method. The copper spark method is more sensitive for some elements and less sensitive for others, but the dc arc method has the advantage that the sample does not have to be dissolved.

Table 2. Detection limits by the semi-micro arc method ( $0.5 \mathrm{mg}$ sample) and the copper spark.

\begin{tabular}{lcc} 
Element & Limit of Detection (nanograms) \\
\cline { 2 - 3 } & $\frac{\text { DC arc }}{2}$ & Copper spark \\
$\mathrm{Cu}$ & 0.5 & -- \\
$\mathrm{Fe}$ & 25 & 50 \\
$\mathrm{Mg}$ & 20 & 1 \\
$\mathrm{Mn}$ & 10 & 2 \\
$\mathrm{Ni}$ & 10 & 10 \\
$\mathrm{Zn}$ & 50 & 200
\end{tabular}

The good sensitivity of the dc arc method probably arises from a combination of factors. It is likely that fluorine from the capillary tube assists in the vaporization of some of the elements through the formation of volatile fluorides. The gallium oxide may also act as a carrier, although its primary purpose is to provide a common matrix. The use of a small electrode reduces the time for total sample evaporation, thus keeping background to a minimum. The controlled atmosphere also helps to reduce background. 
The detection limits can sometimes be improved by appropriate modification of the method. For example, with the use of an undercut electrode and a lower arc current, the detection limits for cadmium and zinc can be reduced by about a factor of four. However, this gives poorer detection limits for some of the other elements.

It may also be possible to further reduce the amount of sample required by the use of a high-aperture spectrograph. It is for this reason, among others, that the $\mathrm{f} / 6.3 \mathrm{spec-}$ trograph purchased for use with the laser probe has been equipped with an arc/spark stand.

\section{Computer Programs}

Previous Annual Reports [2, 3, 4] have mentioned some of the computer programs that have been developed for spectrochemical analysis. NBS Technical Note 407 [8] describes some of the applications, and the Supplement to this Technical Note lists several of the programs together with detailed descriptions of the computation procedures and instructions for use. Two manuscripts have been prepared which describe in detail the computations and evaluate the results obtained. One paper [9] is concerned with the program KAISER for the computations in calibration of photographic emulsions. Extensive tests have shown that the procedure will give good results with most emulsions employed in spectrochemical analysis, provided that the microphotometer is in good adjustment.

A second paper [10] is concerned with procedures for fitting analytical functions, the mathematical equivalent of analytical curves. The programs used for this purpose by us are of two types. In one group of programs, which differ primarily in the form of output, the computations are carried out on a computer permitting conversational-mode operation, and decisions on the form of the equation and whether or not to reject any of the standards are made by the user. The 
BASIC program DRFIT and the FORTRAN program PRESTO include algorithms for making these decisions, and can be used with a batch-operated computer.

Neither procedure for fitting analytical functions is flawless. In this laboratory we must frequently develop new methods of analysis, and it occasionally happens that the calibration data are poorly correlated. When this happens, the functions selected are not always acceptable. This can also happen in other laboratories; the calibration data plotted in Figure 5 are taken from ref. [11]. The two curves drawn in the figure are those selected by two users of the program CFIT2, one of the programs employing conversationalmode operation and decisions by the user. In this case, neither user noted that the standard of lowest silicon content gave a point which did not fit on the same curve as the points for the other standards. The objection to the functions

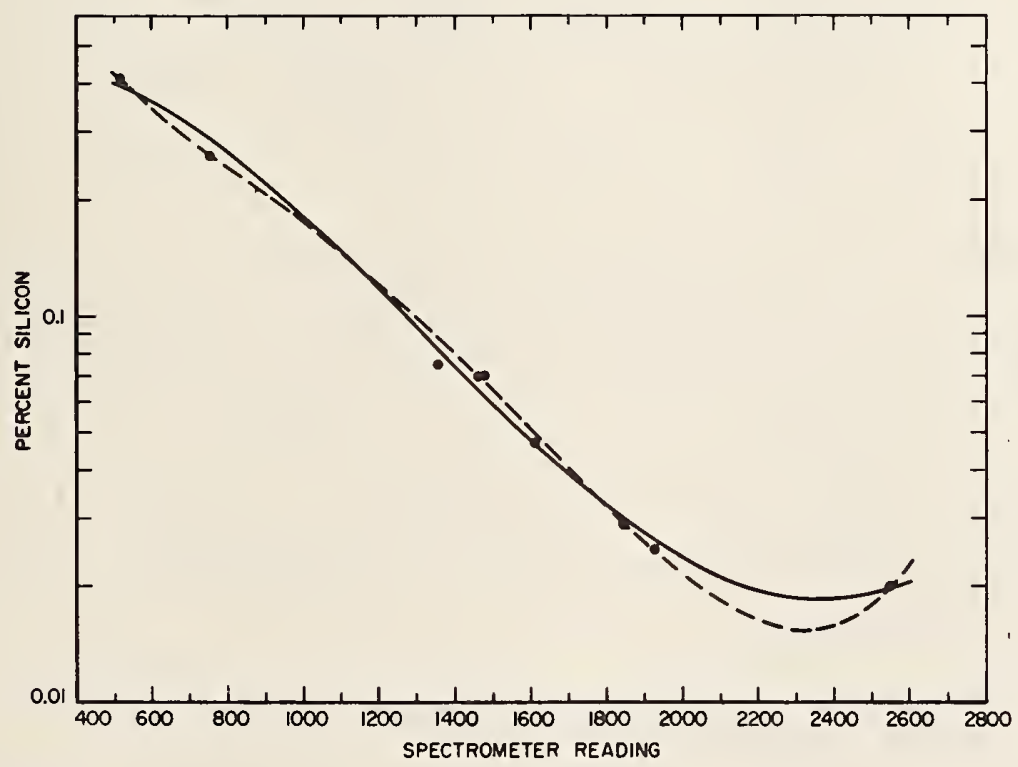

Figure 5. Analytical functions fitted by two operators using the program CFIT2. --- third-degree polynomial; - fourth-degree polynomial. Data from ref. 11 . 
is that the sign of the slope changes within the calibration range. The program PRESTO rejected the lowest standard and selected a straight-line equation through the remaining points.

The new program CFIT3 is a modification of CFIT2 to assist in recognition of unacceptable functions. The relatively slow printing rate of the teletypewriter makes it prohibitive to plot each of the equations which are fitted in the first part of the program. The program has been modified to give an optional plot of the function finally selected. However, all equations are checked for either a region of zero slope or a change in the sign of the slope within the calibration range. If either condition is found, a warning is printed to alert the user.

Both CFIT3 and PRESTO are being used routinely in this laboratory, and have proved to be extremely helpful. The choice of program depends on the amount of data to be processed. When there is little data, the program CFIT3 on the time-sharing computer gives the results within a few minutes. When there is much data, the printing rate of the teletypewriter becomes a serious limitation, and the program PRESTO is then used on a batch-loading computer.

One advantage of the use of the computer for this purpose is that it allows a quantitative estimate to be made of the accuracy of the analysis, which may often be poorer than the precision. This estimate of accuracy is based on the assumption that the samples behave like the standards. Thus, the scatter of the standards around the function is a measure of tre accuracy of the analyses.

\section{Future Computer Applications}

Currently, digital computers have been used in spectrochemical analysis principally to automate existing methods of measurement and computation. These applications have been highly rewarding, particularly when there are many samples to 
be andlyzed or the results must be obtained in a very short time. However, the full power of the modern computer is not being used, and considerable advances in this direction are likely.

The Analytical Chemistry Division of NBS has been giving attention to the role of computers in chemical instrumentation in order to plan for the future. As a part of this effort, we have been giving consideration to probable computer applications in spectrochemical analysis. An invited talk at the recent Pittsburgh Conference [12] gave an opportunity to present the results of these considerations. The talk has been written up for publication in Part B of Spectrochimica Acta. The following is a summary presentation.

An emission spectrum has a large information content. It is possible to resolve several thousand lines on a single photographic plate. Little of this information is now being used in spectrochemical analysis. Typically, intensities are measured for one line of each analyte plus one, or sometimes a second, internal standard line. In photographic methods, the background may be measured next to each line, to allow a correction to be made. In photoelectric spectrometry, it has become common to measure the background intensity at one wavelength and to use this meager information to correct for background at wavelengths up to several hundreds of angstroms aw ay .

Only a minimum of computation is normally done with these minimum data. A calibration curve or calibration function is constructed and used to convert the measured intensities to element concentrations. Computer methods generally follow the graphical techniques, although the computer is sometimes used to make some corrections for interelement effects.

Present techniques make it possible to record much more data than the minimum normally measured. Automated microphotometers have been built in several laboratories and they are now available commercially. With these instruments it is 
feasible to record the entire spectrum in digital format, thus making the complete information content available for use. The amount of digital data is very large, ranging from 50,000 to $1,000,000$ words of data to digitize 10 in. of spectrum, depending on the resolution required. The microphotometer can be made to record the data in a reasonable time, and it should be possible to build the microphotometer so that data are recorded only in the significant portions of the spectrum in order to reduce the amount of data to be carried forward to the next step in the chain.

In the long run, the automated microphotometer will not be satisfactory for all applications. The time needed to develop and read the plate is much too long for many qualitycontrol laboratories. Photoelectric recording of spectra is faster and more precise. The present photoelectric spectrometers, which either have multiple exit slits or scan through the spectrum, are not capable of recording data at hundreds to thousands of wavelengths in a reasonable time. The use of television cameras to record emission spectra appears to be feasible, and television techniques have been used in a few specialized applications, largely for low-resolution spectra of weak light sources [13, 14]. Eventually, a television detector will be wanted for spectrochemical analysis, but such an instrument does not now exist, while the automated microphotometer is a reality.

It is not inexpensive to record large amounts of data, and before instruments to do this are built or purchased it is necessary to decide how the large amounts of data will be used and whether or not the extra cost is justified. A few possible applications are fairly obvious. One is to record many lines for each analyte, rather than one. It will then be possible to average these semi-independent determinations to gain improved precision. The individual determinations may be compared before being averaged, so that aberrent data 
can be recognized and rejected, thus improving accuracy. Intensity data may be recorded over a wavelength range, not merely at the line center, so that a check can be made for interfering lines even when these are so close that they only change the shape or width of the analytical line.

If the cost of programming can be justified, it should be possible to automate the process of examining the spectral plate for a qualitative analysis. The computer program would have to incorporate many decisions, locating the sensitive lines of the elements, finding confirming lines, and checking for possible interferences. The cost of writing such a program will be high, but it would eliminate human error from a now very tedious job.

Further programming may make the automated analyses at least semi-quantitative. A skilled spectroscopist is now able to estimate concentrations from the line intensities, taking into account past experience with similar materials to the one being analyzed. A paper by L. de Galan [15] has explored the possibility of estimating element concentrations from line intensities without comparison standards by using more of the information that is in the spectrum. Briefly, he used this information to determine the temperature and electron density in an arc plasma, and combined these data with physical constants in a set of equations which were established according to a particular physical model of the process by which the sample is evaporated and excited in the arc. The method was tested with only a few samples, but the agreement between the element concentrations estimated and the true values was about as good - $+35 \%$ - as for other semi-quantitative methods. de Galan's method of carrying out an analysis without standards may never be more than semi-quantitative, but a combination of a few standards and corrections based on the measured temperature and electron concentration in the discharge plasma may give quantitative analyses which are more accurate than is now possible. 
Attention should be given, also, to the application of more extensive computations to the reduction of the small quantities of data now being taken on spectrographs and spectrometers. An early study in this direction has been made by Aslund and Cronhjort [16]. Rather than estimating the concentration of each element from the intensity at one wavelength, they used a set of simultaneous equations, each containing terms relating the intensity at one wavelength to the concentrations of all of the elements in the sample. They showed that a significant improvement in the accuracy of analysis could be achieved in this way, and further study of such techniques is clearly warranted. Similar techniques have proved to be useful in $\mathrm{x}$-ray fluorescence spectroscopy [17] and should be in emission spectroscopy as well.

Digital computers have already transformed some scientific subjects. The determination of a crystal structure by $x$-ray diffraction once required two to three years, but the time for the same task has now been reduced to as little as one week through the use of computers in data acquisition and computation. In emission spectroscopy, the advantage to be sought is not primarily speed, though savings in time have already been achieved with computers, but in improving the precision and accuracy of analysis. Also, automation of the more tedious jobs, such as qualitative analysis, will free skilled spectroscopists for other work.

The advantages that can be expected from increased automation are important enough that it appears inevitable that efforts along these lines will be a major part of our research in the next several years. The Spectrochemical Analysis Section will be involved in this work, but the effort is large and a cooperative program may be indicated. For this reason, the general direction of proposed research is being publicized, in the hope that comments and counter-proposals will be received from interested readers. 
E. Applications to Analysis

In addition to the research activities described in this report, the section provides analytical assistance to other research groups at NBS and to other Government agencies. These activities include homogeneity testing and analyses of Standard Reference Materials, and service analyses for a wide variety of materials from other groups. For the period July 1968 through June 1969, analyses were performed by optical emission spectroscopy involving 691 samples, 11,607 determinations, and 117 reports.

\section{Standard Reference Materials}

The program of Standard Reference Materials has been and will continue to be an important activity of the section. This activity consists of three phases; first, an analysis for acceptance of composition, second, a study of homogeneity of the material, and third, a participation in the program of analysis for certification.

Nearly all of the materials, including tnose not intended for use as composition standards, are submitted for semiquantitative analysis for 50 or more elements. This screening process will give information regarding purity and approximate composition, and is often sufficient for acceptance or rejection of a material. Typical materials inspected in the past year include metallo-organic compounds, organic compounds for metallic impurities (urea, creatinine, bilirubin), clay, tin, gold-copper binary wire, calcium carbonate, tungsten, and various ferrous alloys.

In other cases however, a more accurate quantitative analysis for acceptance of a material is necessary. An illustration of this would be the five new low-alloy steel standards now being produced as replacements for the nearly depleted 1161-1168 set. The chemical composition of each of the five materials has been chosen to provide adequate ranges 
for each of 36 elements to be certified. Since these standards will be used as a group, it is important that the aim compositions be achieved in the material finally accepted. The material of each was cast from a vacuum induction furnace melt of $71 / 2$ tons into a 2 l/2-ton ingot and a 5-ton ingot. The smaller ingot will provede for the chemical chip standard and the larger for 1 1/4-in. diameter $x$ 3/4-in. thick spectrochemical standards. Ladle samples taken during the casting of the ingots were carefully analyzed by two or more independent methods to provide a basis for acceptance or rejection of the melt. The preliminary analysis of one of the proposed standards and the individual results of the complementary methods used are shown in Table 3.

Table 3. Proposed low alloy steel SRM

Aim Optical X-ray Other

Element Composition Emission Fluorescence Chemical Wt. Percent

$\begin{array}{lcccc}\mathrm{C} & 0.40 & 0.37 & -- & 0.38^{\mathrm{a}} \\ \mathrm{Mn} & .60 & .67 & 0.66 & .656^{\mathrm{b}} \\ \mathrm{P} & .015 & .017 & -- & .016^{\mathrm{c}} \\ \mathrm{S} & .015 & .013 & -- & .012^{\mathrm{d}} \\ \mathrm{Si} & .20 & .22 & .20 & -- \\ \mathrm{Cu} & .05 & .048 & -- & .044^{\mathrm{b}} \\ \mathrm{Ni} & 2.00 & 2.00 & 1.99 & -- \\ \mathrm{Cr} & 0.70 & 0.69 & 0.68 & -- \\ \mathrm{Mo} & .20 & .21 & .192 & -- \\ \text { W } & .02 & .02 & -- & .015^{\mathrm{b}} \\ \mathrm{Co} & .02 & .023 & -- & .025^{\mathrm{b}}\end{array}$

a - Combustion-gravimetric; b - Neutron activation analysis; c - Spectrophotometric; d - Combustion-iodometric. Other elements determined but not shown include $\mathrm{V}$, Ti, As, Sn, Al, Nb, $\mathrm{Ta}, \mathrm{B}, \mathrm{Pb}, \mathrm{Zr}, \mathrm{Sb}, \mathrm{Bi}, \mathrm{Ag}, \mathrm{Ca}, \mathrm{Mg}, \mathrm{Se}, \mathrm{Te}, \mathrm{Zn}, \mathrm{O}_{2}, \mathrm{~N}_{2}, \mathrm{H}_{2}, \mathrm{Ce}$, La, Pr, Ge. 
Following the acceptance of composition we are next involved in the homogeneity testing of the material. The $21 / 2-$ ton ingot is press forged and rolled into 5-in. diameter by 30-in. long bars. Slices from both ends of all the bars are obtained and analyses are made on these slices to determine the homogeneity of the individual bars and of the entire lot. Subsequent chipping and blending of the material is made on those bars which are shown to be acceptable to provide for the chemical Standard Reference Material. The 5-ton ingot is press forged and rolled into a slab $17 \mathrm{in.} \mathrm{wide} \mathrm{by} 5 \mathrm{in}$. thick and by approximately $30 \mathrm{ft}$. long. Cross section slices are sawed from the slab at specific locations and the homogeneity of the entire slab is determined by an analysis of variance program. After discarding the unwanted portion of the slab, i.e., material corresponding to the top center of the cast ingot, the remainder is rolled into 1 1/4-in. diameter bars to provide for the spectrochemical Standard Reference Material.

Finally, the Section is involved, along with the entire Analvtical Chemistry Division, in the program for chemical analyses of the finished material. Analyses by at least two independent methods within our section, along with other analyses made at NBS, and by cooperators in industry provide for the provisional and final certification.

Materials intended as standards for spectrochemical analysis which have been analyzed in the above described manner during the past year include the special low alloy steels, stainless steel, high silicon steel, high temperature alloys, and electronic and magnetic alloys. A copy of the provisional certificate for the electronic and magnetic alloys is included in the Appendix to this report. 


\section{Other Analyses}

Spectrochemical analyses are made of a wide variety of materials to assist other NBS groups and other Government agencies when their facilities are not capable of doing the work. Many of the analyses are qualitative or semi-quantitative surveys in which 50 to 70 elements are sought. Quite often, these analyses provide sufficient information for the problem. Typical samples analyzed in the past year by these methods were dust, ash, resins, corrosion products, metallic alloys, and chemical reagents. In one case, a $40-\mathrm{g}$ sample of a pure polymer was ashed with care to avoid contamination or losses, and the small residue was analyzed by the semi-micro dc arc method, yielding detection limits for many elements as low as $10 \mathrm{pg} / \mathrm{g}$.

A particular application of semi-quantitative analysis involved the determination of sub-microgram amounts of beryllium in dust collected on filter paper, as part of a safety surveillance program. The samples were ashed in a cupped electrode, excited in a $d c$ arc, and the intensity of the $\mathrm{Be}$ $3130.4 \AA$ line was recorded photoelectrically. Standards were prepared by adding solutions of beryllium sulfate to filter paper. The range of concentrations covered was 0.01 to $1.0 \mu \mathrm{g}$. The method was rapid enough to permit handling of several hundred samples, and at the same time gave adequate accuracy and precision, particularly since even an approach to the hazard level for beryllium would have been the signal for work to be stopped and the contaminated area to be cleaned up.

Quantitative analyses are frequently performed to determine whether or not a part of a machine or structure is the alloy specified by the designer. Such analyses are usually part of a detailed failure study made at NBS. An example of this is the investigation of the causes of collapse of the bridge on the Ohio River at Point Pleasant, West Virginia on December 15, 1967. A section of an eyebar in which the initial fracture 26 
apparently occured was analyzed, along with several other pieces of the bridge, to verify alloy composition. Another example is the analysis of an aluminum propellor hub which failed, causing the loss of an aircraft. Other examples include the analysis of a magnesium anode and a steel guard rail for the District of Columbia Department of Highways and Traffic, analyses of aluminum sheet used in mail handling equipment, and analyses of three steel files for the General Services Administration. In this last example, the files were submitted with the information that one of them had been found to have a useful life about ten times greater than the other two. Spectrochemical analysis revealed that the superior file was a different alloy. Large quantities of these files are being used in power-driven filing machinery, and the specification of a particular alloy can result in considerable savings to the government.

Among the unusual materials resulting from research activities at NBS this year, which we have been called upon to analyze, was one called "anomalous water." This material, which is prepared by a simple procedure discovered by B. V. Deragin [18], has highly unusual properties. It is about 15 times as viscous as water, has a density 20 to 30 percent higner, and does not boil until the temperature reaches $200^{\circ} \mathrm{C}$. It forms a glassy solid at $-50^{\circ}$. The problem of analyzing this material for possible metal content is complicated by the fact that it can be prepared at present only in very small amounts, with a typical sample weight of about $1 \mu \mathrm{g}$.

Samples were analyzed with the laser probe and the electron probe microanalyzer. Figure 6 shows a drop of the sample, at 200X magnification. For laser probe analysis, the drop had been placed on a sheet of acrylic polymer. The many small ripples seen in this photograph testify to the high viscosity of the material. Figure 7 shows the same sample after it was exposed to the laser probe. These are apparently the first analyses of "anomalous water" for metallic elements, and the 


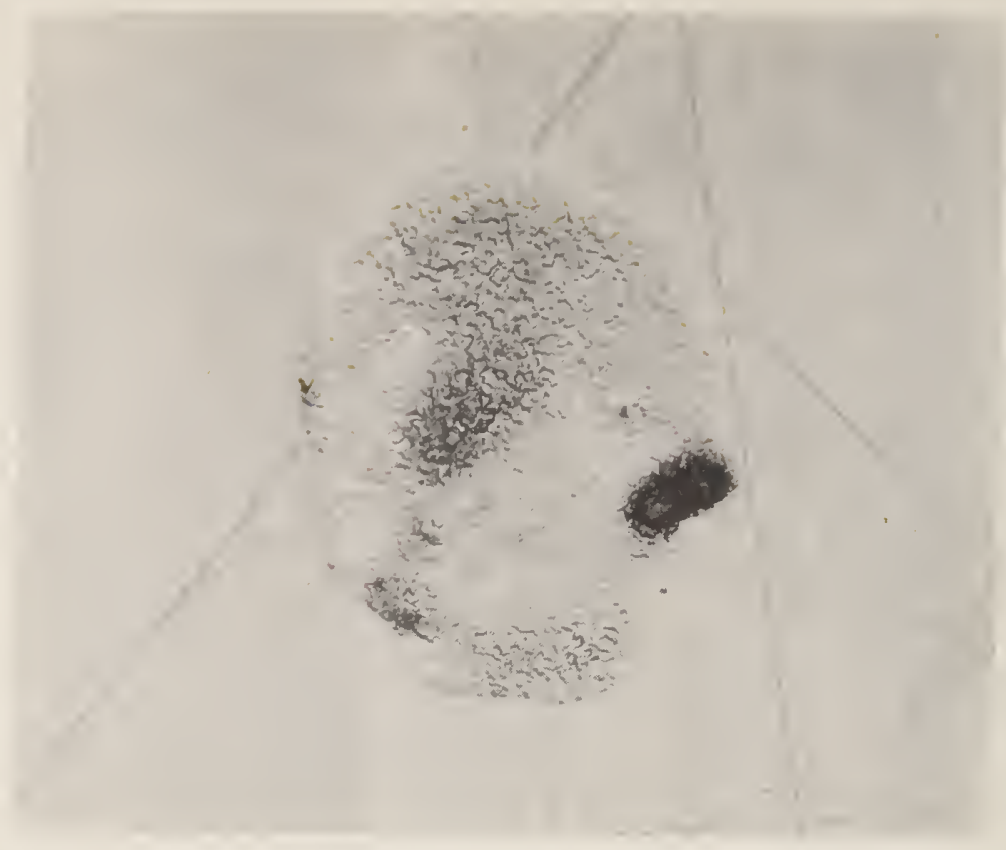

Figure 6. Drop of anomalous water, approximately $l \mu g$.

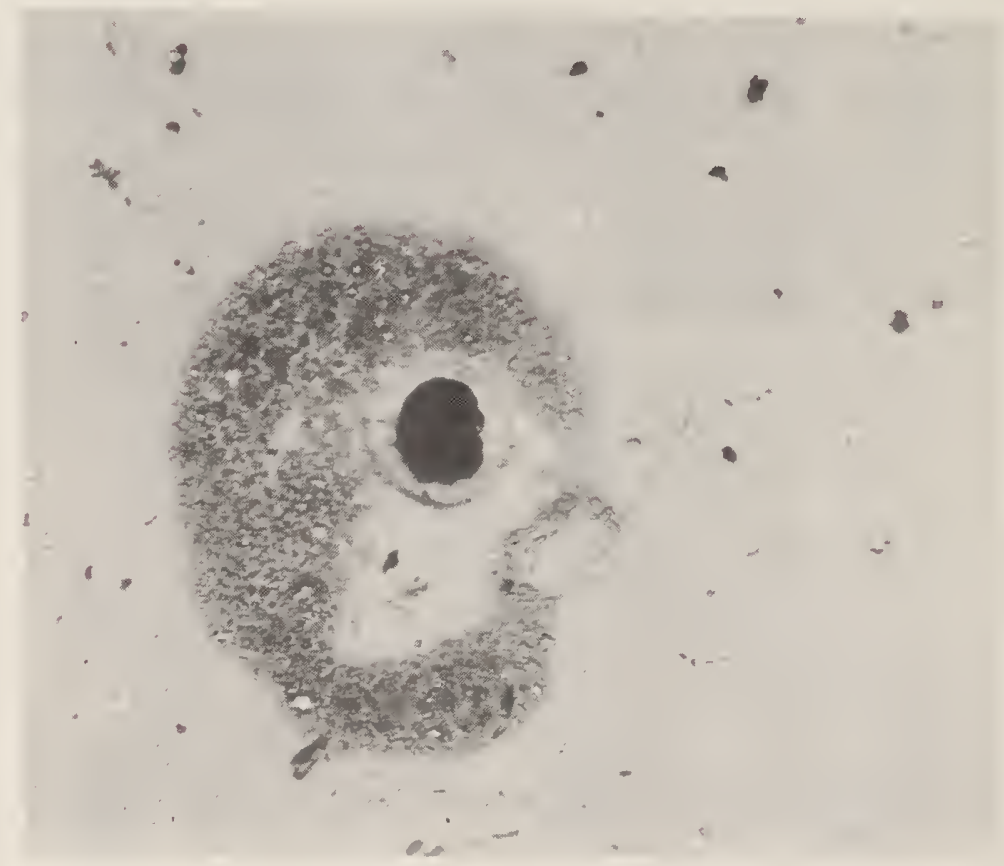

Figure 7. Same sample of anomalous water after sampling with the laser probe. Bits of polymer substrate and graphite from the electrodes are scattered around the sample. 
results indicate that the unusual properties are not related to such impurities. This work is included in a recent summary of properties and structure of the anomalous water by Lippincott, et al. [19].

Many other similar applications of analyses were made during the past year, principally through the able work of Mrs. M. M. Darr, Mrs. V. C. Stewart, and Mr. D. M. Bouchette.

M. Margoshes, J. L. Weber, Jr. 
As in previous years, the impact of electron probe microanalysis on science and technology has further increased. In addition, scanning electron microscopes are now commercially available, and the use of electron beam scanning techniques for topographic investigation is becoming commonplace in many laboratories. Consequently, progress in both the spectroscopic and microscopic aspects of electron probe instruments is of great practical importance

The research effort of the Spectrochemical Analysis Section, is oriented towards contributing to the progress in areas of general interest in microprobe analysis, as well as in other fields of spectrometry. In this report, the progress achieved during the last fiscal year will be described.

\section{A. Quantitative Analysis}

In a recent publication [20] we analyzed the sources of error which can contribute to inaccuracy in electron probe microanalysis. The method is based on the determination of the ratio of $x$-ray intensities emitted from the specimen and those emitted, under identical experimental conditions, from an appropriate standard. For practical reasons it is impossible in many cases to prepare and characterize a standard of composition matching that of the specimen area under investigation. The alternative is to use as the standard an element or a simple compound. Since in this event the physical events in the target (electron deceleration, electron backscattering, and production of secondary $x$-rays) differ from standard to specimen, correction calculations must be performed to obtain the mass-fraction of the element in question from the observed intensity ratio.

The accuracy of this procedure is limited by imperfect knowledge of the theory, and of physical parameters - such as mass absorption coefficients - which are used in the 
calculation. Furthermore, the complete calculation is tedious and, in the past, simplifications of doubtful validity were introduced in the computation. In the last year, we began the preparation of an extensive computer program which includes all physical factors known at present. J. Hénoc, a guest worker, has finished the writing of a FORTRAN sub-program which permits determining the effect of fluorescent radiation excited by the continuum. This program is based on previous work of Hénoc [21], with modifications derived from our work on the calculation of mass absorption coefficients [22]. This sub-program permits for the first time the inclusion of this complex correction in automatic computer iteration programs. The other stages of the main program, which will include correction for fluorescence by characteristic lines, the atomic number correction, and the absorption correction, are near completion. This program will be issued with full documentation and commentary, in order to allow modification by prospective users. S. D. Rasberry and R. L. Myklebust have been most helpful in giving their assistance in various aspects of programming.

B. Standard Reference Materials

Since the calculation methods which are presently available are of a semi-empirical nature, and since adjustments must be made for the imperfect knowledge of the physical parameters involved, it is of utmost importance to possess standard reference materials on which the proposed correction procedures can be tested. Such standards must be homogeneous on a microscopic scale, and their composition must be accurately known. It is very difficult to prepare adequate standard reference materials for electron probe microanalysis, and, as shown in the aforementioned publication [20], lack of such standards has in the past contributed significantly to uncertainties in quantitative electron probe microanalysis. 
The issuance of the NBS Standard Reference Materials 481 and 482 will greatly improve this situation. SRM 481 is a set of gold-silver alloys, of nominally $20 \%, 40 \%, 60 \%$, and $80 \%$ gold. The pure metals are also included in the series of standards which are in wire form. Homogeneity of the alloys on a $\mu \mathrm{m}$ scale was achieved through lengthy and tedious thermal treatment, and more than a thousand microprobe measurements were performed on each alloy, to establish whether sufficient homogeneity for the purpose of the standard was achieved. The chemical composition was determined independently by three laboratories, with satisfactory agreement. The results of analyses and homogeneity tests are described in the Certificate of Analysis which is reproduced in the Appendix to this report.

The NBS Standard Reference Material 482 is a series of gold-copper alloys, analogous in all aspects of preparation, composition, and characterization to SRM 481.

The homogeneity measurements were performed in three groups: on several cross-sections of the wire in order to confirm homogeneity along the entire wire; two series of points along orthogonal diagonals were performed on each crosssection, in order to obtain information concerning compositional changes as a function of distance from the center of the wire; and homogeneity on a micron scale was tested by means of the matrix generator device described in last year's report.

The large number of data obtained in the last procedure (100 points/matrix) required the development of computational methods which provide statistical information (stanaard deviation, range, frequency distributions), as well as topographical information. Great effort was expended in order to overcome effects of instrumental drift. The effects of defocusing of the $\mathrm{x}$-ray spectrometers could not be entirely eliminated. The cooperation of S. D. Rasberry, who developed the computer programs necessary for the matrix tests, is gratefully acknowledged. 
Our experience with the matrix generator indicates that this method will lend itself to many useful applications, particularly in the analysis of multiphase materials. There are intriguing possibilities of applying stereometric methods to the results. On the other hand, the differentiation of random patterns from topographic features poses problems of pattern recognition which unfortunately have not been fully resolved and put to test, due to lack of time. It is proposed that such problems and hence the exhaustive analysis of complex structures in solid materials, should be handled by interfacing the instrument with a small computer for data collection and evaluation. We have studied the desirable features and limitations of such a system, and we hope to be able to further explore these possibilities in the future.

Additional standard reference materials will be needed for full exploration of the proposed correction procedures for quantitative analysis. We plan to extend our studies to systems containing elements of low atomic number. A system which seems eminently suitable is that of binary and ternary borides. We propose to study these compounds, which are good electric conductors, in cooperation with the NBS Metallurgy Division.

Another area which requires clarification is that of nonconductors, such as oxides and silicates. The prospect of the recovery of lunar specimens dramatizes this situation. At present, a host of standards is used in the analysis of geological specimens, and it is not known if a general technique of standardization and data correction, such as used in the analysis of alloys, will be successful with materials of low electric and thermal conductivity. We plan to investigate the possibility of such a procedure in cooperation with several laboratories involved in the analysis of such materials.

Further efforts in the production of standards for ferrous alloys, and in the microscopic standardization of existing NBS standards, are probably warranted. 
We will appreciate receiving any comments with respect to efforts in this direction.

Once the necessary number of standard reference materials is obtained, the proposed analytical methods and parameters will be extensively tested with the aid of the computation program that is being developed.

The group also performed measurements on microbeads of cation-loaded ion exchange resins (prepared elsewhere in our Division), in order to determine their suitability as microstandards for chemical elements. Measurements of the $\mathrm{Ca}$ and $\mathrm{S} K$-alpha lines on Ca-loaded beads showed that the ratio of the respective $x$-ray intensities is constant over a wide range of bead sizes (Figure 8 ). Since the sulfur is contained in the radicals to which the cations are attached, this is a promising method for checking uniformity of loading of the resin beads. Measurements on $\mathrm{Na}$-loaded beads gave erratic results, probably due to the high absorption of the soft $\mathrm{Na}$ K-alpha line. Further experiments will be performed to define the range of applicability of this technique.

\section{Non-diffractive Techniques of Qualitative and Semi- quantitative Analysis}

Since microprobe analysis is usually employed for topographic exploration on a microscale, it is frequently desirable to provide qualitative information at several points on a specimen. The slowness of the wavelength scanning procedure used for this purpose limits the number of points which can be explored in a reasonable time span. The non-diffractive detectors described in a previous report [4, p. 29], in combination with pulse-height analysis, allow us to perform a complete qualitative analysis in three to four minutes. A flow-proportional detector is used to cover the range from $0.2 \mathrm{keV}$ to $2 \mathrm{keV}$, and a lithium-drifted silicon detector covers the range from $1 \mathrm{keV}$ to the maximum energy levels 


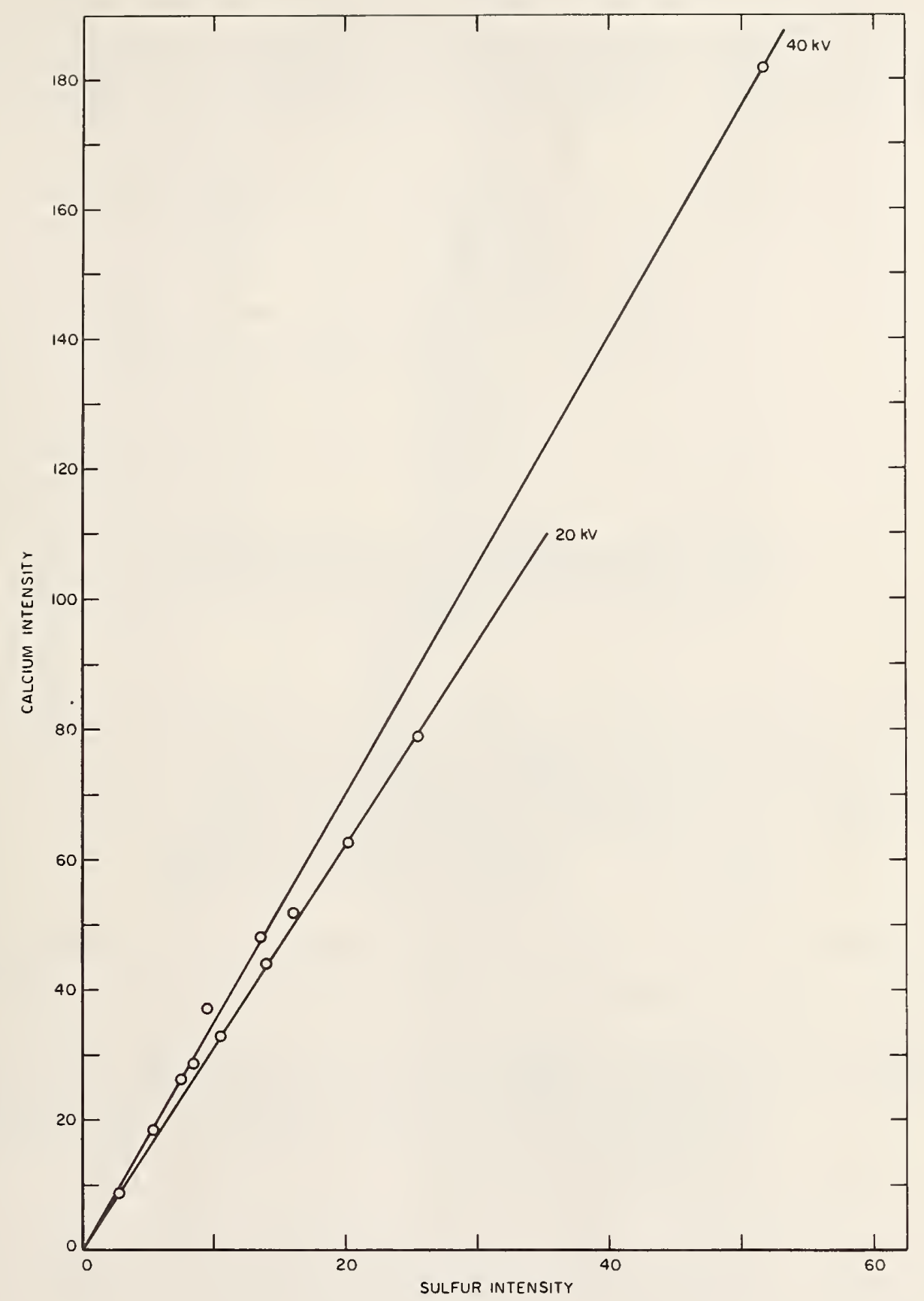

Figure 8. Integral measurements of intensities of $\mathrm{Ca}$ $\mathrm{K} \alpha$ and $\mathrm{S} K \alpha$ from ion exchange resin beads loaded with $\mathrm{Ca}$. Range of bead diameter: $4-30 \mu \mathrm{m}$. 
emitted from the specimen, which depend upon the operating voltage employed. Figure 9 shows examples of applying the pair of detectors. The spectra were sorted by a range of 800

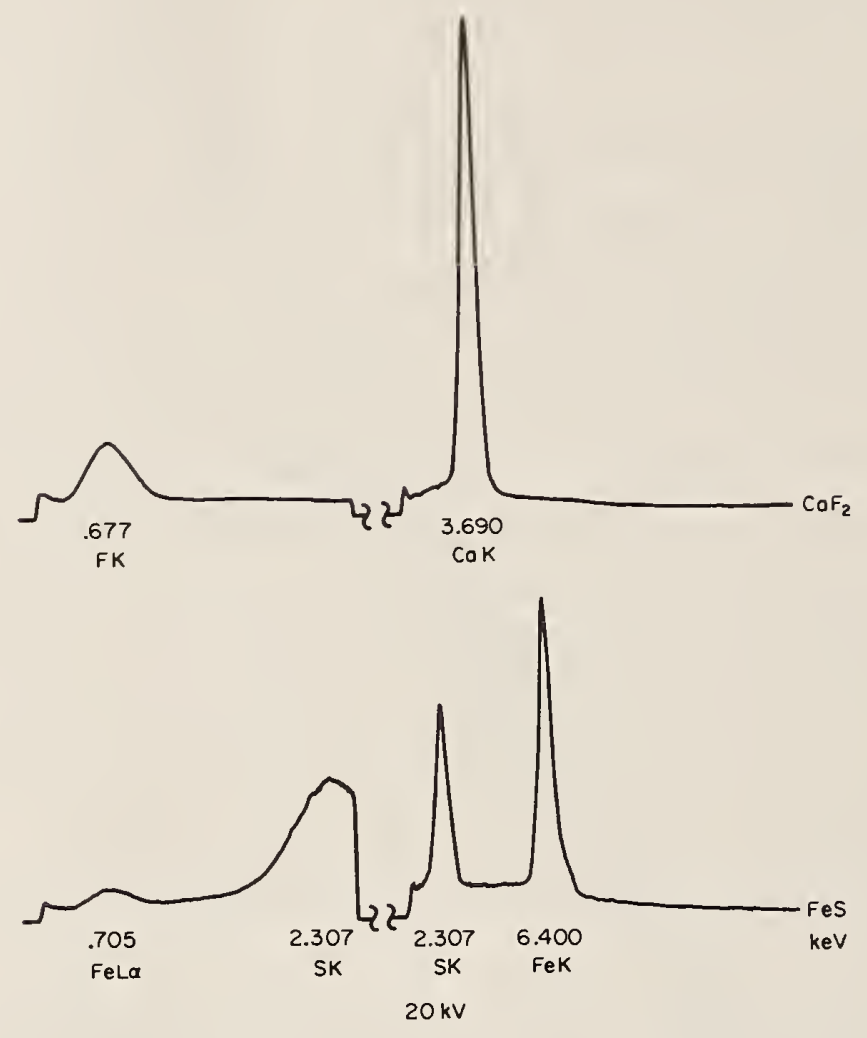

Figure 9. Non-diffractive spectra obtained at $20 \mathrm{keV}$ and $2 \times 10^{-8} \mathrm{~A}$, in 4 minutes. Left: flowproportional detector. Right: Li-drifted silicon detector.

channels of the multi-channel analyzer, and recorded on an $x-y$ recorder. Although the resolution and line-to-background ratios are considerably poorer than those obtainable with crystal spectrometers, they are sufficient to identify the major and sub-major components (concentrations above 1\%) of the specimen. The resolution is further improved by the use of an analog device (DuPont Curve Resolver) which enables us to perform a rapid analog-deconvolution in a few minutes (Figure 10). 


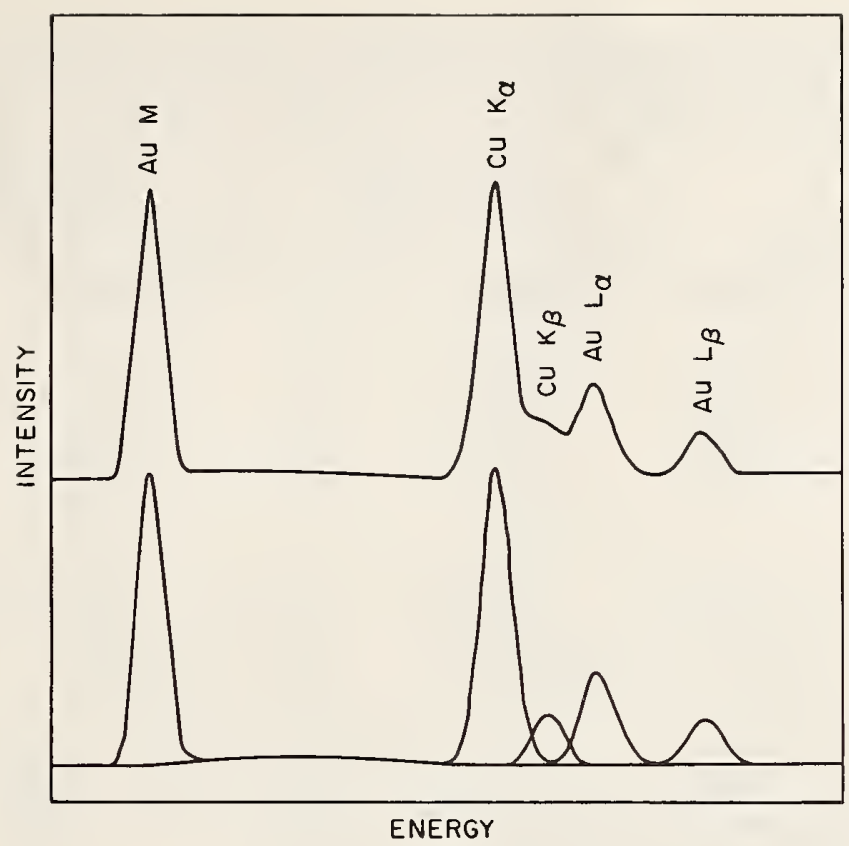

Figure 10. Spectrum of a $\mathrm{Cu}-\mathrm{Au}$ alloy obtained with the silicon detector, and reconstructed on the Curve Resolver. Upper curve: unresolved spectrum, background-corrected. Lower curve: peak components.

Preliminary investigations indicate that the spectrum recordings can be evaluated semiquantitatively, and even close to quantitatively, particularly if correction procedures are used on the basis of the intensity ratios derived from the graphs. Such a procedure will frequently suffice to indicate the nature of an inclusion or phase of unknown composition. Some preliminary results are shown in Table 4.

By using a single-channel analyzer locked on a characteristic line in an energy spectrum, a signal usable in matrix-techniques can be derived. This signal offers the advantage of eliminating the defocusing effects which are observed with crystal spectrometers when the electron beam is deflected in the matrix procedure. Further studies in this area are planned. 
Table 4. Analyses of copper-gold alloys by nondispersive detection and pulse height analysis.

Observed

Element ${ }^{C_{\text {chem }}} \quad \mathrm{k}_{\text {peak }} \quad \mathrm{k}_{\text {int }} \mathrm{C}_{\text {peak }} \mathrm{C}_{\text {int }}$

Copper

(K)

Gold

(M)
0.83

.65

.43

.22

.71

.49

.30

.15
Calculated

0.79

.61

.40

0.79

.59

.37

$.21 \quad .18$

$.78 \quad .79$

$.59 \quad .60$

.40

.20

.21
0.83

.67

.46

.26

.70

.48

.30

.14

Legend: C ... mass fraction

k ... intensity ratio

chem ... from chemical analys is

peak ... measured from peak height

int ... measured from integrated area below peak

These measurements were performed at $20 \mathrm{keV}$, using the Lidrifted silicon detector, and evaluating the graphic record of pulse-height analysis.

D. New Technique and Instrumentation for Target current Scanning.

While secondary electrons provide essentially topographic information, the target current signal, which depends upon the backscattering of electrons, varies with both composition and topographic changes of the specimen surface. In microprobe analysis, it is frequently desirable to start with a purely topographic exploration. However, in inhomogeneous specimens the topographic information is often obscured by large differences in atomic number. We have developed a concept of handing the target current signal in a way that permits separating and emphasizing the topographic aspects at will. 
This may render unnecessary in many cases the installation of secondary detectors and associated electronics. We have constructed an amplifier (Figure ll) in which the target current signal and its first derivative are amplified independently and recombined in any desirable proportion. If

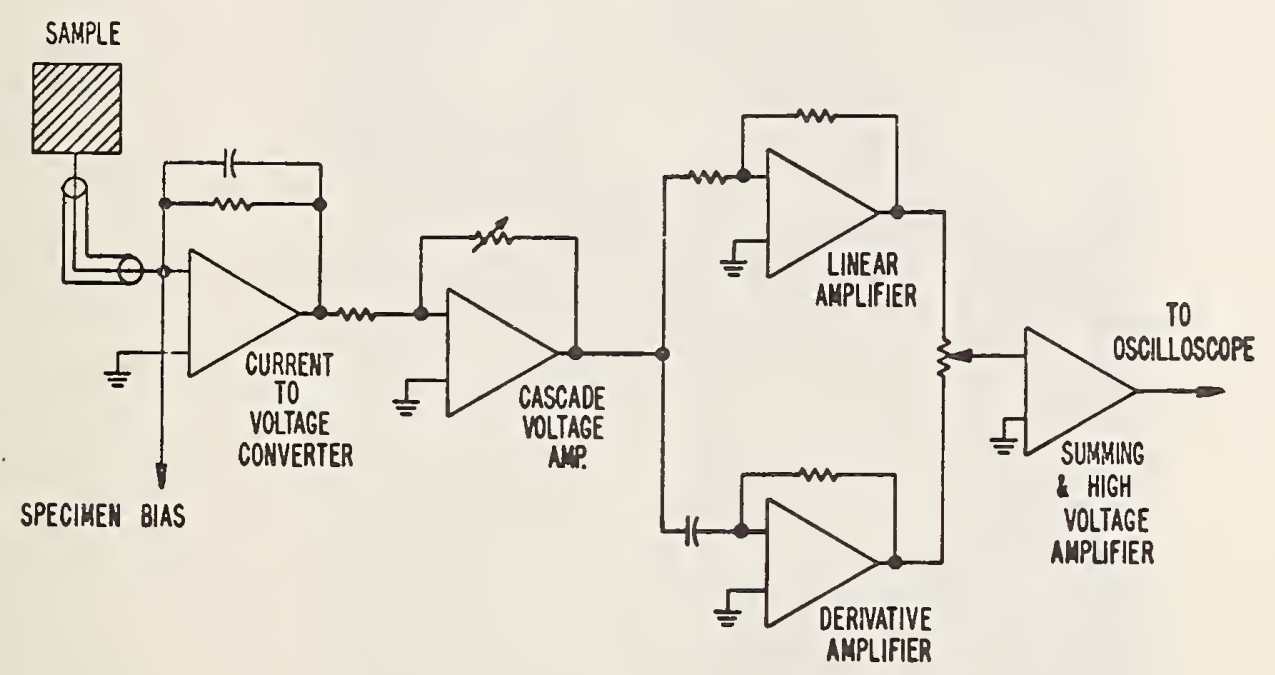

Figure 11. Schematic diagram of the target current amplifier with linear and derivative component. (Detailed circuit diagram is available on request.)

the purely derivative signal is used for modulating the brightness of the oscilloscope, the topographic details of all phases appear clearly on a gray background. Passage from one intensity level to another (when passing from low to high atomic number or vice versa) is merely indicated by a bright or dark boundary line. By using the combined signal we can obtain a proper balance of the change of brightness due to atomic-number variations, and of the topographic features (Figures 12 and 13). 


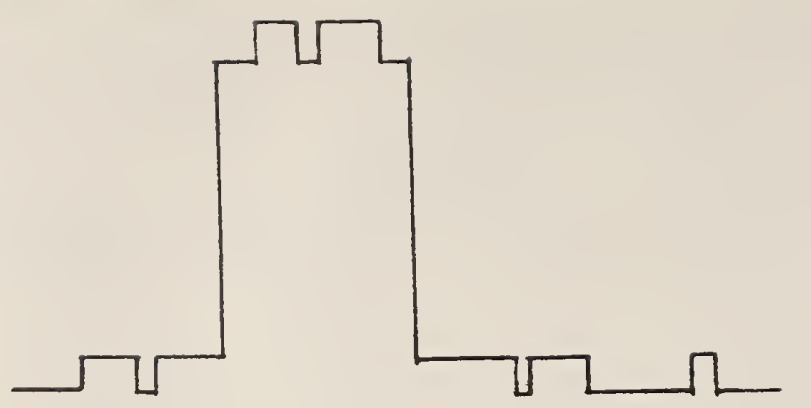

a
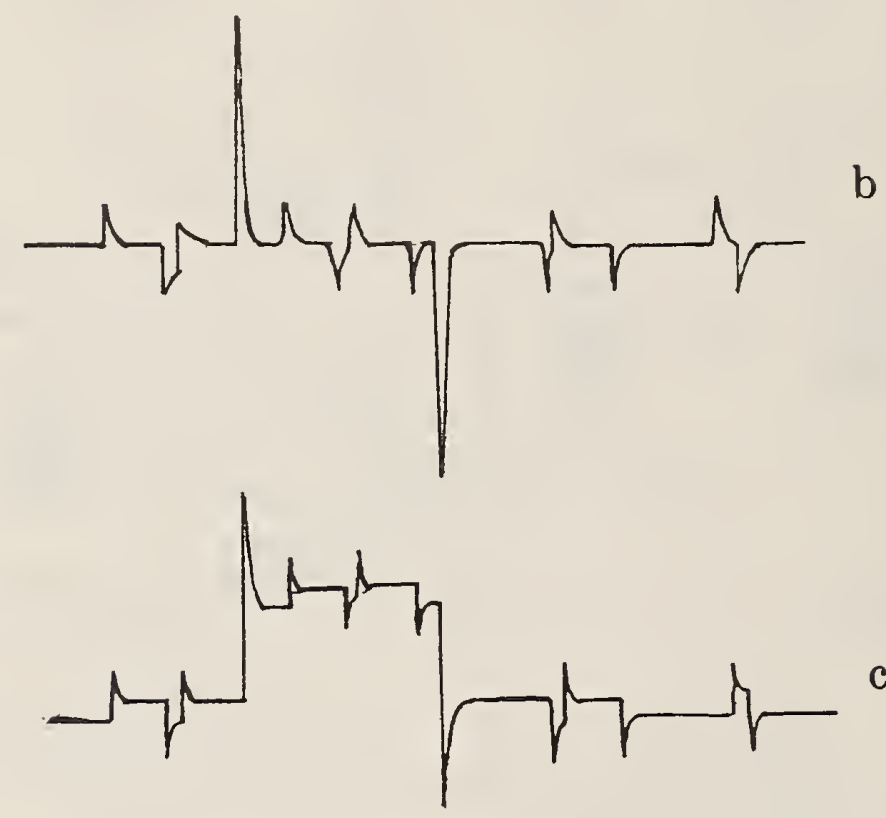

Figure 12. Target current signal, a. linear, b. first derivative, and c. combined signals. Vertical intensity scales are arbitrary.

E. Further Improvements in Target Current Scanning

1. In the construction of the new target current amplifier, low-noise integrated operational amplifiers were used. Ground-loops in the target current circuitry were carefully eliminated. This results in a considerable reduction of noise and hum. At the present state of development, we can obtain images of good quality at a target current of $10^{-9} \mathrm{~A}$ or lower. This is very useful in the investigation of specimens which are susceptible to damage by the electron beam. 


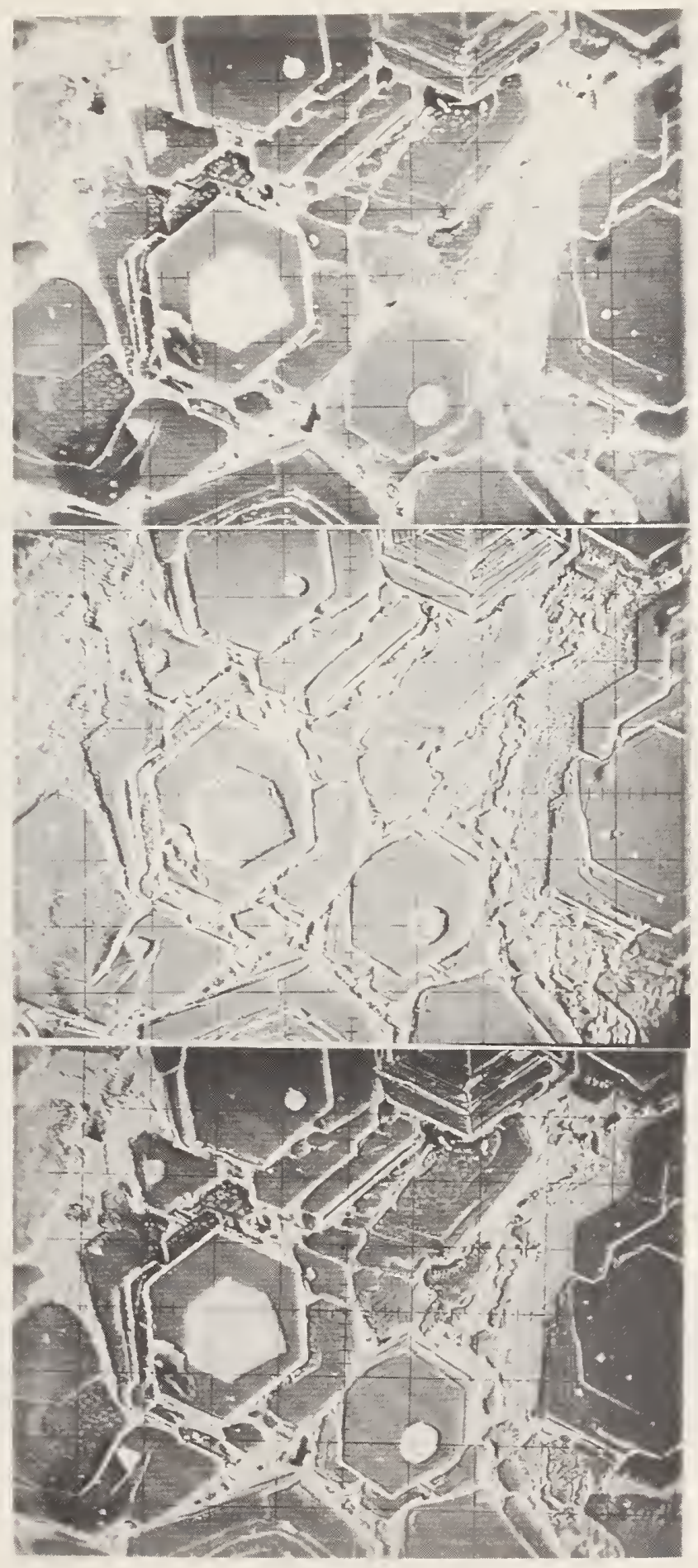

Figure 13. Target current scans of titanium boride contaminated with iron. The iron is present in the bright phase of the upper image. Upper image: linear target current, showing atomic number differences. Middle image: derivative image, showing topography. Lower image: combination of both signals. 
2. In order to obtain scanning images at low magnification for a preliminary orientation, we have modified the specimen stage connections in "such a way that target current scans can be performed with the specimen at several $\mathrm{cm}$ below the normal position. Thus, we obtain images of satisfactory quality at magnifications as low as $12 \mathrm{X}$ at $20 \mathrm{keV}$, and even lower at lower voltages (Figure 14).

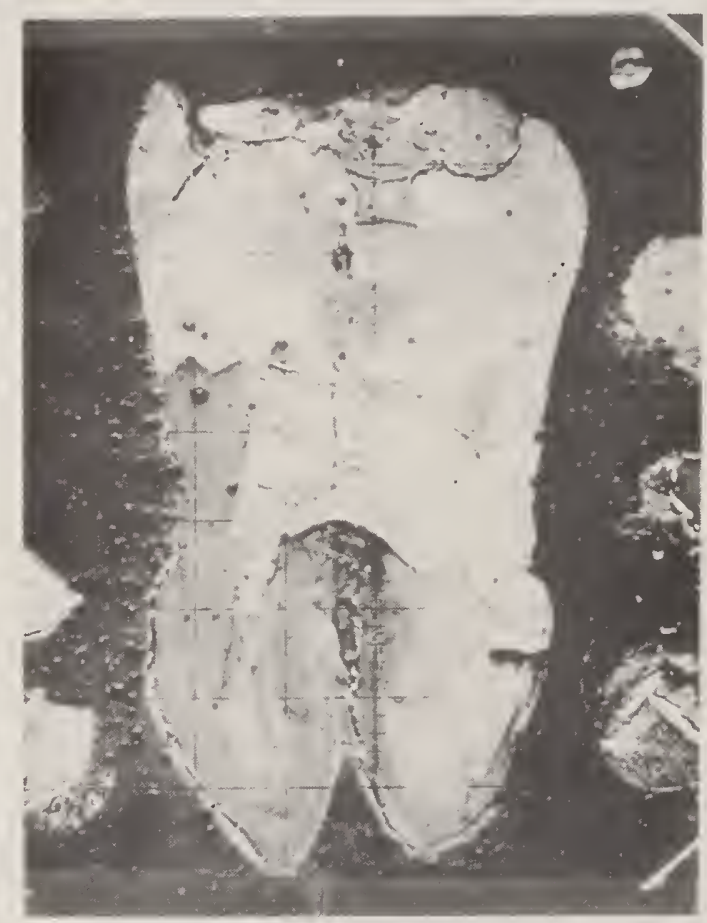

Figure 14. Scanning target current image of human tooth. $2 \mathrm{keV}, 1 \times 10^{-9} \mathrm{~A}$. Magnification: $4.5 \mathrm{X}$

3. Replacement of electrostatic beam deflection by electro-magnetic scanning coils has resulted in considerable improvement in the quality of the scanning images, which have full resolution at the edges of the scanning field. We have also increased the stability of the power supplies for beam formation and for the scan generator, and have improved our beam alignment procedures, so that uniformly sharp beam focusing is obtained in routine operation (Figure 15). 


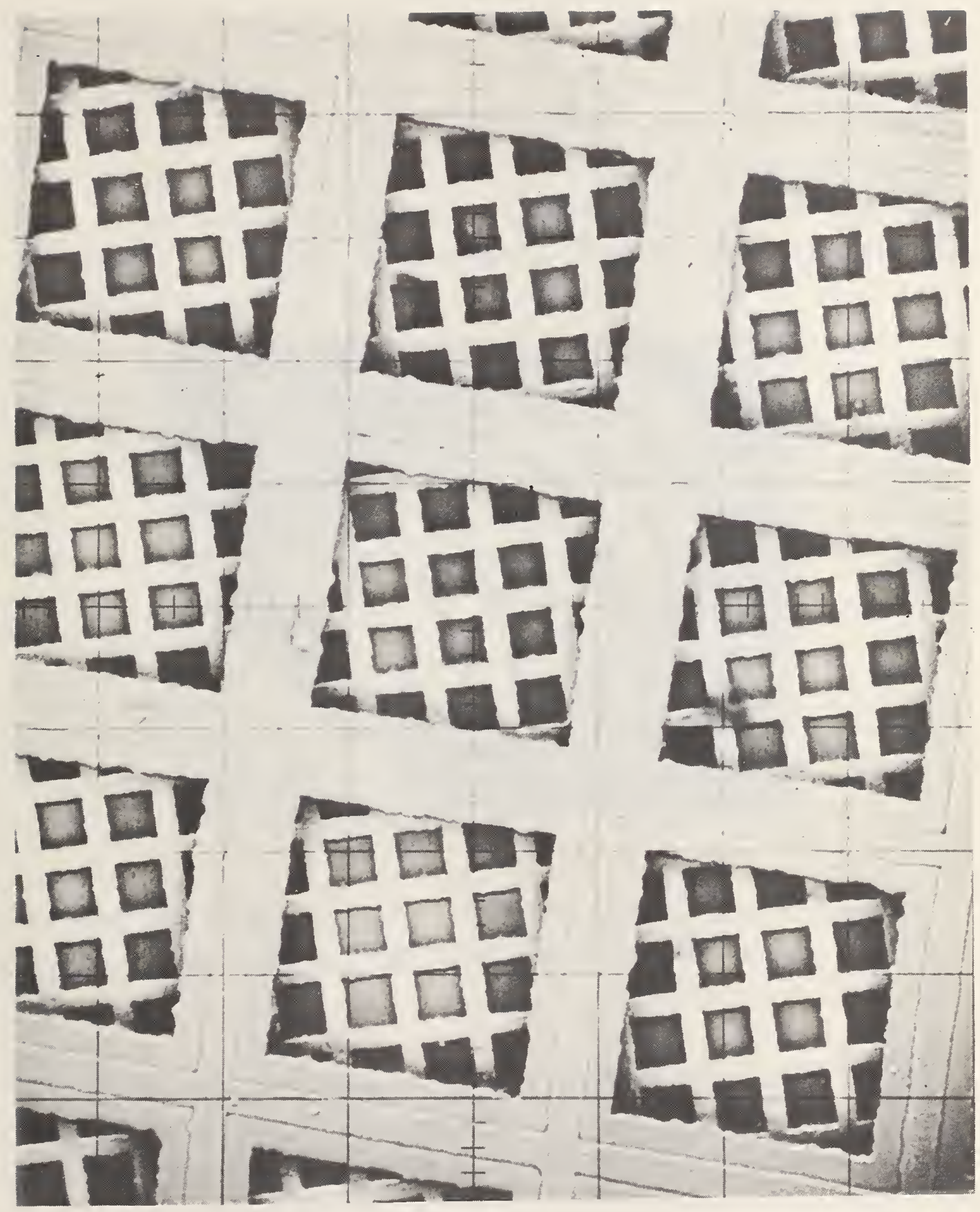

Figure 15. Target current of metal grids, $20 \mathrm{keV}, 10^{-8} \mathrm{~A}$. The width of the bars of the small grid is $3.5 \mathrm{\mu m}$. Notice full resolution at corners. 
The improved capabilities of our electron probe as a scanning microscope are illustrated in Figure 16. The image shows the end of a filament of a light bulb after failure. The admixture of derivative signal enhances the topography of the wire surface showing recrystallization, except for the cooler part of the filament attached to the post. The great depth of focus of the technique can also be noted.

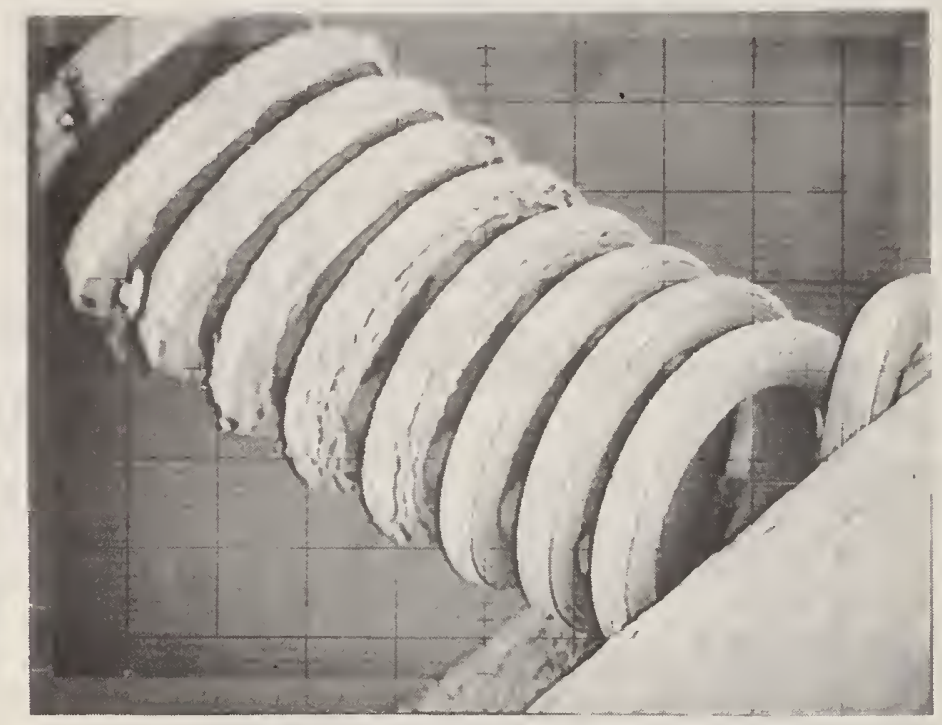

Figure 16. Scanning electron micrograph of a partially recrystallized lamp filament. $20 \mathrm{keV}$, 10-8A. Mixed target signal. Magnification: $200 x$.

For the extensive and skillful work in developing the new electronic equipment and in upgrading previously existing devices we are greatly indebted to C. Fiori, of our Section, and to Mr. L. A. Marzetta, (Measurement and Engineering Division, NBS).

F. Color Composite X-ray Scans

The advantages of a simple technique for preparing composite color images of several $x$-ray scans has been discussed previously [4, p. 31]. A detailed description of our 44 
method, with appropriate illustration, has appeared in the Journal of Research, NBS [23].

This method has been further refined by including also topographic information. The target current scan obtained with the new amplifier is represented on the gray scale, and up to three x-ray scans are added in the primary colors red, green, and blue. The resulting images show clearly the topography of the specimen surface which resembles the image obtainable with a light microscope, while the colors add information concerning the distribution of up to three elements. The usefulness of this technique has been proven in several applications to service work. The color composites can be prepared routinely, in a procedure similar to that described in reference [23]. The new technique will be published shortly.

G. Applications to Analysis

We have continued to devote a large part of our effort to service work of a diverse nature, with 21 reports issued during this fiscal year. Some of them - such as the characterization of the standard reference materials - report the results of extensive and complex investigations.

Considerable work was performed on binary diffusion couples of the $\mathrm{Ag} / \mathrm{Ag}-\mathrm{Cd}$ system. The silver and cadmium concentrations were determined at approximately 200 points in a line across the diffusion zone. Adjacent points could neither differ in composition by more than $1 \%$ nor be more than $200 \mu \mathrm{m}$ apart. The results were calculated and plotted using an OMNITAB procedure.

Many of the specimens examined required only qualitative analyses. The lithium-drifted silicon detector and thin window flow-proportional detector enabled rapid identifications of inclusions in steel, metal inclusions in sapphire, and of different phases in iron-titanium-borides. Several specimens of anomalous water were also examined by this technique and 
all of these were shown to contain sodium as a contaminant.

Color composite photographs were used to locate various elements in corroded aluminum specimens, iron-titanium-borides and a steel specimen from a broken eyebar of a collapsed bridge.

Quantitative analyses were performed on many of the specimens. The different phases in alloys, such as platinumvanadium, platinum-chromium, and tungsten-rhenium, were examined as well as a microscopic sphere of a complex phosphate-silicate. The relative $x$-ray intensities obtained from these analyses were converted to concentrations using a time-shared computer. Corrections were made for pulsecoincidence losses, beam intensity drift, background, x-ray absorption, secondary fluorescence, and atomic number effects.

In addition to the specimens already described, the examination of other materials was performed employing one or more of the techniques mentioned.

\section{H. Literature Research}

Work on the bibliography of electron probe microanalysis has continued, although at a slow pace. We hope to issue an updated bibliography during the coming fiscal year.

K. F. J. Heinrich, R. L. Myklebust 


\section{X-RAY FLUORESCENCE SPECTROMETRY}

The program and instrumentation for $x$-ray fluorescence spectrometry have been reviewed in prior technical notes of this series $[1,2,3,4]$. The research on improved methods of calibration and correction techniques for interelement interferences has yielded a successful new technique. The use of this technique has been essential in the analysis of high-temperature alloys and nickel-base electronic alloys proposed for use as NBS Standard Reference Materials (SRM).

Stimulated by the request to analyze several thin metal foils, we have extended our research into the area of $x$-ray absorptiometry. Adding some novel twists to some very old $x$-ray methods, we have been able to present an improved way to simultaneously determine the entire composition and the mass per unit area ( $\rho x)$ of thin metal foils.

Approximately one-half of the effort expended in the $x$-ray fluorescence project has been directed toward the analysis of chemical compositions and the determination of plating thickness for certification of SRM's. Support to the office of Standard Reference Materials also has included homogeneity testing, specimen sorting, and rapid verification of composition of labeled specimens.

\section{A. Research Activities}

The manuscript "Applications of Digital Computers in Spectrochemical Analysis - Fitting of Analytical Functions" [10] has been accepted for publication by Analytical Chemistry.

A manuscript is currently being prepared to present our technique for the analysis of thin, multi-component metal foils by x-ray absorptiometry. This method does not require standards for analysis; however, for purposes of testing the method, a variety of "synthetic standards" have been made by 
stacking pure metal foils. Determinations have been made with accuracies between $1 \%$ and $4 \%$, relative, for foils in the thickness range of $2 \times 10^{-4} \mathrm{~cm}$ to $2 \times 10^{-3} \mathrm{~cm}$. Elements studied include copper, nickel, iron, vanadium, and titanium. A FORTRAN V computing program, called EDGE2, has been written to perform the calculations necessary in these analyses.

A comparison of given composition and the composition found by $x$-ray absorptiometry in the analysis of synthetic standards is given in Table 5. The Ti-V results, example 1 , are representative of the best obtained, while those obtained for $\mathrm{Ni}-\mathrm{Cu}$, example 2, are typical of the less accurate analyses. In the third example the possible presence of cobalt was allowed for in the EDGE2 computation for the same Ni-Cu sample, even though Co was known to be absent. This caused a change of approximately $1 \%$, relative, in the estimate of the $\mathrm{Cu}$ and less for the $\mathrm{Ni}$.

Table 5. X-ray absorptiometric analysis of metal foil synthetic standards.

Concentration (in \%)

\begin{tabular}{|c|c|c|c|c|c|c|}
\hline Example & $\underline{\mathrm{Ti}}$ & $\underline{V}$ & $\underline{\mathrm{Ni}}$ & $\underline{\mathrm{Cu}}$ & Co & $\begin{array}{c}\text { Thickness } \\
(\text { in } \mu \mathrm{m})\end{array}$ \\
\hline Given & 68.22 & 31.78 & -- & -- & -- & 22.02 \\
\hline Found & 68.15 & 31.85 & & & & 22.40 \\
\hline Given & -- & -- & 59.3 & 40.7 & -- & 11.63 \\
\hline Found & & & 61.2 & 38.8 & & 11.68 \\
\hline Given & -- & -- & $59 \cdot 3$ & 40.7 & 0.0 & 11.63 \\
\hline Found & & & 61.0 & 39.2 & -0.2 & 11.75 \\
\hline
\end{tabular}


The FORTRAN $V$ program IEMAT, mentioned in last year's report [4], has been completed and renamed EXCELS (Empirical X-ray Correction Employing Least Squares). This program employs a new technique for matrix size reduction (matrix is used here in the mathematical sense) which allows calibration and correction for interelement interferences in cases where the usual empirical correction approach fails due to insufficiencies in the standards. Thus far, tests of this program have centered around the high-temperature-alloy, nickel-basealloy, and stainless steel systems. In these systems, iron, nickel, and chromium are the principal constituents and give rise to extreme absorption and enhancement effects. As an example, Figure 17-A illustrates the serious calibration problem for $\mathrm{Ni}$ in $\mathrm{Ni}-\mathrm{Fe}-\mathrm{Cr}-\mathrm{Co}$ systems. Figure 17-B shows data for the same standards and relative intensities after correction in EXCELS.

B. Applications

The application of $\mathrm{x}$-ray fluorescence and the EXCELS program to the analysis of eight high-temperature alloys, and electronic and magnetic alloys has already been mentioned. Further support has been given to the SRM program through rapid preliminary analysis and homogeneity tests of incoming material for a new set of low alloy (special steel) SRM's. This program of quick testing of each incoming heat of steel has been beneficial in two ways. First, the acceptability of the material could be evaluated; and second, adjustments to the aim composition of future heats could be specified in order to maintain the over-all balance of the set.

The computations program for homogeneity analysis, CODEAV, has been partially rewritten during the past year to overcome difficulties arising from the adoption by the NBS Computation Center of a new FORTRAN compiler for the UNIVAC 1108 computer. it the time of this revision, substantial improvements also 

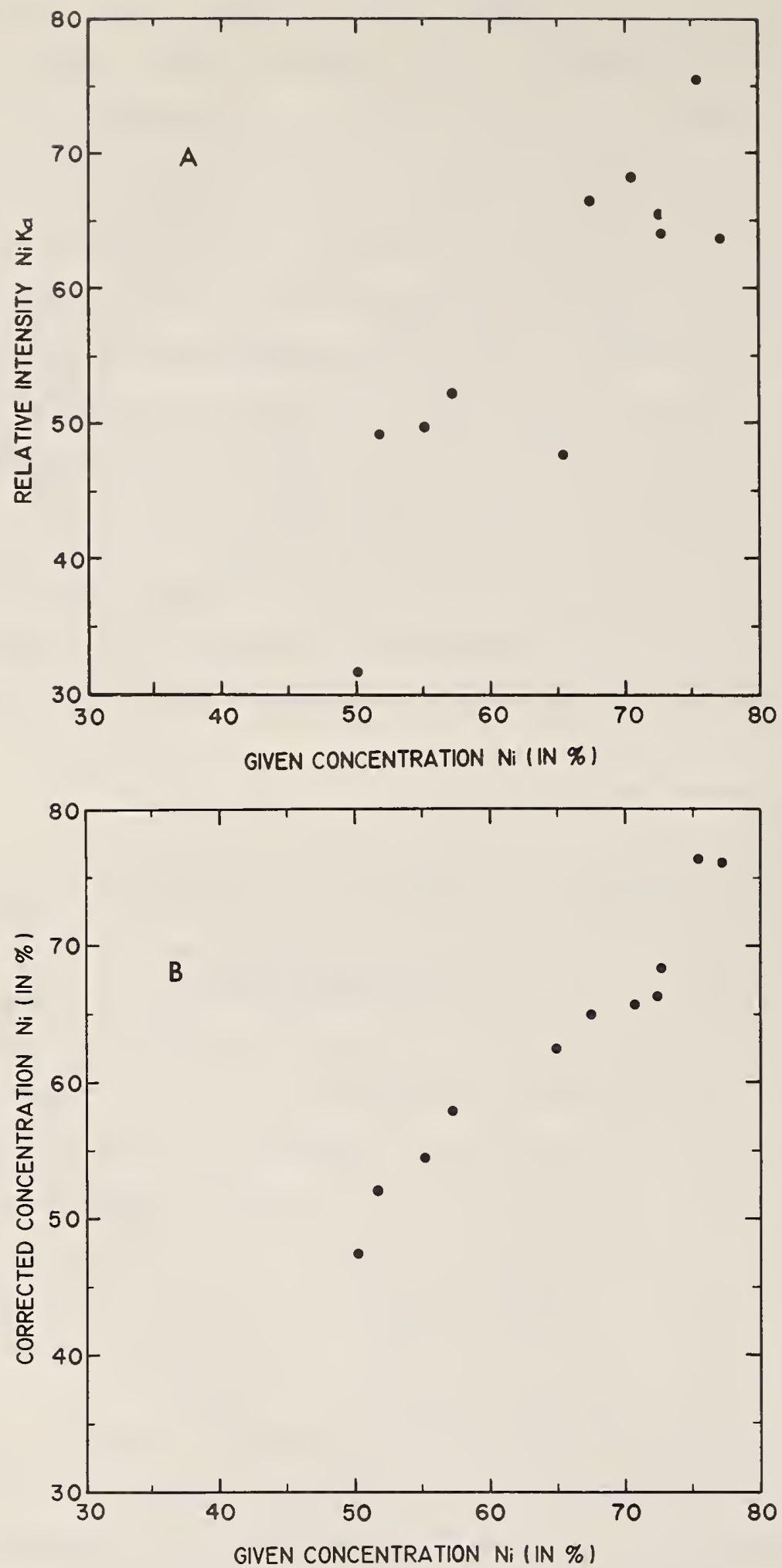

Figure 17. Determination of $\mathrm{Ni}$ in $\mathrm{Ni}-\mathrm{Fe}-\mathrm{Cr}-\mathrm{Co}$ alloy by $\mathrm{x}$-ray fluorescence. A - no correction; B corrected by EXCELS program. 
were made to the output format of CODEAV. One of the features added is the automatic scaling of concentrations to be printed so that the programmed round-off can be accomplished at the proper level of significance.

In the determination of vanadium at the $4 \%$ level in titanium an interesting application arose for the use of a technique for line interference correction presented earlier [24]. The overlap of $V K \alpha$ and $T i K \beta$ (the major constituent) precluded measurement of $V K \alpha$, so $V K \beta$ was selected as the analytical line. At first, the potential problem of $V \mathrm{~K} \beta$ and $\mathrm{Cr} \mathrm{Ka}$ line interference was underestimated, because $\mathrm{Cr}$ was present only at $0.0 \%$ to $0.2 \%$. However, an $x$-ray estimate of $4.24 \% \mathrm{~V}$ compared to a value of $4.07 \% \mathrm{~V}$ by wet chemical analysis of the same specimen stimulated us to try the correction mentioned. The corrected result for $x$-ray fluorescence analysis was $4.08 \% \mathrm{~V}$.

Typical materials analyzed in the past year, other than those already discussed, include ferrosilicon, copper foils, failed steel components, dental gold alloy, and dental silver alloy. Approximately 600 discrete elemental determinations were listed in 20 separate reports.

C. Contributions of NBS Personnel

Doward M. Bouchette has performed quantitative analyses and test of homogeneity, and James L. Izlar assisted in specimen identification and label checking by $x$-ray methods. We gratefully acknowledge the assistance of the late Clarence W. Gifford in the successful completion of the homogeneity testing of incoming ferrosilicon material.

Fielding Ogburn, Jacob Smit, and Virginia Pennington (from the Metallurgy Division) have been part-time guest workers carrying out a project of thickness measurements on electroplated metal coatings.

S. D. Rasberry 
Analysis by stable isotopic dilution with spark source mass spectrometry has been applied to the determination of trace impurities in high purity gold (SRM 685) and a NBS iron standard reference material. An investigation on the determination of impurities in various grades of acids is now in progress and exploratory work has been performed for the determination of trace elements in glasses using isotopic dilution methods. A discussion of this phase of our work is given in section 6 of this report. Two papers were written (see Section 7B) reporting the use of stable isotopic dilution with the spark source for the determination of trace elements in platinum SRM 681 and for trace elements in zinc SRM 728, 683. The trace characterization of Platinum SRM 681 by the spark source ion samples was examined in detail.

Referring to the mass spectrometer (CEC 21-110), modifications were made to the ion source pumping system, and the photographic plate pumping system was replaced with a larger pump to provide faster pump down and lower base pressures. A new development procedure for reducing plate background was adopted and the use of a fine mesh grid over the first aperture, to reduce charge broadening of matrix lines, was investigated. Support for the Standard Reference Materials program was provided through quantitative isotopic dilution analysis and spark source survey analysis of materials for trace elements.

\section{A. Instrument Modifications}

\section{Source pump}

The original source pumping system, using an oil diffusion pump, was replaced two years ago with a higher speed system [3, p. 52] based on titanium sublimation pumping combined with 
ion pumping. Compared to the original system lower base pressures were obtained, pump down was faster, and, most important in terms of improved instrument performance, 10 to 20 times lower pressures were maintained during sample sparking. A proportional improvement was found in instrument gas background. In this system a 6-in. gate valve sealed off the ion pump; however, the sublimation area was vented with the source each time a sample was loaded. With extended use the start-up time with the pump increased, although the ultimate vacuum was not adversely affected. This problem was apparently caused by the build up of a porous layer of titanium and titanium compounds. Because of this problem the system was redesigned and rebuilt. The new system, shown in Figure 18, was constructed from the components of the old system.

In the new system the 6-in. gate valve (item A) prevents the venting of the sublimation area. This positioning of the valve also decreases the volume of the system being vented, which in itself speeds pump-down time. Sublimation filaments (item B) are inserted into the 6-in. diameter stainless steel tubing leading to the 200 liter-per-second ion pump (item $\mathrm{C}$ ). The area in the tubing where titanium is sublimed is cooled with an external water jacket. Roughing of the system is done through a trap-valve situated behind the $90^{\circ}$ elbow at the top of the gate valve.

\section{New Pump for Plate Prepump Section}

The original photoplate pumping system provided with the instrument, which had an estimated conductance of 10 to 20 liters/s, has been replaced by a high speed system with a speed of approximately 400 liters/s. The pump, Figure 19, was purchased as a complete system of assembled matching components consisting of gate valve, liquid nitrogen cold trap, oil diffusion pump, vent valve, etc. With the original system, overnight pumping was required to prevent the plates from 


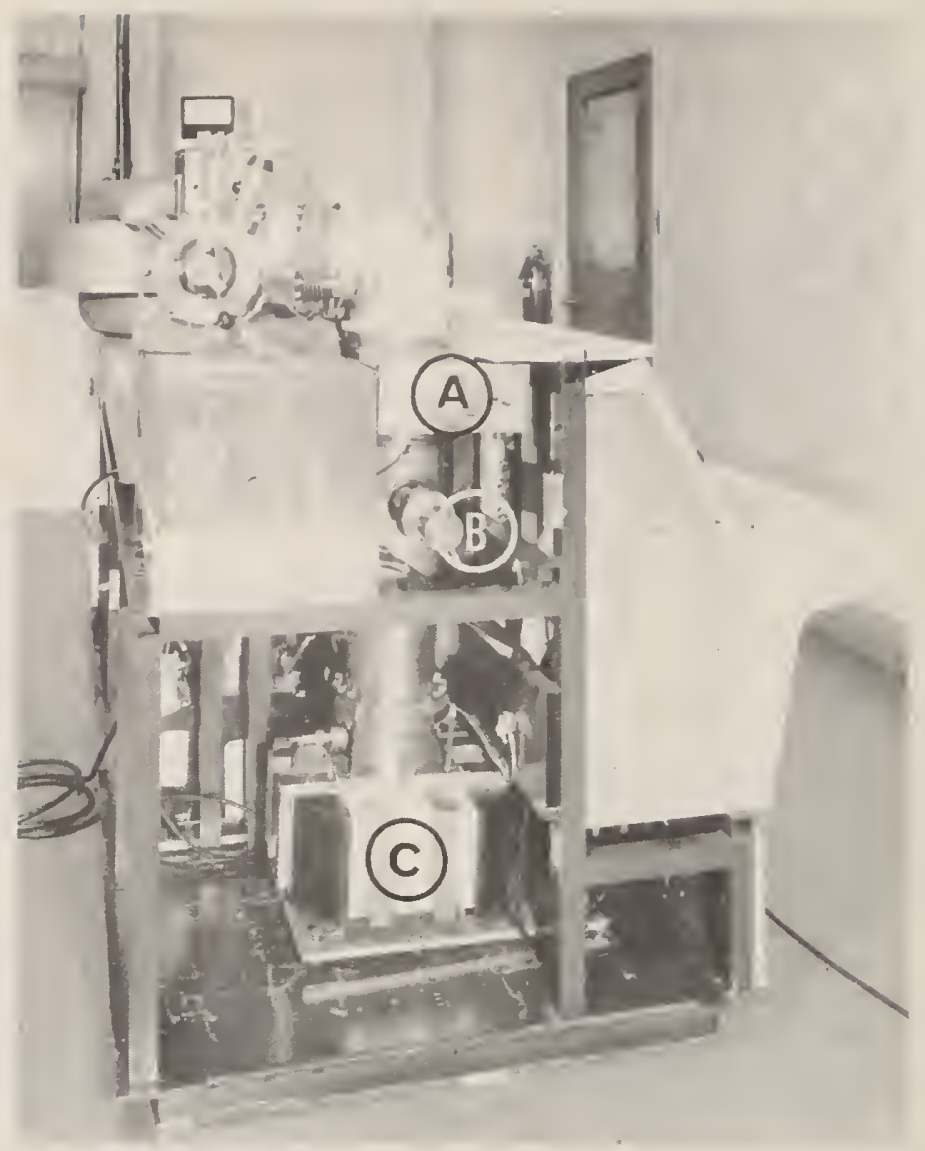

Figure 18. Rebuilt source pumping system. A. 6-in. gate valve. B. - sublimation filaments. C. - $200 \mathrm{l} / \mathrm{s}$ ion pump.

causing a significant rise in pressure when they were inserted into the magnetic analyzer. The new system provides faster pump-down speeds and a lower ultimate vacuum. A set of four new plates can be pumped to pressures in the high $10^{-7}$ torr range in two hours. Overnight pumping is presently providing a base pressure of $1 \times 10^{-7}$ torr in the plate prepump section.

B. Use of 100-mesh Grids to Remove Matrix Line Broadening

We have investigated the use of a grid over the first aperture to reduce charge broadening of major lines, as described by Franzen [25]. During the past year Ni, Mo, W, and $\mathrm{Au}$ 100-mesh grids with about $80 \%$ open space were tested. 


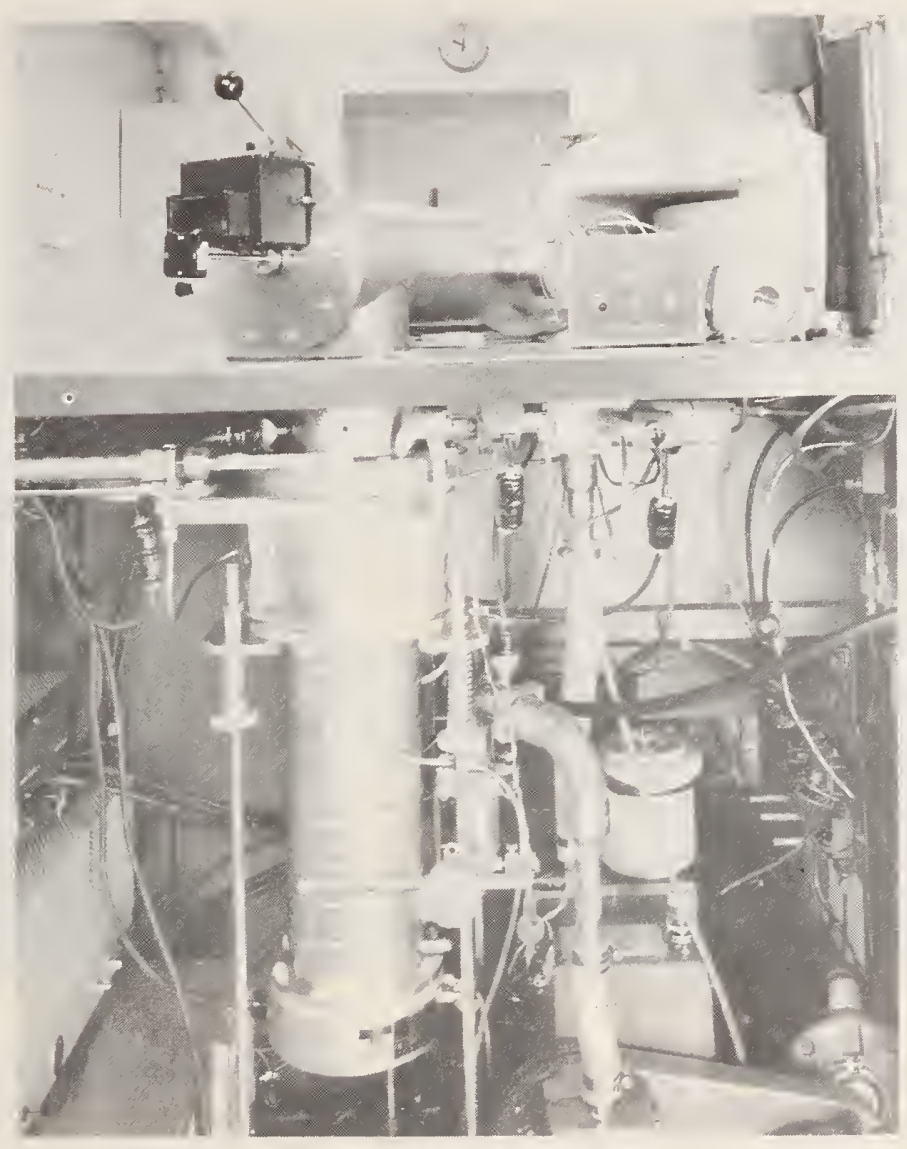

Figure 19. New pumping system for photographic plates.

Figure 20 shows the dramatic decrease in matrix line broadening brought about by the use of one such grid. Four sets of equal exposures were made on doped Pt (NBS SRM 681), (top to.bottom $1 \times 10^{-11}, 1 \times 10^{-10}, 1 \times 10^{-9}, 1 \times 10^{-8}$ coulombs), the top exposure of each pair being made using a 100-mesh Au grid. The grids tested so far have two drawbacks: ( 1 ) the grid material shows up in the spectrum (the gold lines come from the grid and not the Pt) and (2) the 100-mesh grid decreases the ion beam current by a factor of approximately three, which for all practical purposes results 


\section{III $10^{-11}$}

III I $10^{-10}$

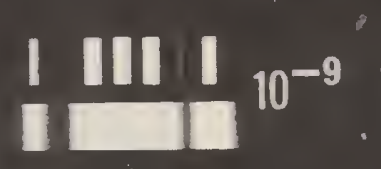

Figure 20. Exposures of Pt SRM 681 with and without a 100-mesh Au grid. The collected charge (coulombs) is given for each set of exposures.

in a 3-times poorer detection limit for elements in general. Charge broadened lines normally cause us trouble only when they overlap nearby elements such as in the case for Ir in Pt. Our measurement of integrated peak-intensity areas [2] compensates for any line width variation.

\section{Plate Development}

Cavard [26] has recently published a processing procedure using a bleach followed by development with an "internal image developer" (MK-7). This development procedure is now used routinely for all plates. Figures 21,22 , and 23 illustrate how the use of a grid over the first aperture and MK-7 developer can improve the detection of impurities near matrix 


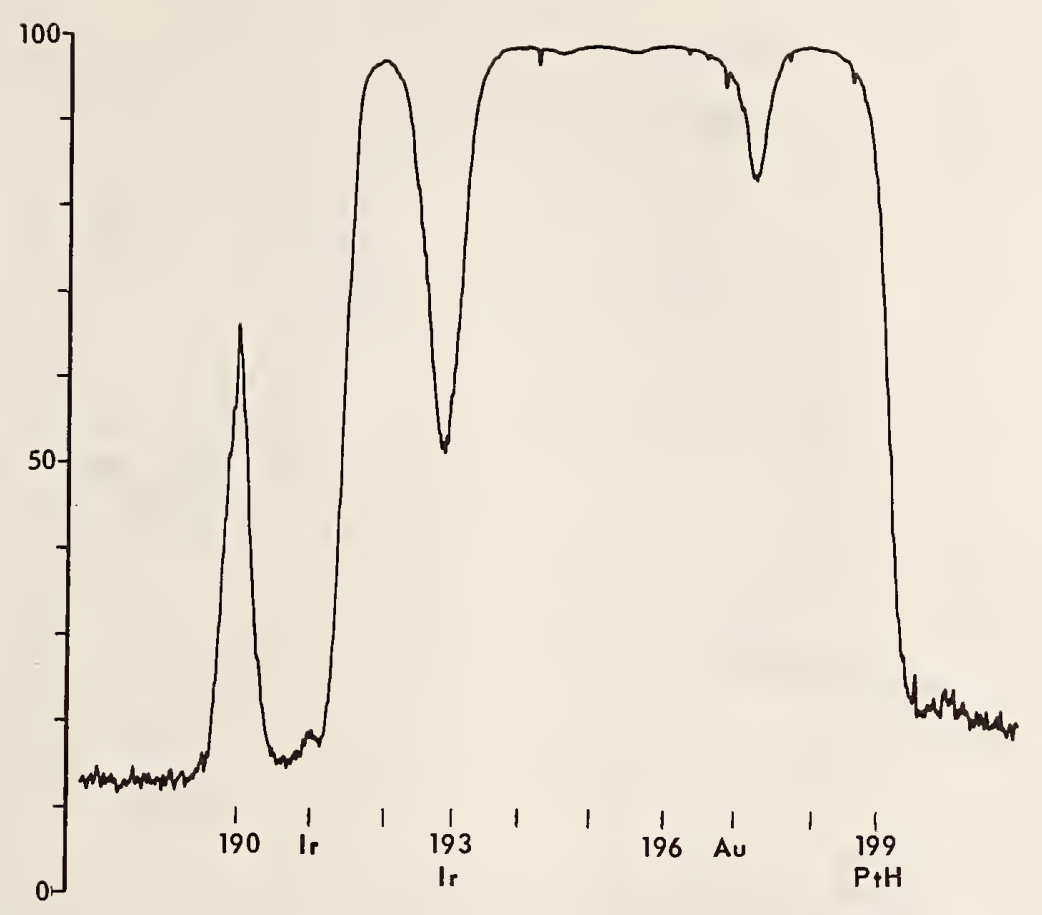

Figure 21. Mass spectrum of Pt SRM 681 without grid, using Cavard!s developer (MK-7).

lines. All absorption traces were made on $1 \times 10^{-8}$ coulomb exposures of the same platinum sample (SRM 681). Figure 21 shows a spectrum obtained without a grid (using MK-7) -- the $10 \mathrm{ppm}$ Ir in the sample is just detectable but not measurable at the 191 isotope; the spectrum in Figure 22 was made using a grid and developed with D-19 -- both Ir isotopes are now detected, all lines are sharper, the 194, 5, 6 Pt isotopes are resolved, and lines for $\mathrm{Au}$ and ${ }^{198} \mathrm{Pt}^{+}$are now visible; the spectrum in Figure 23 was obtained using a grid and MK-7 developer and shows a marked decrease in background as compared to Figure 22 . 


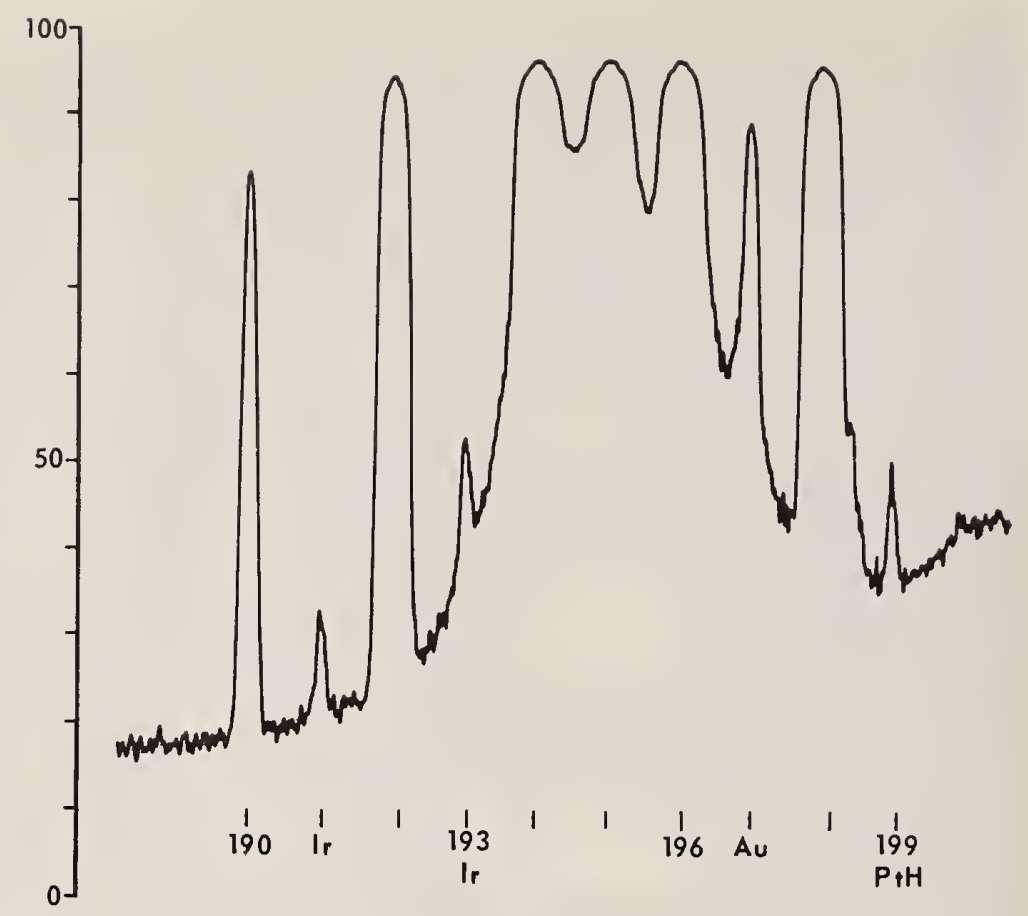

Figure 22. Mass spectrum of Pt SRM 681 with grid, using D-19 developer.

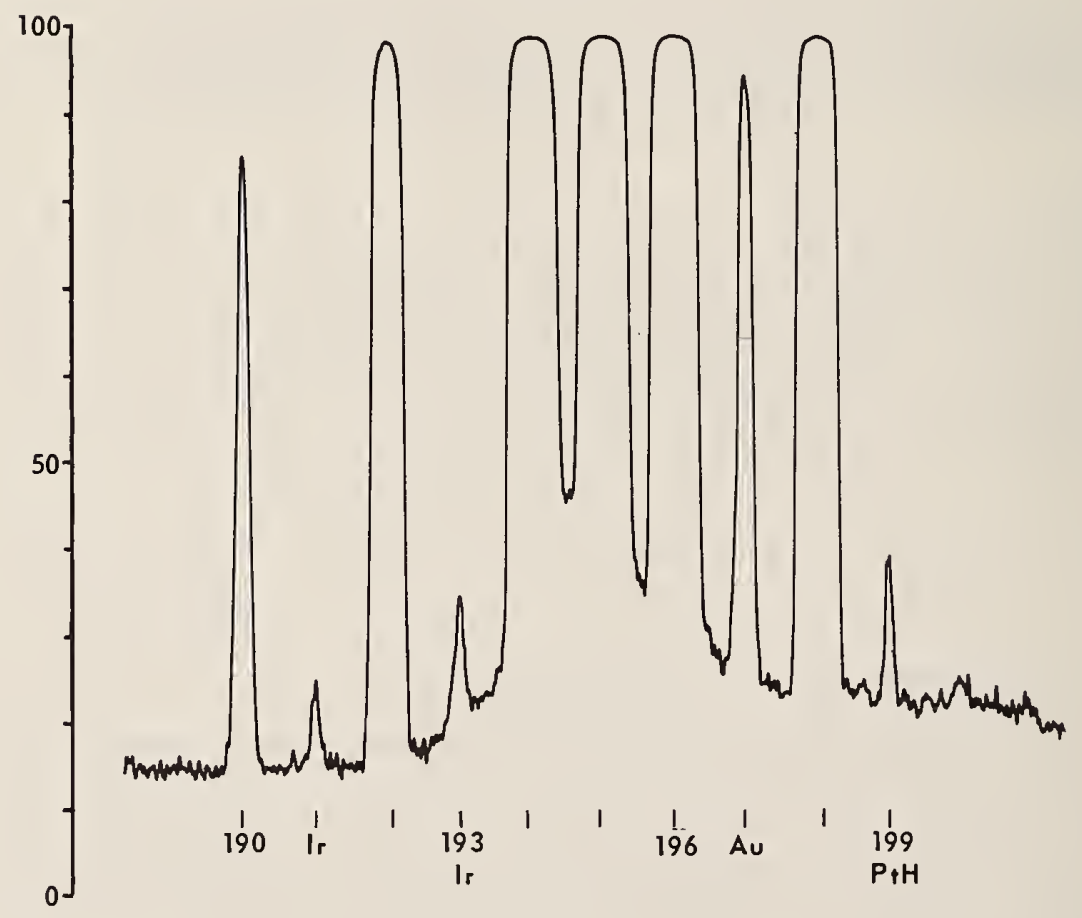

Figure 23. Mass spectrum of Pt SRM 681 with grid, using Cavard's developer (MK-7). 
D. Homogeneity Testing of Iron in High Purity Gold SRM 685

Spark source mass spectrometry was used to perform extensive testing for all impurities by direct sparking of the gold SRM 685 produced this year. In addition, isotopic dilution analysis was attempted on $\mathrm{Cu}$, In, $\mathrm{Fe}$, and $\mathrm{Ag}$ in the gold (see Section 6). Composition information on these elements plus oxygen is given on the certificate using a number of different techniques of analysis. Homogeneity tests were performed by direct sparking for iron but not for $\mathrm{Cu}$, In, and $\mathrm{Ag}$ which did not give adequate signals. Samples from four portions of the gold wire were all compared to the same sample of commercially pure gold (iron content unknown). A test sample of SRM 685 and the commercial gold were exposed on the same plate using alternate positions on the photoplate. Alternation of exposures allows an averaging of any variation in plate sensitivity from one side of the plate to the other. Table 6 shows the ratio of the iron content in high purity gold to that in the commercially pure gold for four selected portions of the high purity gold wire. The \pm value is the 95\% confidence interval on the limiting mean ( $t .95 \mathrm{~s} / \sqrt{\mathrm{H}}$ ).

Table 6. Homogeneity tests for iron in gold SRM 685

Sample
$1-1$
$1-2$
$13-1$
$13-3$

Ratio Fe content in Au $685 / \mathrm{Fe}$ in commercial gold

$$
\begin{aligned}
& 0.178 \pm 0.014 \\
& .192 \pm .020 \\
& .184 \pm .021 \\
& .180 \pm .013
\end{aligned}
$$


There is no significant difference in the iron content of the four portions of iron wire within these precision limitations. When all the data from the four portions of wire are combined, the ratio is $0.183 \pm 0.007$ (with a coefficient of variation of $11 \%$ for a single determination).

E. Analysis of High Purity Materials

A number of analyses were performed on high purity metals for the Standard Reference Materials Program. An analysis of high purity tin SRM 741 is an example of this work. This tin is to serve as a freezing point standard on the International Practical Temperature Scale. Extensive testing of this material had been performed by measurement of its residual resistivity ratio (RRR). Based on the variations in the RRR, two samples were selected to represent portions that RRR predicted to contain the most and the least amount of the electrically active impurities. These were the samples submitted for analysis by the spark source in order to determine which elements were responsible for the differences in RRR values for the material. Antimony and possibly iron were suspected as the offending elements. The samples were run twice, the first time with a normal first aperture in order to obtain the maximum sensitivity for all elements and a second time using a grid on the first aperture in order to improve the detection of $\mathrm{Sb}$. Charge broadening of the Sn matrix lines can cause considerable trouble for Sb unless a grid is used. The samples were compared to an NBS tin standard SRM 435. Table 7 gives the results of this analysis.

The sulfur values found were considerably higher than expected in these samples. An additional comparison was then made to a tin sample run previously. Melting point and RRR data on the older sample indicated it was less pure than the SRM 741 under investigation. This "old" sample was found to contain at least 50 times less sulfur than SRM 741 , however 
Table 7. Analysis of high-purity tin SRM 741.

ppm by weight

$\begin{array}{ccc} & \text { Bar A } & \text { Bar B } \\ \text { S* } & 28 & 13 \\ \mathrm{Cu} & 0.11 & 0.07 \\ \mathrm{Fe} & <.1 & <.1 \\ \mathrm{As} & .06 & .04 \\ \mathrm{Sb} & <.5 & <.5 \\ \mathrm{~Pb} & .3 & .5\end{array}$

*The sulfur content of SRM 435 is not certified, therefore sulfur values were computed from an estimated sensitivity whose absolute value is good only to a factor of 3 to 10 .

the "old" sample did contain more $\mathrm{Cu}, \mathrm{Zn}, \mathrm{Pb}$, and $\mathrm{As}$. The. SSMS analysis does not contradict the freezing point and RRR information on these samples since the sulfur content of tin does not appreciably affect either of these parameters. The sample is designed to serve as a freezing point reference and not as a composition standard.

\section{F. Survey Analysis of a Steel Sample}

A series of special low-alloy steel SRM's is now in preparation. Acceptance tests are being performed by a number of techniques in order to ensure that the aim composition has been obtained before these materials are processed into samples and analyzed for certification. Tables 8 and 9 give the results of the spark source analysis of one such sample in comparison to results from other techniques. The SSMS measurements were referenced to NBS steel sample SRM 461 which served as a standard. The second column in Table 8 lists the concentrations determined with the spark source, based on three line measurements each for standard and sample. The third column reports 
Table 8. Mass spectrometric survey analysis of steel using a standard.

ppm by wt

\begin{tabular}{lrrr} 
Element & $\begin{array}{c}\text { Spark Source } \\
\text { VS. } 461\end{array}$ & Other Methods & $\begin{array}{c}\text { Percent } \\
\text { Difference }\end{array}$ \\
\cline { 2 - 3 } & 0.09 & 150 & $45 \%$ \\
$\mathrm{~Wb}$ & 270 & 100 & 23 \\
$\mathrm{Sn}$ & 130 & 4 & $33^{*}$ \\
$\mathrm{Ag}$ & 3 & 2,000 & 17 \\
$\mathrm{Mo}$ & 2,400 & 200 & 0 \\
$\mathrm{Nb}$ & 200 & 200 & 46 \\
$\mathrm{As}$ & 370 & 450 & 21 \\
$\mathrm{Cu}$ & 570 & 20,000 & 13 \\
$\mathrm{Ni}$ & 23,000 & 240 & 33 \\
$\mathrm{Co}$ & 360 & 6,600 & 8 \\
$\mathrm{Mn}$ & 7,200 & 7,100 & 3 \\
$\mathrm{Cr}$ & 6,900 & 120 & 62 \\
$\mathrm{~V}$ & 74 & 190 & $120 *$ \\
$\mathrm{Ti}$ & 66 & 130 & $67^{*}$ \\
$\mathrm{~S}$ & 390 & 12 & $48 *$ \\
$\mathrm{O}$ & 23 & 3,700 & 16 \\
$\mathrm{C}$ & 3,200 & & 24 \\
& & Average & 24
\end{tabular}

*Since determinations for these elements listed on the certificate were not certified, these differences were omitted in computing the average.

the average values by the other methods of analysis, and the last column the percentage difference between the spark source results and those of the other techniques. The average difference is shown to be $24 \%$. 
Table 9 lists the spark source results for elements which were not certified in SRM 461 and therefore the values are based on estimated sensitivity factors. Common practice is to claim that the accuracy of the estimation method is

Table 9. Mass spectrometric survey analysis of steel using estimated sensitivity factors.

Spark Source

Element vs.Matrix Sens. Other Methods Error Factor ppm by wt

$\begin{array}{lccc}\mathrm{Bi} & 2.9 & 6 & 2.1 \\ \mathrm{La} & 19 & 8 & 2.4 \\ \mathrm{Te} & 40 & 4 & 10 \\ \mathrm{Zr} & 70 & 100 & 1.4 \\ \mathrm{Zn} & 5.0 & 7 & 1.4 \\ \mathrm{Ca} & 9.2 & 1 & 9.2 \\ \mathrm{Mg} & 47 & 1.5 & \text { A1 } \\ & & & \text { Average }\end{array}$

no better than a factor of 3 to 10. The last column lists an "error factor", a ratio of the results of spark source to other techniques. The average error factor for this set of elements is 8.2. The estimation is based on all elements having equal atomic sensitivity and then correcting for changes in plate sensitivity with mass. As is the case here, the estimation method usually gives high results for the alkalies and alkaline earths.

P. J. Paulsen, C. W. Mueller 
G. Trace Characterization of Spark Source Ion Samples of SRM Platinum 681

\section{Introduction}

The precision and accuracy with which materials (solids) can be trace characterized by Spark Source Mass Spectrometry continue to be a problem of concern to all using this analytical technique. In the annual report last year [4] methods for measuring the homogeneity of ion sensitive plates were described and results for Q-2 plates were presented. In that work advantage was taken of the wide spread in relative abundances of the isotopes of platinum. Using SRM platinum 681 , replicate exposures of $5 \times 10^{-11}$ coulombs to the monitor were made. These adequately recorded the platinum 192 isotope, the concentration of which is about $7800 \mathrm{ppma}$.

In the experiments reported herein, replicate exposures of $5 \times 10^{-9}$ coulombs are made. This adequately records the platinum 190 isotope whose concentration is 123 ppma. It also records most of the trace elements certified in SRM Pt 681 that are present in the 1 to 100 ppma range. Data from such replicate exposures characterize the trace ions in the recorded ion samples and yield information on the precision achieved under the prevailing experimental conditions.

\section{Results}

Data for platinum and for trace elements copper, lead, and palladium are presented in Figure 24. The integrated value of the ion beam profile of the mass line in question is plotted on the vertical axis and the succession of 21 replicate exposures is delineated on the horizontal axis. The above integrated values are normalized by dividing by the average of the specific trace values from the 21 exposures recorded. During the six exposures indicated by triangular points, the 


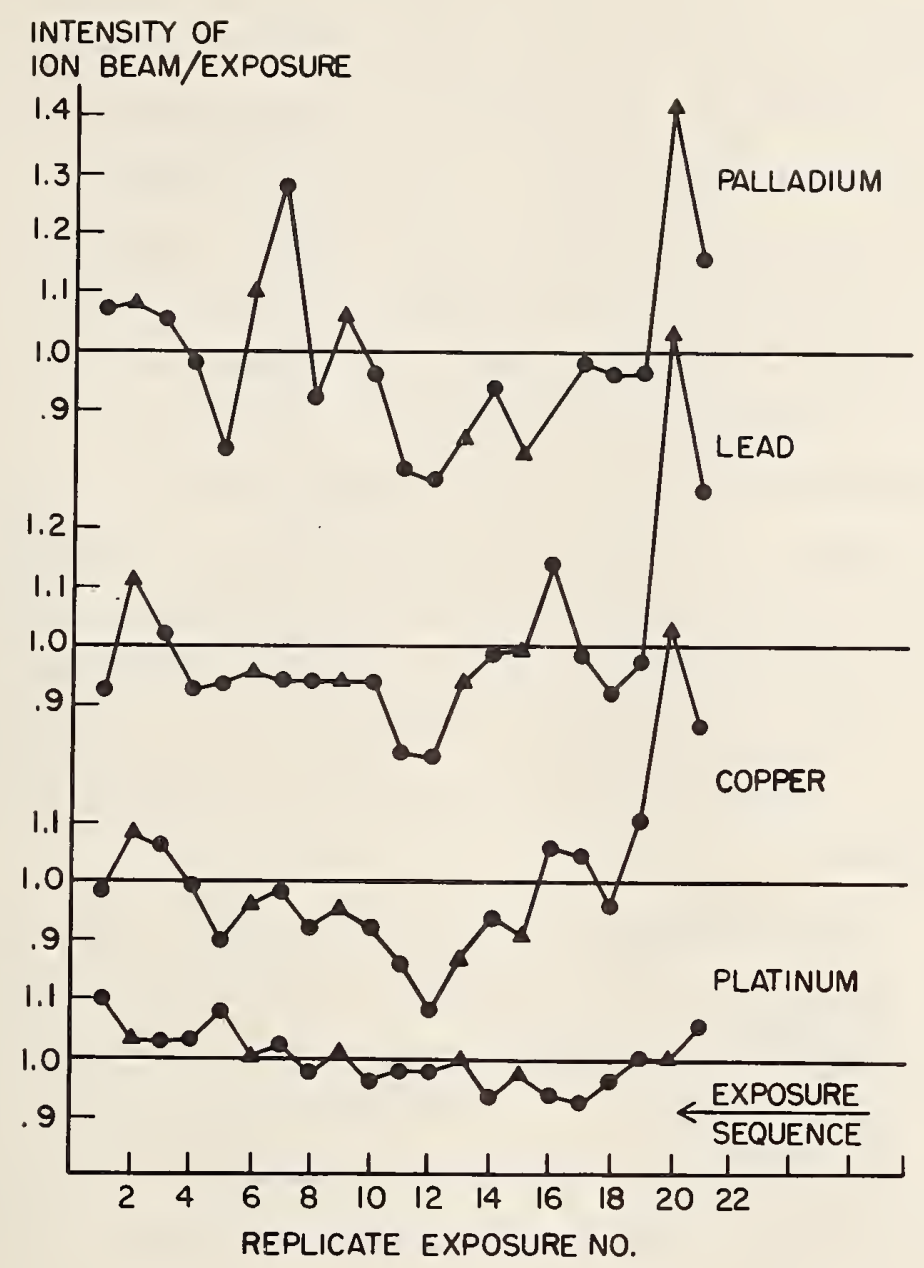

Figure 24. Normalized ion beam measurements of trace elements in spark source ion sample Pt SRM. - - satisfactory run. - - spark stopped, restarted.

spark stopped and was restarted by decreasing the electrode separation. For all three trace elements shown in Figure 24 and for the seven trace elements measured but not shown here, the integrated beam value for exposure 20 was significantly greater than for exposures 19 and 21 . For the other exposures, during which the spark stopped, smaller differences between this integrated beam value and its adjacent values were observed. A substantial number of them gave lower beam values. 
Nevertheless, for these six exposures extensive changes in one spark parameter were occurring. Due to electrode consumption, the separation increases to the point where it is too large to sustain the spark. When the spark is restarted, this gap is substantially less than the maximum at which the spark is sustained. Because of these major gap changes, all data for these six exposures were deleted in compiling results presented in Tables 10 and 11 .

Table 10 presents relative standard deviations for the integrated beam values of each of the 10 trace elements and platinum. Corresponding to the elements listed in the first column, the second column lists the relative standard deviation for the data remaining after the deletions indicated above. Note that it varies from $15.7 \%$ for phosphorus to $6.8 \%$ for iron and rhodium.

The ratio of the reading for a particular trace element to the corresponding value for lead at each exposure was then calculated. The relative standard deviation of these ratios is given in the third column. The relative standard deviations of the various trace element/lead ratios to be expected, if the trace element readings varied independently of one another, are given in the fourth column of Table 10. The difference between the observed values in column 3 and those ir column 4, expected on the basis of independent fluctuations, clearly shows that the integrated beam values for the trace elements do not in general fluctuate independently.

The data of Table 10 also show that the fluctuations in the integrated beam values of the trace elements are greater -in many cases substantially greater -- than those due to instrumental factors alone as revealed by the $4.6 \%$ value for the major component platinum.

Two alternative interpretations of the data of Table 10 are:

a. The number of trace element ions in the recorded 


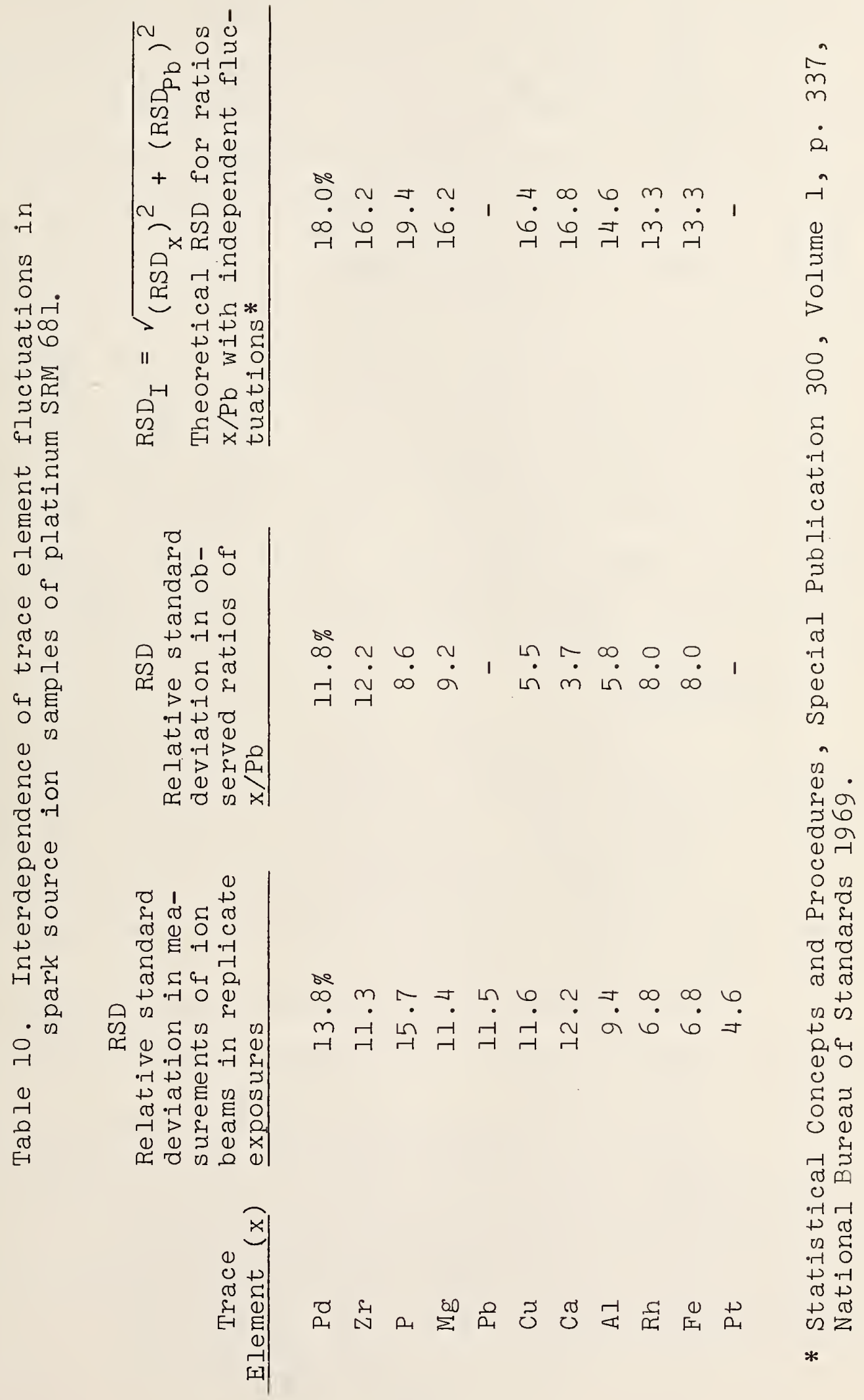


ion sample may fluctuate in successive exposures due to variations in the spark source parameters not under control.

b. This number may fluctuate in successive exposures because the platinum sample itself is inhomogeneous.

In any event, it seems clear from Table 10 that the trace elements in this platinum do not fluctuate independently.

Table 11 presents the trace element composition of ion samples from SRM platinum 681. Results are given from two different plates, one of which (plate 105D) furnished the data of Figure 24 and Table 10. The $\mathrm{ts} / \mathrm{n}^{1 / 2}$ values give the 95\% confidence interval. The concentrations listed are the ratio of the integrated ion beam of the trace element to that of the platinum 190 ion corrected for isotope effects, mass effect, and ionization pattern. The NBS certified values for a number of the trace elements are included in Table 11. Relative Sensitivity Factors (the average of the two SSMS values divided by the NBS certified value) are also listed.

\section{Discussion}

a. In these replicate tests, the relative standard deviation for a trace element in the recorded ion samples is greater in general than for the major component platinum.

b. This probably indicates that there are fluctuations ( 1 ) in the relative production of trace element ions in the spark source and/or (2) in the transmission of these ions from this source to the detector.

c. The fluctuations in the concentrations of the several trace elements in the ion sample recorded are not independent of each other.

d. An alternative interpretation of item a in terms of sample inhomogeneity must not be overlooked. On this basis item $c$ would indicate that the trace elements in the sample tend to have the same topographical distribution.

Further study will be made to ascertain the causes of the observed variability. 


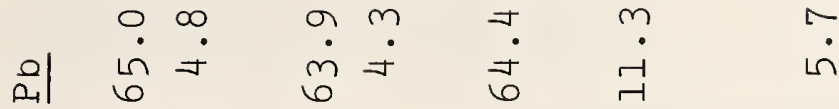

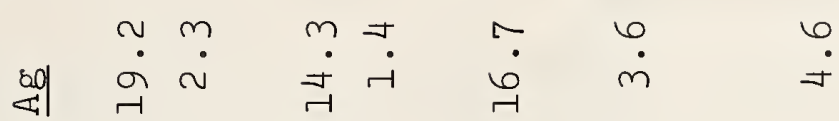

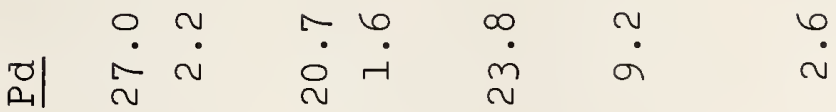

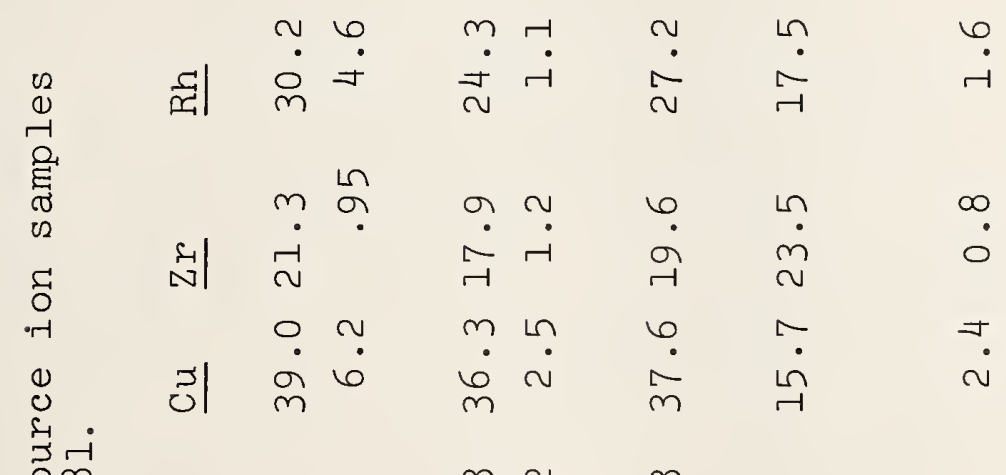

$0 \infty 6$

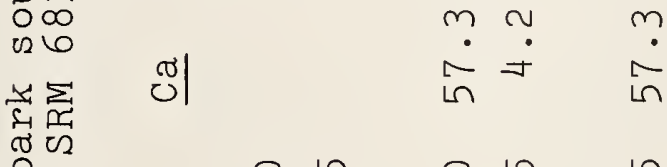

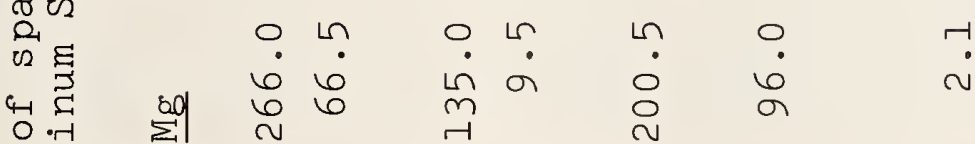

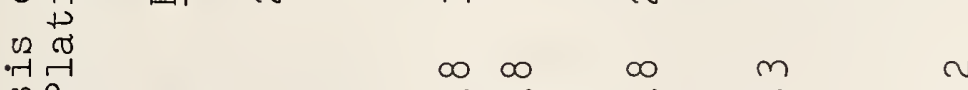

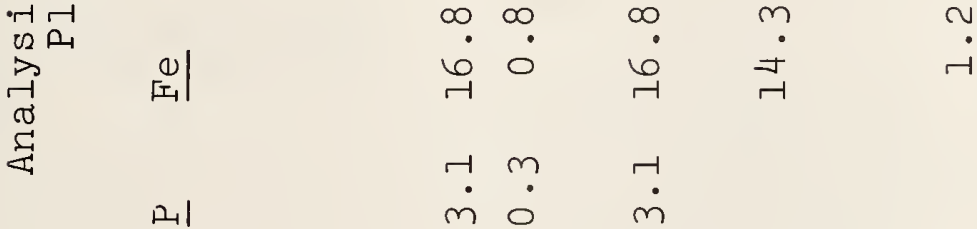

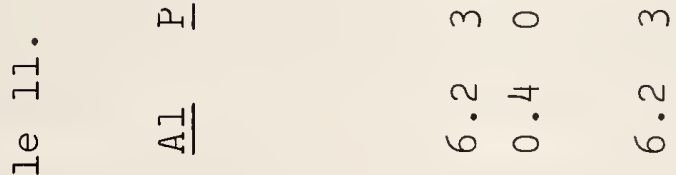

है

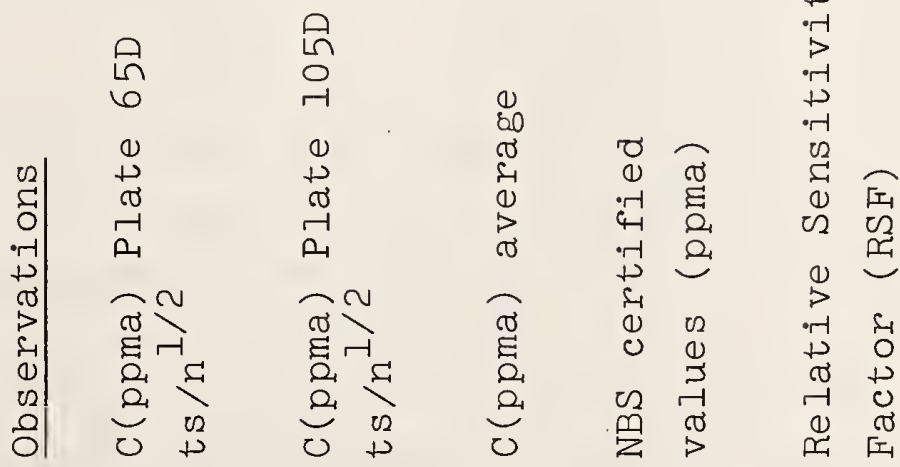


A. High Purity Metals

In last year's annual report [4], we outlined stable isotope dilution - spark source mass spectrometric (ID-SSMS) methods developed for simultaneously determining several trace elements in zinc and platinum. The platinum procedure has been published in the June 1969 issue of Analytical Chemistry; the zinc method is scheduled for publication in Volume $24 \mathrm{~B}$ of Spectrochimica Acta. In the zinc procedure, the isotopically altered trace elements were electrodeposited onto gold wires from the zinc solution in one operation. The gold wires were then sparked in the spectrograph. In the platinum method, the spiked trace elements were separated from the platinum solution by ion-exchange and then were electrodeposited onto gold wires for sparking. The electrodeposition step, which is common to both methods, provides the trace elements in an adherent form relatively free of anions. In the platinum method, the analytes are also relatively free of hydrocarbons from the ion exchange resin. The presence of these species during sparking can complicate the spectrum. Moreover, because electrodeposition requires fewer manipulations than the alternative of evaporating a solution of the analytes onto gold wires, it is less subject to contamination.

To determine $\mathrm{Ag}, \mathrm{Cu}, \mathrm{Fe}$, and In in a high purity gold material, subsequently issued by NBS as Standard Reference Material 685, an ID-SSMS method was developed. In the procedure, aqua regia and known amounts of the enriched isotopes were added to a weighed sample. The resulting solution was then evaporated to dryness to remove the excess acid. Water was added to the residue and the solution passed through a cation exchange column. After elution from the column, the acid eluate containing the spiked analytes was neutralized with ammonia and the trace elements were electrodeposited onto 
gold wires for sparking in the spectrograph. The concentrations determined ranged from $0.2 \mathrm{ppm}$ for Fe to $0.004 \mathrm{ppm}$ for In. Indium, at this concentration of $4 \mathrm{ppb}$, was at the threshold of detectability by a direct SSMS examination of the gold wire material, SRM 685W. The preconcentration step of the ID-SSMS procedure provided sufficient intensity for the isotope mass lines to yield these individual results: $0.0040,0.0039,0.0036 \mathrm{ppm}$ In. For In and Ag, the method blanks were an order of magnitude lower than the concentrations being determined. The spiked blanks were run at the same time and under the same environmental conditions as the samples. For the more common elements, $\mathrm{Cu}$ and $\mathrm{Fe}$, the blanks were higher. This was to be expected considering the relatively large number of manipulations that the method required. Fe, corrected for blank, was found to be $0.20 \mathrm{ppm}$ compared to the NBS Certificate value of $0.3 \mathrm{ppm}$, which includes polarographic and spectrophotometric results. For $\mathrm{Cu}$, a value of $\leq 0.1 \mathrm{ppm}$ was reported, because of the magnitude and large variations in the blank. The certificate value is $0.1 \mathrm{ppm}$.

B. Ingot Iron and Steels

In 1955, a set of ingot iron and steels was prepared primarily to serve as standards for spectrochemical analysis. Designated as NBS 1161-1168, their compositions include trace elements appearing in ferrous-base materials either as tramp elements or as additions. Many of these elements were not certified because of their seemingly innocuous effect on the properties of steel. Since then some of these elements have been found to be significant and there has been an increasing interest in accurate determinations. A renewal set of iron and steel SRM's is in preparation and reliable results for these trace elements are desirable. 
Although the ID-SSMS methods that have been developed have been applied only for trace element determinations in high-purity metals, the methods have a broader scope. Consequently an ID-SSMS method has been applied to the simultaneous determination of $\mathrm{Ag}, \mathrm{Cu}$, Mo, and $\mathrm{Ni}$ in ingot iron ranging from $0.0005 \%$ for $\mathrm{Ag}$ to $0.026 \%$ for $\mathrm{Ni}$. Moreover, in the analysis of NBS 1165, a relatively constant ratio of the mass lines produced by the Co nuclide and a $\mathrm{Ni}$ isotope has been observed because of the chemical similarity of the two elements. This enables the determination of $\mathrm{Co}$, which is mononuclidic in nature, at the same time. In the analytical procedure developed, known amounts of enriched isotope solutions are added to the samples being dissolved. The iron is extracted and the trace elements are electrodeposited onto gold wires for sparking. In addition to the altered isotope ratios, the Co to $\mathrm{Ni}$ isotope ratios are also determined. The procedure will be detailed in a manuscript being prepared for publication.

\section{c. Simulated Lunar Glasses}

These proposed standard reference materials contain additions of $0.02,1,50$ and $500 \mathrm{ppm}$ of 61 elements in a soda lime glass. This base material was selected because it dissolves a great number of elements over a wide concentration range. It is anticipated that reliable determinations made on these samples, thus providing certified values, would assist analysts to detect possible systematic errors in their analytical procedures.

Very preliminary experimentation on the 50-ppm addition SRM indicates that at least ten elements are determinable simultaneously using one separation scheme. Particularly for the 1 and $0.02 \mathrm{ppm}$ SRM's, an experimental design is being investigated to enable all operations of sample dissolution, 
enriched isotope spiking, and separation of the equilibrated trace elements to be performed in the same vessel.

\section{Ultra-Pure Liquid Reagents}

Reagent purity often limits the minimum concentration of a trace element that can be determined by an analytical method. The acids employed are particularly important because of the relatively large volumes required for sample dissolution. Before undertaking a complex analytical problem, such as the previously described method for determining ultra-trace impurities in high-purity gold, it would obviously be advantageous to select the purest acid with respect to the trace elements of interest. An ID-SSMS method for analyzing ultrapure reagents is being investigated. Enriched isotope solutions of approximately ten different elements are added to 100-ml samples, and 20-ml aliquots are evaporated to about $200 \mu l$ in a clean environment. The liquid residue is pipetted onto gold wires and evaporated to dryness. The wires are sparked in the mass spectrograph. A qualitative examination of the spectra often suffices for selection of the acid that is to be used in the analytical procedure. However, by measuring the appropriate isotope ratios, a precise determination of impurities can be made.

R. Alvarez, P. J. Paulsen, C. W. Mueller 


\section{A. Personnel Listing}

Spectrochemical Analysis Section

Bourdon F. Scribner, Section Chief

Arthur J. Ahearn, Research Physicist

Karen L. Loraski, Section Secretary

Brenda J. Brown (Summer Assistant, 1968)

Group I. Optical Spectrometry

Marvin Margoshes, Chemist (Resigned, June 1969)

Joseph L. Weber, Jr., Physicist

Martha M. Darr, Chemist

Virginia C. Stewart, Chemist

Doward M. Bouchette, Physical Science Technician

Kimberly V. Koppe (Summer Assistant, 1969)

Group II. X-Ray Spectrometry and Electron Probe Microanalys is

Kurt F. J. Heinrich, Chemist

Donald L. Vieth, Physical Metallurgist (On extended leave)

Robert L. Myklebust, Chemist

Stanley D. Rasberry, Physicist

Jean R. Hénoc, Physicist (Guest Worker)

Barry L. Hammond, Chemist (Research Associate)

Charles E. Fiori, Electronic Technician

Marcia D. Mayfield (Summer Assistant, 1968)

Jerome S. McKay, Jr. (Temporary)

Jeremy R. Winick (Summer Assistant, 1969)

Katherine C. Burress (Summer Assistant, 1969)

Part Time Guest Workers:

Harvey Yakowitz, NBS Metallurgy Division

Fielding Ogburn, NBS Metallurgy Division

Group III. Spark Source Mass Spectrometry

Paul J. Paulsen, Chemist

Charles W. Mueller, Chemist

Daniel E. Kelleher (Transferred, Sept. 1968)

Larry L. Shank (Summer Assistant, 1969)

Group IV. Enrichment Techniques

Robert Alvarez, Chemist 
B. Publications

1. Yakowitz, H., and Heinrich, K. F. J.

Inclusion Identification by Means of Electron Probe Microanalysis, Metallography I, 55-79 (1968).

2. Scribner, B. F. (Editor)

Spectrochemical Analysis Section: Summary of Activities July 1967 to June 1968, NBS Tech. Note 452, Sept. 1968.

3. Heinrich, K. F. J. (Editor)

Quantitative Electron Probe Microanalysis, NBS Spec.

Publ. 298 Oct. 1968, 299 pp.

4. Heinrich, K. F. J., and Yakowitz, H.

Quantitative Electron Probe Microanalysis: Fluorescence Correction Uncertainty, Mikrochim. Acta 1968, 905-916.

5. Heinrich, K. F. J.

Common Sources of Error in Electron Probe Microanalysis, Advances in X-ray Analysis, Vol. 1l, 40-55, (1968),

Plenum Press, N. Y.

6. Veillon, C., and Margoshes, M.

An Evaluation of the Induction-coupled, Radio-frequency

Plasma Torch for Atomic Emission and Atomic Absorption Spectrometry, Spectrochim. Acta, 23B, 503-12 (1968).

7. Veillon, C., and Margoshes, M.

A Pneumatic Solution Nebulization System Producing Dry Sample Vapor for Atomic Spectroscopy, Spectrochim. Acta, 23B, 553-5 (1968).

8. Heinrich, K. F. J .

Electron Probe Microanalysis: A Review, Appl. Spectroscopy 22, 395-403 (1968).

9. Ampian, S. G., and Myklebust, R. I.

Intermediate Phases in the Solid State Synthesis of $\mathrm{Na}_{2} \mathrm{ZrSiO}_{5}$, J. Am. Ceramic Soc. 51, 605-7 (1968).

10. Ahearn, A. J.

Homogeneity of Ion Sensitive Emulsions and Precision of Ion Beam Measurements in Spark Source Mass Spectrometry (A Summary), Sixteenth Annual Conference on Mass Spectrometry and Allied Topics, Pittsburgh, Pa., May 1968, pp. 271-3. 
11. Ahearn, A. J., and Paulsen, P. J. Workshop on Mass Spectrometric Analys is of Solids, Anal. Chem. 4I, Feb., 79A-8IA (1969).

12. Alvarez, R., Paulsen, P. J., and Kelleher, D. E. Simultaneous Determination of Trace Elements in Platinum by Isotope Dilution and Spark Source Mass Spectrometry, Anal. Chem. 4l, No. 7, pp. 955-8 (1969).

13. Yakowitz, H., and Heinrich, K. F. J.

Color Representation of Electron Microprobe Area-Scan Images by a Color Separation Process, J. Res. NBS, 73A, No. 2, pp. 113-23 (1969).

14. Heinrich, K. F. J.

Review: 3rd National Conference on Electron Microprobe Analysis and the lst Annual Meeting of the Electron Probe Analysis Society of America, Chicago, 31 July - 2 August 1968, Appl. Optics 8 , No. 4, 862-3 (1969).

15. Heinrich, K. F. J. Advances in the Metallurgical Applications of Electron Probe Microanalysis, Proceedings V International Congress on X-ray Optics and Microanalysis, Tuebingen, West Germany, Sept. 1968 (In press).

16. Heinrich, K. F. J., and Yakowitz, H.

Propagation of Errors in Correction Models for Quantitative Electron Probe Microanalysis, Ibid. (In press).

17. Margoshes, M.

Linearization of Characteristic Curves in Photographic Photometry, Appl. Optics (In press).

18. Margoshes, M., and Rasberry, S. D. Application of Digital Computers in Spectrochemical Analysis. I. Computational Methods in Photographic Microphotometry, Spectrochim. Acta, Part B, (In press).

19. Paulsen, P. J., Alvarez, R., and Kelleher, D. E. Determination of Trace Elements in Zinc by Isotope Dilution Spark Source Mass Spectrometry, Spectrochim. Acta, Part B (In press).

20. Margoshes, M., and Rasberry, S. D.

Fitting of Analytical Functions with Digital Computers in Spectrochemical Analysis, Anal. Chem. (In press). 
21. Margoshes, M.

The Future of Data Acquisition and Computation in Spectrochemical Analysis, Spectrochim. Acta, Part B (In press).

C. Talks Given

1. Heinrich, K. F. J., "Propagation of Errors in Correction Models for Quantitative Electron Probe Microanalysis," 5 th International Conference on X-ray Optics and Microanalysis, Tübingen, Germany, September 10, 1968.

2. Heinrich, K. F. J., "Metallurgical Applications of Electron Probe Microanalysis," 5th International Conference on X-ray Optics and Microanalysis, Tubingen, Germany, September 12, 1968.

3. Margoshes, M., "Laser Probe Spectrochemical Analysis," Scientific Apparatus Manufacturers Association, NBS, Gaithersburg, Ma., September 17, 1968.

4. Margoshes, M., "Use of the Computer Where Flexibility is Needed," Eastern Analytical Symposium, New York, N. Y., November 14, 1968.

5. Heinrich, K. F. J., "Energy Dispersion with Electron Excitation," Eastern Analytical Symposium, New York, N. Y., November 15, 1968.

6. Paulsen, P. J., "Isotopic Dilution Analysis with the Spark Source Mass Spectrograph," Eastern Analytical Symposium, New York, N. Y., November 15, 1968.

7. Heinrich, K. F. J., "Data Collection and Evaluation in Microprobe Analysis," Midwest Probe Users' Group, St. Louis, Mo., December 5, 1968.

8. Scribner, B. F., "Modern Developments in Spectrometric Analysis," Clarion State College, Clarion, Penn., December $11,1968$.

9. Alvarez, R., "Simultaneous Trace Element Determinations by Isotope Dilution Techniques and Spark Source Mass Spectrometry," Society for Applied Spectroscopy, Clarksville, Ma., January 28, 1969.

10. Rasberry, Stanley D., "Automatic Collecting and Processing of Microprobe Data," Society for Applied Spectroscopy, Clarksville, Md., January 28, 1969. 
11. Ahearn, A. J., "Trace Characterization of Materials by Spark Source Mass Spectrometry," 4th Middle Atlantic Regional Meeting of the American Chemical Society, Washington, D. C., February 14, 1969.

12. Alvarez, R., "Multi-element Trace Determinations by Isotope Dilution Techniques," 4th Middle Atlantic Regional Meeting of the American Chemical Society, Washington, D. C., February 14, 1969.

13. Heinrich, K. F. J., "New Instrumentation for Electron Microprobe Analysis and Scanning Electron Microscopy," American Institute of Mining, Metallurgical and Petroleum Engineers, Washington, D. C., February 17, 1969 .

14. Ahearn, A. J., "The Role of New Instruments for Mass Analysis in Metallurgy," American Institute of Mining, Metallurgical and Petroleum Engineers, Washington, D. C., February 17, 1969.

15. Rasberry, Stanley D., "Analysis of Thin Metal Foils by X-ray Absorptiometry," The Pittsburgh Conference on Analytical Chemistry and Applied Spectroscopy, Cleveland, Ohio, March 3, 1969.

16. Ahearn, A. J., "Trace Characterization of Solids by Spark Source Mass Spectrometry," Pittsburgh Conference on Analytical Chemistry and Applied Spectroscopy, Cleveland, Ohio, March 4, 1969.

17. Alvarez, R., "Simultaneous Trace Element Determinations in a New NBS High-Purity Gold (SRM 685) by Isotope Dilution, Spark Source Mass Spectrometry," Pittsburgh Conference on Analytical Chemistry and Applied Spectroscopy, Cleveland, Ohio, March 4, 1969.

18. Margoshes, M., "A Spectrograph/Spectrometer System for Use with the Laser Probe," Pittsburgh Conference on Analytical Chemistry and Applied Spectroscopy, Cleveland, Ohio, March 4, 1969.

19. Margoshes, M., "Approach to Automation in Spectrochemical Measurement and Computation," Pittsburgh Conference on Analytical Chemistry and Applied Spectroscopy, Cleveland, Ohio, March 5, 1969.

20. Rasberry, S. D., "Computers in Spectroscopy: Introduction to Computer Usage," Society for Applied Spectroscopy, Clarksville, Md., March 11, 1969. 
21. Margoshes, M., "Computer Applications - Emission Spectrochemical Analysis," Professional Development Program, Society for Applied Spectroscopy, Clarksville, Md., May 20, 1969.

22. Heinrich, K. F. J., "Measurement Techniques Used and Problems Encountered in Certification of NBS Standard Reference Materials -- Microprobe," Symposium on an International Standard Reference Materials Program -Workshop, NBS, Gaithersburg, Md., May 22, 1969.

23. Weber, J. L., Jr., "Measurement Techniques Used and Problems Encountered in Certification of NBS Standard Reference Materials -- Complex Steels," Symposium on an International Standard Reference Materials Program -Workshop, NBS, Gaithersburg, Md., May 22, 1969.

24. Heinrich, K. F. J., "Electron and Ion Microprobe Analysis," loth Symposium on Electron, Ion, and Laser Beam Technology, NBS, Gaithersburg, Md., May 23, 1969.

25. Scribner, B. F., "New Types of Spectrometric Standard Reference Materials and Their Accurate Characterization," XV Colloquium Spectroscopicum Internationale, Madrid, Spain, May 27, 1969.

26. Alvarez, R., "The Determination of Trace Elements, Simultaneously and with High Precision by Isotope Dilution and Spark Source Mass Spectrometry," XV Colloquium Spectroscopicum Internationale, Madrid, Spain, May 29, 1969.

27. Margoshes, M., "Two Programs for Fitting Spectrochemical Analytical Curves on Digital Computers, XV Colloquium Spectroscopicum Internationale, Madrid, Spain, May 30 , 1969.

28. Margoshes, M., "Use of Computers in Spectrochemical Analysis," Chemistry Department, Imperial College of Science and Technology, London, England, June 6, 1969.

29. Heinrich, K. F. J., "Electron Probe Microanalysis," American Chemical Society, Analytical Chemistry Symposium, Athens, Ga., June 12, 1969. 
B. F. Scribner

Member, ASTM Committee E-2 on Emission Spectroscopy Member, ASTM Committee E-13 on Absorption Spectroscopy Chairman, Student Awards Committee, Eastern Analytical Symposium, 1969

Delegate to Governing Board, EAS, 1968

Titular member, Commission on Spectrochemical and Other Optical Methods of Analysis, International Union of Pure and Applied Chemistry

Member, Advisory Board, Spectrochimica Acta, Atomic Section

Member, International Advisory Board, XV Colloquium

Spectroscopicum Internationale, Madrid, 1969

Chairman, Nominating Committee, Society for Applied

Spectroscopy, 1968

Member, Committee on Honorary Members, SAS, 1969

Past-Chairman, Baltimore-Washington Section, SAS, 1968-69

Member, Nominating Committee, National Capital Section,

Optical Society of America, 1969

Member, Analytical Standards Committee, NBS Analytical

Chemistry Division

Member, Analytical Services Committee, NBS Analytical

Chemistry Division

M. Margoshes

Editor, Spectrochimica Acta, Atomic Section

Member, Publications Committee, Society for Applied Spectroscopy, 1968

Member, Professional Development Committee

Baltimore-Washington Section, SAS, 1968-69

K. F. J. Heinrich

President, Electron Probe Analysis Society of America, 1969

Assistant Editor, Mikrochimica Acta

Secretary, Organizing Committee, loth Symposium on

Electron, Ion, and Laser Beam Technology, NBS,

Gaithersburg, Md. 1969

A. J. Ahearn

Chairman, Subcommittee VII, ASTM Committee E-14 on Mass Spectrometry and Allied Subjects

Co-Chairman, Workshop on Spark Source Mass Spectrometry,

NBS, Nov. 1968 
Member, Subcommittee VII, ASTM Committee E-14 on Mass Spectrometry and Allied Subjects

Co-Chairman, Workshop on Spark Source Mass Spectrometry, NBS, Nov. 1968

\section{R. Alvarez}

Member, ASTM Committee E-2 on Emission Spectroscopy

J. L. Weber, Jr.

Member, ASTM Committee E-2 on Emission Spectroscopy, Subcommittees IV, VII, and IX

Member, ASTM Committee B-7 on Light Metals and Alloys, Cast and Wrought

Secretary, Baltimore-Washington Section, SAS, 1969-70

S. D. Rasberry

Member, Laser Task Group, ASTM Committee E-2

Technical Coordinator, Spring Session, SAS, BaltimoreWashington Section, Professional Development Program for Scientists: Computers in Spectroscopy 


\section{ACKNOWLEDGMENTS}

The operations of our laboratory have been assisted by persons in other groups and by the supporting services of NBS including library, plant, and shops; we gratefully acknowledge our dependence on these services. Some individuals who were especially helpful are named below.

Dr. Robert J. Arms and Clayton L. Albright of the Computer Services Division have provided very useful advice on computer programming problems.

Mr. Louis Marzetta and others of the Electronic Instrumentation group contributed valued assistance on electronics problems .

Mr. Harvey Yakowitz of the Metallurgy Division continued his close collaboration with our microprobe group which has resulted in several papers co-authored with members of our group.

Dr. Jean Hénoc, guest worker, and Mr. Barry Hammond, research associate, contributed much to the efforts in quantitative electron probe microanalysis. These cooperative programs with outside agencies supporting good research men have proved highly successful in our laboratory.

Mrs. Rosemary Maddock and her group have continued most helpful assistance to us in the area of publications including the planning and preparation of illustrations and slides.

Miss Karen Loraski, our Section Secretary, has provided invaluable assistance to members of the section in a variety of activities, including typing of complex manuscripts and reports. 
[1] Scribner, B. F., ed., "Spectrochemical Analysis:

Optical Spectrometry, X-Ray Fluorescence Spectrometry, and Electron Probe Microanalysis Techniques, July 1964 to June 1965," NBS Technical Note 272, Oct., 1965 .

[2] Scribner, B. F., ed., "Activities of the NBS Spectrochemical Analysis Section, July 1965 through June 1966," NBS Technical Note 401, Sept., 1966.

[3] Scribner, B. F., ed., "Activities of the NBS Spectrochemical Analysis Section, July 1966 through June 1967," NBS Technical Note 422, Jan. 1968.

[4] Scribner, B. F., ed., "Spectrochemical Analysis Section: Summary of Activities July 1967 to June 1968," NBS Technical Note 452, Sept., 1968.

[5] Svoboda, V., Appl. Spectry. 20, 219 (1966).

[6] Piepmeier, E. H., and Malmstadt, H. V., Anal. Chem. 4l, 700 (1969).

[7] Nachtrieb, N. H., "Principles and Practice of Spectrochemical Analysis," McGraw-Hill, New York, 1950, p. 272 .

[8] Rasberry, S. D., Margoshes, M., and Scribner, B. F., "Applications of a Time-Sharing Computer in a Spectrochemistry Laboratory: Optical Emission and $\mathrm{X}$-ray Fluorescence," NBS Technical Note 407, Feb., 1968 .

[9] Margoshes, M., and Rasberry, S. D., Spectrochim. 'Acta 24B, in press.

[10] Margoshes, M., and Rasberry, S. D., Ana . Chem., in press.

[11] LeRoy, J.R., Annu. ISA (Instrum. Soc. Amer.) Conf. Proc. 21 (3), 6.1-1-66 9 pp. (1966).

[12] Margoshes, M., "Approach to Automation in Spectrochemical Measurement and Computation," Paper No. 172, Pittsburgh Conference on Analytical Chemistry and Applied Spectroscopy, Cleveland, Ohio, March 5, 1969. 
[13] Gloersen, P., J. Opt. Soc. Amer. 48, 712 (1958).

[14] Anderson, J. E., Rev. Sci. Instrum. 37, 1214 (1966).

[15] Galan, L. de, Anal. Chim. Acta 34, 2 (1966).

[16] Aslund, N. R. D., and Cronhjort, B. T., IBM F. Res. Devel. 1 , 160 (1964).

[17] Eick, J. D., Caul, H. J., Smith, D. L., and Rasberry, S. D., Appl. Spectry. 21, 324 (1967).

[18] Deragin, B. V., Churaev, N. V., Fedyakin, N. N., Talaev, M. V., and Ershova, I. G., Izv. Akad. Nauk SSSR, Ser. Khim. 2178 (1967); English translation, Bull. Acad. Sci. USSR, Div. Chem. Sci. 2095 (1967).

[19] Lippincott, E. R., Stromberg, R. R., Grant, W. H., and Cessac, G. L., Science 164, 1482-7 (1969).

[20] Heinrich, K. F. J., Advances in X-ray Analysis, Vol. II, 1968, p. 40, Plenum Press, N. Y.

[21] Hénoc, J., Quantitative Electron Probe Microanalysis, NBS Spec. Publ. 298, p. 197 (1968).

[22] Heinrich, K. F. J., The Electron Microprobe, J. Wiley, N. Y., 1966, p. $2 \overline{96}$.

[23] Yakowitz, H., and Heinrich, K. F. J., J. Res. NBS 73A, No. 2, 113-23 (1969).

[24] Rasberry, S. D., Caul, H. J., and Yezer, A., Spectrochim. Acta 23B, No. 5, 345-51 (1968).

[25] Franzen, J., and Schuy, K. D., Z. Anal. Chem. 222, 295 (1967).

[26] Cavard, A., "Improvements in Ion Detection by Photographic Development Process," in Advances in Mass Spectrometry Vol. 4, London, Institute of Petroleum, $1968, \mathrm{pp} \cdot 419-20$. 


\section{Standard Reference Material 682 High-Purity Zinc ${ }^{1}$}

This standard of very high-purity zinc metal is issued as a special research material to further both chemical and physical methods of characterization. Two other zinc metal standards of a lesser degree of purity are also available: SRM 683 in the form of semicircular bar segments and SRM 728 in shot form. The same starting material was used for all three standards; however, this high-purity zinc material was further purified by vapor distillation, zone-refining, and degasification.

$\begin{array}{lccc}\text { Element } & \begin{array}{c}\text { Recommended } \\ \text { Value } \\ (\text { ppm by wt. })\end{array} & \begin{array}{c}\text { Range of Values } \\ \text { Reported }^{3} \\ \left(\mathrm{ppm}^{2} \text { by wt. }\right.\end{array} & \begin{array}{c}\text { Method of } \\ \text { Analysis }\end{array} \\ \text { Copper } & 0.042 & (0.038-0.050) & \text { AAS., SPPH } \\ \text { Cadmium } & (0.1)^{5} & --- & \text { SSMS-ID } \\ \text { Iron } & (0.1) & --- & \text { SSMS-ID } \\ \text { Silver } & (0.02) & --- & \text { SSMS - ID } \\ \text { Tin } & (0.02) & --- & \text { SSMS - ID }\end{array}$

1. The material is in the form of semicircular bar segments about $21 / 4$ inches in diameter 1 inch deep at mid-diameter, and $3 / 4$ inch long.

2. In the course of analyses by spark-source mass spectroscopy and by neutronzctivafon othatefents were detected as being present. These are listed below with an estimated conservative upper lin it of forregtration; all values are given in parts per million by weight:
$\mathrm{Al}<0.03$
$\mathrm{B}<.01$
$\mathrm{Ca}<.2$
$\mathrm{Be}<.03$
$\mathrm{Cl}<.5$
Cr $<0.06$
$\mathrm{F}<.03$
$\mathrm{K} \approx 1$

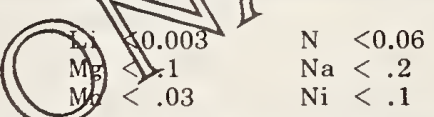

O $<0.5$

$\mathrm{Si}<5$

$\mathrm{Ti}<.2$

Spark-source mass spectrographic results om som sample dizes of 20 to $50 \mathrm{mg}$ showed definite evidence of gross inhomogeneity for the elements $\mathrm{Bi}, \mathrm{Pb}$, an $\mathrm{Tl}$. This wa. partially confirmed for $\mathrm{Pb}$ as determined by isotopic dilution techniques and polarography using $K$ sam les, bick both showed $\mathrm{Pb}$ heterogeneity to a much lesser degree. Residual resisitivity ratio measurements a do the $15 \mathrm{~g}$ samples also indicated some limited variability for the electrically active elements sych as $\mathrm{Ai}$, PD Jand Tl; however, the minimum ratio of $33,000\left(\mathrm{R}_{273 \mathrm{~K}} / \mathrm{R}_{4 \mathrm{~K}}\right)$ would be inconsistent with any geppof the thre dements exceeding $0.1 \mathrm{ppm}$ (by weight) on a $10-15 \mathrm{~g}$ sample size.

No other elemerts te totested, with most elements having an estimated limit of detection by spark source mass spectrographic andffses of 0.01-0.05 ppm. Direct interference by Zn on S precluded any reasonable estimate for this element. Slight inferference also occurred for $\mathrm{Ba}, \mathrm{Cs}, \mathrm{Hg}$, and $\mathrm{Pt}$, but each was not detected at about the 0.2 to $1 \mathrm{ppm}$ level.

By neutron activation analysis ${ }^{4}$, the elements $\mathrm{As}, \mathrm{Ga}, \mathrm{Sc}$, and W were not detected at about the $0.005 \mathrm{ppm}$ level and $\mathrm{Au}$ was not detected at about the $0.02 \mathrm{ppb}$ level.

3. The range of values reported is that of the eight individual determinations made by the two analytical methods used. The recommended value is based on considerations of the estimated systematic bias of each of the methods. Six of the eight values reported were in the range from 0.040 to $0.044 \mathrm{ppm}$.

4. AAS - Atomic Absorption Spectrometry (T. C. Rains)

SPPH - Spectrophotometry (R. W. Burke)

SSMS-ID - Spark-Source Mass Spectrometry - Isotope Dilution (R. Alvarez and P. Paulsen)

NAA - Neutron Activation Analysis (B. A. Thompson and D. A. Becker)

5. Values in parentheses are not certified for accuracy since only one method of analysis was used, but are provided for additional information on the composition.

Washington, D. C. 20234

July 9,1968
W. Wayne Meinke, Chief

Office of Standard Reference Materials 
This standard is intended as research material which should be of interest to the chemist, physicist, and materials engineer. Its very high purity makes it ideal as a starting material for the preparation of phosphors and as a solid-state matrix, where a knowledge of the purity of the material is important It will also meet the urgent needs of analysts working at trace level concentrations of elements in high-purity zinc. The material should serve for the development of new or improved methods and techniques in extending the sensitivity of detection in the determination of tace constituents by chemical, optical emission and spark source mass spectrochemical, activation, and resistivity methods. The material was prepared by Cominco American, Inc. from a special lot of high-grade electrolytic zinc which was further punifed by vacuum distillation, zone-refining, and degasification. Each bar was etched, dried, and sealed in a polyethylene pouch to minimize contamination.

Homogeneity testing was performed by VPS Washington and NDS Boulder with samples selected for the testing carefilly chosen to represent the extreme variations that might be expected as a result of the preparation procedures. Although the spark-source mass scectegraphic results indicated gross inhomogeneity for lead, thallium, and bismuth, the residual resistivity measurements incicate that this segregation should be minimized provider the sample size is increased to ten grams or more and is representative of the full cross section. Activation results revealed some relatively minor inhomogeneity for sodium and antimony. Residual resistivity ratio $\left(R_{273 \mathrm{~K}} / \mathrm{R}_{4} \mathrm{~K}\right)$ results varied from 33,000 to $32,000$.

The technical and support aspects involver in the preparation, certification, and issuance of this Standard Reference Material were coordinater through the Office of Standard Reference Materials by R. E. Michaelis.

\section{CAUTION}

Beiore use, it is resommender that posible murace contamination be removed hy placing the sample in high-purity dilute nitric acid for about one minute, followed by rinsing in Gistiller water. 
U. S. Departnente Commerce

\section{Standard Reference Material 683} Zinc Metal ${ }^{1}$

This standard of zinc metal is issued as a special research material to further both chemical and physical methods of characterization. Two other zinc metal standards are also available: SRM 682, High-Purity Zinc, and SRM 782, Intermediate-Purity Zinc. All three standards were prepared from the same starting material.

\begin{tabular}{|c|c|c|c|c|}
\hline Element $^{2}$ & $\begin{array}{l}\text { Recommended } \\
\text { Value } \\
\text { (ppm by wt.) }\end{array}$ & \multicolumn{2}{|c|}{$\begin{array}{c}\text { Range of Values } \\
\text { Reported }^{3} \\
\text { (ppm by wt.) }\end{array}$} & $\begin{array}{l}\text { Method of } \\
\text { Analysis }\end{array}$ \\
\hline Lead & 11.1 & $(9.6$ & $-11.3)$ & SSMS - ID, POL \\
\hline Copper & 5.9 & $(5.3$ & $-6.1)$ & SSMS - ID, POL \\
\hline Iron & 2.2 & $(1.7$ & $-3.1)$ & POL, SPPH \\
\hline Silver & 1.3 & $(1.0$ & $-1.4)$ & SSMS - ID, NAA \\
\hline Cadmium & 1.1 & $(1.0$ & $-1.2)$ & SSMS - ID, POL \\
\hline Thallium & $(0.2)^{5}$ & $(0.17$ & $-0.18)$ & - ID \\
\hline Tin & $(0.02)$ & $(0.0$ & - & SSMS - ID \\
\hline
\end{tabular}

1. The zinc is in the form of semicircular bar segments about $21 / 4$ frches in diameter, 1 inch deep at mid-diameter, and $3 / 4$ inch long.

2. In the course of analysis by neutron activation, addifonal elaments were sought. The following elements were not detected and are reported with an estimated upper innit or ogncentration in parts per million by weight:

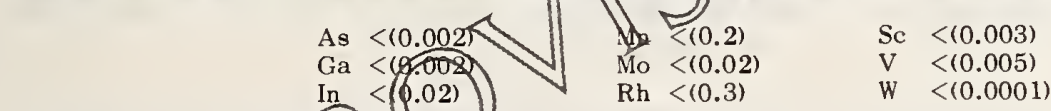

Potassium was not defected bo fithentame emission spectroscopy or by neutron activation at the $0.2 \mathrm{ppm}$ level.

Aluminum, antimony and sdium were detected by several techniques. The results were variable, but in no case are these elements present da greater concentration than $3 \mathrm{ppm}$. Gold appears to be $<0.02 \mathrm{ppm}$.

3. The range of values reported is the extreme variation of the individual results reported by the methods of analysis used. The recommended value is based on considerations of the estimated systematic bias of each of the methods employed. From 7 to 13 individual determinations were made for each element certified.

4. SSMS-ID - Spark-Source Mass Spectrometry - Isotopic Dilution (R. Alvarez and P. Paulsen)

POL - Polarography (E. J. Maienthal)

SPPH $\quad-$ Spectrophotometry (E. R. Deardorf)

NAA - Neutron Activation Analysis (B. A. Thompson and D. A. Becker)

5. Values in parentheses are not certified since only one method of analysis was used, but are provided for additional information on the composition.

Washington, D. C. 20234

July 9,1968
W. Wayne Meinke, Chief

Office of Standard Reference Materials 
This standard has been established to provide a homogeneous reference material for the analysis of pure zinc and analogous metals. It should also serve a useful function for the physicist and materials engineer involved in the preparation and characterization of phosphors and other solid-state compounds, where a knowledge of the purity of the starting material is important. The material was prepared by Cominco American, Inc. from a special lot of high-grade electrolytic zinc which was homogenized and cast in the form of semicircular bars. Each bar was etched, dried, and sealed in a polyethylene pouch to minimize contamination.

Extensive homogeneity testing was performed by NBS Washington and Boulder and the material was found to be satisfactory for the elements certified. The samples selected for testing were carefully chosen to represent the extreme variations that might be expected as a result of the preparation procedures. However, practical limitations precluded the testing of the number of samples from each bar that would have been required to guarantee absolute limits of homogeneity. Therefore, some inhomogeneity in the untested material is possible but not probable. The testing was performed using combinations of the following methods: optical emission and sparksource mass spectrographic analysis, polarographic analysis, flame emission and atomic absorption analysis, neutron activation analysis, and electrical measurements for residual resistivity ratios.

Although the spark-source mass spectrographic measurements indicated homogeneity with respect to microsamples, it is recommended that samples as large as possible be utilized, preferably representative of the full cross-section.

The technical and support aspects involved in the preparation, certification, and issuance of this Standard Reference Material were coordinated through the Office of Standard Reference Materials by R. E. Michaelis.

\section{CAUTION}

Before use, it is recommended that possible surface contamination be removed by placing the sample in dilute high-purity nitric acid for about one minute, followed by rinsing in distilled water. 


\section{Standard Reference Material 685 High-Purity Gold}

This standard is provided as a reference source of gold of high purity. It is issued in two forms, wire and rod.l The wire form is intended for applications such as spark-source mass spectrometry where the low level of impurities in the standard should make it useful for evaluating instrument and system blanks. The rod form is intended for use in other methods of characterization and in other scientific applications.

\section{INFORMATION ON THE COMPOSITION}

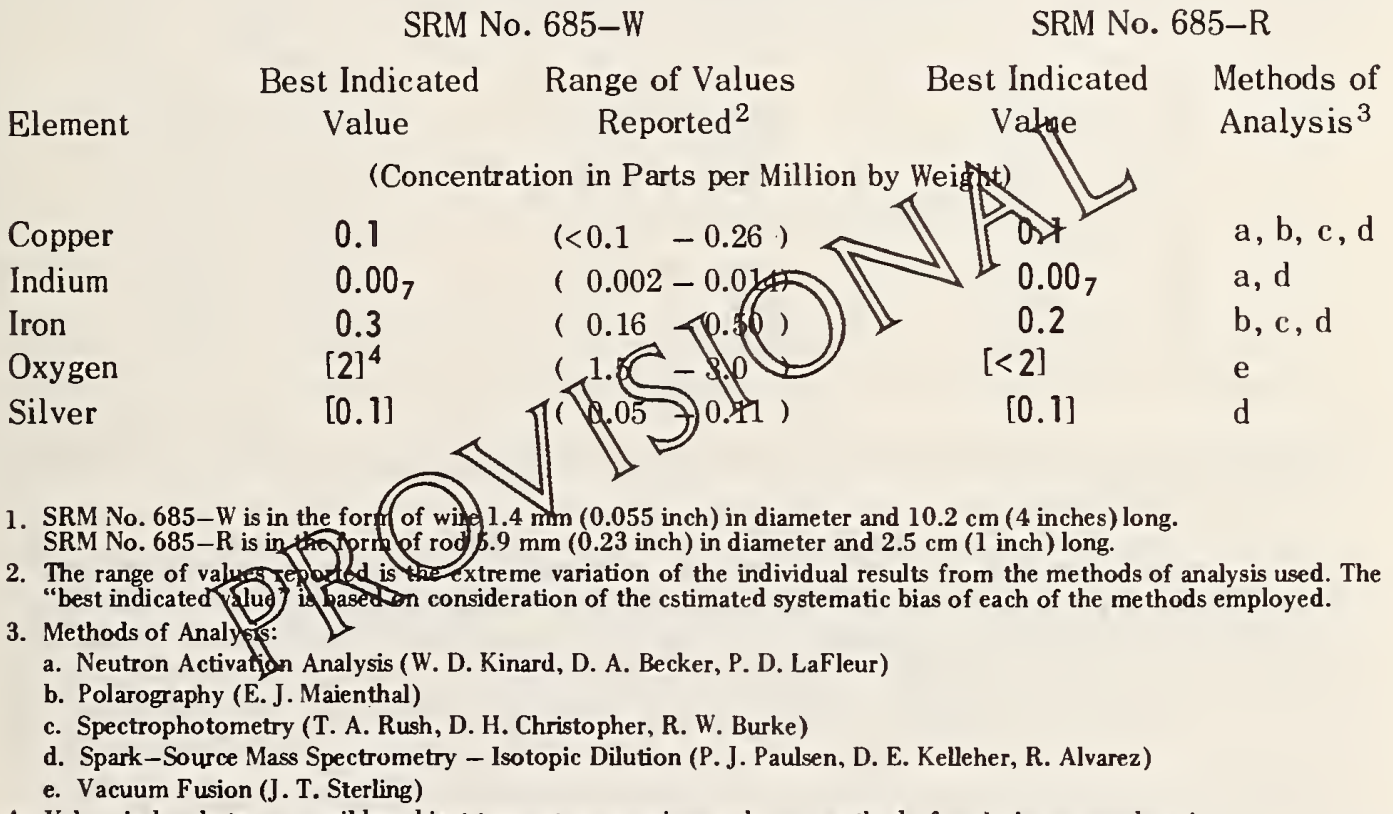

4. Values in brackets are possibly subject to greater error since only one method of analysis was employed.

The overall direction and coordination of the technical measurements leading to certification were performed under the chairmanship of B. F. Scribner.

The technical and support aspects involved in the preparation, certification and issuance of these Standard Reference Materials were coordinated through the Office of Standard Reference Materials by R. E. Michaelis.

Washington, D. C. 20234

September 26, 1968
W. Wayne Meinke, Chief

Office of Standard Reference Materials 
This standard has been established to provide a homogeneous reference material of high-purity gold primarily for application in spark-source mass spectrometry. It should also be of interest to the chemist, physicist, and materials engineer since gold has numerous scientific and industrial applications, especially in the electronics industry. The material should serve for the development of new or improved methods and techniques in extending the sensitivity of detection in the determination of trace constituents by chemical, optical emission, spark-source spectrochemical, activation, and resistivity methods. The material was prepared by Cominco American, Inc. from a special lot of highly purified gold which was homogenized and processed into the wire and rod forms.

In the course of analysis by spark-source mass spectrometry (P. J. Paulsen, D. E. Kelleher), other elements were found to be present. These are listed below with an estimated upper limit of concentration in parts per million by weight. Because of possible contamination at these extremely low levels of concentration, some of the elements listed may not arise from the gold itself. The concentrations were estimated from relative sensitivity coefficients computed by assigning all elements the same atomic sensitivity as gold and correcting for the variation of photographic plate sensitivity with mass.

$\begin{array}{ll}\mathrm{Al} & <0.3 \\ \mathrm{Ba} & <.03 \\ \mathrm{C} & <.1 \\ \mathrm{Ca} & <1 \quad \text { (est } 0.1) \\ \mathrm{Cl} & <0.1 \\ \mathrm{Cr} & <.05 \\ \mathrm{~F} & <.02\end{array}$

\begin{tabular}{|c|c|}
\hline K & $<0.2$ \\
\hline $\mathrm{Mg}$ & $<.2$ \\
\hline $\mathrm{Mn}$ & $<.01$ \\
\hline $\mathrm{N}$ & $<.03$ \\
\hline $\mathrm{Na}$ & $<.2$ \\
\hline $\mathrm{Nb}$ & $<.1$ \\
\hline $\mathrm{Ni}$ & $<.05$ \\
\hline
\end{tabular}

$\begin{array}{ll}\mathrm{S} & <0.07 \\ \mathrm{Sc} & <.01 \\ \mathrm{Si} & <.3 \\ \mathrm{Sn} & <.07 \\ \mathrm{Sr} & <.03 \\ \mathrm{~V} & <.05 \\ \mathrm{Zn} & <.04\end{array}$

No other elements were detected with most having estimated limits of detection in the range of 0.01 to $0.05 \mathrm{ppm}$.

Extensive homogeneity testing was performed at the NBS laboratories in Gaithersburg, Md., and in Boulder, Colo., and the material was found to be satisfactory within the limits of precision of the analytical methods used. The samples selected for testing were chosen to represent the extreme variations that might be expected as a result of the preparation procedures. However, practical limitations precluded testing the number of samples of the wire and rod material that would have been required to guarantee absolute limits of homogeneity. The testing was performed by using combinations of the methods of analysis indicated under footnote 3 (see over), but also including optical emission spectrochemical analysis (R.Alvarez), and electrical measurements for residual resistivity ratios (J. C. Moulder, V. A. Deason, R. L. Powell).

\section{CAUTION}

Before use, it is recommended that possible surface contamination be removed by placing the sample in warm aqua regia $\left(3 \mathrm{HCl}+1 \mathrm{HNO}_{3}\right)$ for approximately five minutes, and then followed by rinsing in distilled water. 


\section{Uertificate af Analyzis}

\section{Standard Reference Material 481 Gold-Silver Wires for Microprobe Analysis}

These standard reference materials are designed for use in quantitative clemental microprobe analysis. Although the selection of this particular system was circumscribed by the requircments of standard reference materials for electron probe microanalysis, the materials will be equally useful for other micro techniques. Accurate chemical characterization and the achievement of homogeneity on a microscopic scale was given special emphasis.

\begin{tabular}{|c|c|c|c|c|c|c|c|c|c|}
\hline \multirow[t]{3}{*}{$\begin{array}{l}\text { SRM } 481 \\
\text { wire }\end{array}$} & \multirow[t]{3}{*}{$\begin{array}{l}\text { Color } \\
\text { code }\end{array}$} & \multirow[t]{3}{*}{$\begin{array}{l}\text { Nominal } \\
\text { comp }\end{array}$} & \multirow{2}{*}{$\begin{array}{r}\text { Cominco } \\
\text { American }^{\mathrm{a}} \\
\mathrm{Au}\end{array}$} & \multicolumn{2}{|c|}{$\begin{array}{l}\text { U.S. Bureau } \\
\text { of the Mint }\end{array}$} & \multicolumn{2}{|c|}{$\mathrm{NBS}^{\mathrm{c}}$} & \multicolumn{2}{|c|}{$\begin{array}{l}\text { Average } \\
\text { Value }^{d}\end{array}$} \\
\hline & & & & $\mathrm{Au}$ & $\mathrm{Ag}$ & $\mathrm{Au}$ & $\mathrm{Ag}$ & $\mathrm{Au}$ & $\mathrm{Ag}$ \\
\hline & & & \multicolumn{3}{|c|}{ Percent by weight } & & & & \\
\hline A & Gold & Au 100 & --- & --- & --- & --- & --- & $100.0_{0}$ & --- \\
\hline B & Gray & $\mathrm{Au} 80-\mathrm{Ag} 20$ & 80.00 & 80.02 & 20.00 & 80.13 & 19.93 & $80.0_{5}$ & $19.9_{6}$ \\
\hline $\mathrm{C}$ & Yellow & Au60-Ag40 & 60.01 & 60.11 & 39.85 & 60.04 & 39.98 & $60.0_{5}$ & $39.9_{2}$ \\
\hline D & Blue & Au40-Ag60 & 39.99 & 40.03 & 59.90 & 40.06 & 59.96 & $40.0_{3}$ & $59.9_{3}$ \\
\hline $\mathrm{E}$ & Red & Au20-Ag80 & 22.42 & 22.42 & 77.59 & 22.46 & 77.56 & $22.4_{3}$ & $77.5_{8}$ \\
\hline $\mathrm{F}$ & Silver & Ag100 & --- & --- & --- & --- & --- & --- & $100.0_{0}$ \\
\hline
\end{tabular}

a The fire assay method was employed for the determination of Au by Cominco American.

b At the U.S. Bureau of the Mint, Au was determined by fire assay and Ag was determined by titration as AgCl.

c At NBS, Au was determined from the residue after treatment of the alloys with $\mathrm{HNO}_{3}$. The $\mathrm{Au}$ residue was dissolved in aqua regia, filtered, the $\mathrm{Au}$ precipitated by sulfurous acid, and weighed. $\mathrm{Ag}$ was determined gravimetrically as $\mathrm{AgCl}$ in all four alloys, and also coulometrically in the 80 percent $\mathrm{Ag}$ alloy.

d The results of individual laboratories agree within a range of \pm 0.1 percent absolute from the average values. The agreement between results by the different inethods and analysts, and the summation of results close to 100 percent for each binary alloy, indicate that the averages are frce from significant bias.

The set of standard reference materials, SRM 481, consists of six wires each having a diameter of approximately $0.5 \mathrm{~mm}$ and a length of approximately $5 \mathrm{~cm}$. For identification, the four alloy wires were covered with an easily removable colored coating.

The overall direction and coordination of tcchnical measurements leading to certification were performed under the chairmanship of B. F. Scribner.

The technical and support aspccts involved in the preparation, certification, and issuance of these standards were coordinated through the Office of Standard Rcference Materials by R. E. Michaelis.

Washington, D. C. 20234

February 14, 1969
W. Wayne Meinke, Chief

(over) Office of Standard Refcrence Matcrials 
Preparation and Purity: The standards were prepared by Cominco American Inc. in the form of wircs approximately $\mathbf{1 5 0}$ meters long. The end members of the series, as well as the starting materials for the alloys, were of the highest purity grade and precautions werc taken to minimize contamination. Two of the alloy standards were heat-treated at NBS to improve inicrohomogencity. The pure metal standards were examined by the residual resistivity ratio technique and the total of electrically active impurities in each was cstimated to be about 0.001 percent. The gold-silver wires were examined spectrographically for metallic impurities; no significant impurities were found at detection limits ranging from 0.0001 to 0.010 percent.

LONGITUDINAL HOMOgENEITY: Variation in composition along the full length of each alloy wire was investigated by electron probe microanalysis for areas $25 \mu \mathrm{m}$ diameter on cross sections at three to five positions along the wire including the two ends. The observed differences in composition for the positions, expressed as the range between the highest and lowest values for cach alloy, wcre as follows:

Nominal Composition

Observed rangea
Au80

$0.3 \%$
Au60

$0.6 \%$
$\mathrm{Au} 40$

$0.3 \%$
$\mathrm{Au} 20$

$0.5 \%$

Homogeneity along the wires was also tested by measurement of the residual resistivity ratio. These measurements indicated that the variation (macroscopic) of composition along all standard wires was less than 0.1 percent absolute. Further information on longitudinal homogeneity of the wires was obtained by determinations of Au at the extreme ends of the alloy wires by the Bureau of the Mint; the data also indicate that the extreme variation along the wires is less than 0.1 percent absolute.

Transverse And Micro Homogeneity: Variation in composition within the above mentioncd cross sections of the wires was investigated by electron probc microanalysis. For each cross section, ineasurements werc made along two diagonals at right angles. On each diagonal, determinations were made at 25 points, $1 \mu \mathrm{m}$ or less in diameter, starting and ending at approximately $25 \mu \mathrm{m}$ from the edge. For each alloy, the element which could be determined with the better precision was used in the evaluation. The variation was calculated in terms of the standard deviation for an individual detcrmination for each traverse. In the table below, the variation is presented as the range between the lowest and highest observed standard deviations for the six to eight traverses pcrformed on each alloy.

Nominal Composition

Au80

Au60

$\mathrm{Au} 40$

A 420
Element Determined

$\mathrm{Ag}$

$\mathrm{Au}$

$\mathrm{Au}$

$\mathrm{Au}$
Range of Standard

Deviation for Traverses ${ }^{a}$

$$
\begin{gathered}
0.08-0.11 \% \\
.08-.16 \\
.08-.13 \\
.12-.37
\end{gathered}
$$


The homogeneity on a microscopic scale was further investigated by performing quantitative measurements in two arrays of $10 \times 10$ points $(1 \mu \mathrm{m}$ diameter $)$ on each of the cross sections. The distance between adjacent points was $3.5 \mu \mathrm{m}$. This was repeated on scveral cross sections so that 6 to 8 arrays were obtained on each alloy. For the element which could be measured with better precision, the range is given between the lowest and highest observed standard deviation for an individual determination for the 6 to 8 arrays for each alloy.

\section{Nominal Composition}

Au80
Au60
Au40
Au20

Element Evaluated

$\mathrm{Ag}$
$\mathrm{Au}$
$\mathrm{Au}$
$\mathrm{Au}$

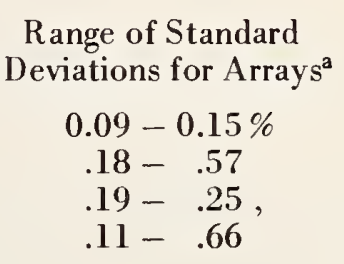

(Note: This range and the two ranges in the following tables are close to the precision of the method and should be considered upper limits of estimates of inhomogeneity.)

Extensive homogeneity studies were performed with the electron probe microanalyzer at NBS by M. A. Giles, R. L. Myklebust, C. E. Fiori, and K. F. J. Heinrich. Measurements of residual resistivity ratio were made at NBS, Boulder, Colorado, by $\mathrm{R}$. L. Rutter, J. G. Hust, and R. L. Powell. Heat treatment of the alloys at NBS was performed by G. E. Hicho and M. R. Meyerson. Spectrographic survey analyses were made at NBS by V.C. Stewart. Determinations of composition were made at Cominco American, Inc., Spokane, Washington, by T.A. Rice; at the U.S. Bureau of the Mint, Washington, D. C., by H. G. Hanson, Jr.; and at NBS by R. A. Durst, G. Marinenko; and C. E. Champion. 



\title{
C. Rumith \\ Secrotary

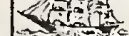 \\ National Bareata of Standards \\ A. V. Astin, Birector \\ Certifícate of Analysits Standard Reference Material 1051b Barium Cyclohexanebutyrate
}

\author{
(Standard for Determination of Barium in Petroleum Products)
}

This compound was prepared to insure material that is essentially free from other metals and has suitable solubility, compatibility, and uniformity for use in the preparation of a standard of barium in lubricating oils. The compound is certified to one part per hundred of barium, and every effort should be made to maintain a uniform procedure by following the directions in this certificate.

\section{CHEMICAL AND SPECTROGRAPHIC ANALYSES}

Barium, percent. . . . . . . . 28.7 \pm 0.1

The uncertainty shown represents the 95 percent confidence limit of the mean based on fifteen determinations and allows for the effects of possible sources of known error.

Barium was determined by wet-ashing a $0.5 \mathrm{~g}$ sample (dried for 72 hours over phosphorus pentoxide) and the resulting insoluble material removed by filtration, ignited at $900{ }^{\circ} \mathrm{C}$ and weighed as barium sulfate.

The compound was examined spectrographically for metallic impurities. A $5 \mathrm{mg}$ sample of the compound was excited in a direct-current arc and the photographed spectrum was examined for the characteristic lines of $5 \mathrm{l}$ elements. No significant impurities, other than strontium, were found.

The strontium content of this material was the only impurity element present that would interfere with the barium determination. Samples, $0.5 \mathrm{~g}$, were wet-ashed, diluted and analyzed by both flame-emission and atomic-absorption spectrometry. A strontium content of 0.05 percent was found. The barium determination given above has been corrected to account for this interference.

STABILITY.--Tests show that standard lubricating-oil solutions of this compound with concentrations of barium up to $500 \mathrm{ppm}$ are stable for several weeks when prepared by the directions given on the reverse of this certificate.

COMPATIBILITY.--Lubricating-oil solutions of this compound have been found to be compatible with lubricating-oil solutions of the other compounds in this series. Blends of several different compounds have been prepared by the procedures given in the certificates for the other compounds. (Tests have not been carried out to insure compatibility with the various additives that may be in the oils to be analyzed.)

The barium cyclohexanebutyrate was prepared by Distillation Products Industries of Rochester, N.Y. Chemical analysis was conducted by B. B. Bendigo, spectrochemical analysis by V. C. Stewart, and flame-emission and atomic-absorption analysis by T. C. Rains.

The overall direction and coordination of the technical measurements leading to certification were performed under the chairmanship of J. K. Taylor.

The technical and support aspects involved in the preparation, certification, and issuance of this Standard Reference Material were coordinated through the Office of Standard Reference Materials by T. W. Mears.

Washington, D. C. 20234

July 15, 1968
W. Wayne Meinke, Chief

Office of Standard Reference Materials

(over) 


\section{DIRECTIONS FOR PREPARING LUBRICATING-OIL SOLUTIONS OF BARIUM CYCLOHEXANEBUTYRATE}

Transfer approximately $0.2 \mathrm{~g}$ of this compound to a small beaker and dry at $110^{\circ} \mathrm{C}$ for 2 hours (alternatively, the sample may be dried over phosphorus pentoxide for 72 hours.) (Tightly close the bottle containing the remainder of the compound.) Quickly and accurately transfer $0.174 \mathrm{~g}$ of this dried salt to a weighed $200-\mathrm{ml}$ flask. (This weight of salt is equivalent to $50 \mathrm{mg}$ of barium.) Add $3 \mathrm{ml}$ of xylene and $5 \mathrm{ml}$ of 2-ethylhexanoic acid and heat the flask on a hot plate, with swirling and without charring, until a clear solution forms. Add to the hot solution 80 to $90 \mathrm{ml}$ of lubricating oil and gently shake the flask to mix the contents. Allow the flask to cool to room temperature and add enough lubricating oil to bring the total weight of the contents of the flask to $100 \pm 0.5 \mathrm{~g}$. Stopper the flask and shake gently to insure a homogeneous solution. The concentration of barium in this solution is $500 \mathrm{ppm}$. 
National Bureat of Standards

A. V. Astib. Director

\section{Certificate of Analysio \\ Standard Reference Materials 1159, 1160 Electronic and Magnetic Alloy Standards}

Element
Carbon
Manganese
Phosphorus
Sulfur
Silicon
Copper
Nickel
Chromium
Molybdenum
Cobalt
Iron

$\begin{array}{cc}\text { SRM 1159 } & \text { SRM } 1160 \\ \text { Percent } & \text { (by weight) } \\ 0.007 & 0.019 \\ .30_{5} & .55_{0} \\ .003 & .003 \\ .003 & .001 \\ & \\ .32 & .37 \\ .038 & .021 \\ 48.2 & 80.3 \\ 0.06 & 0.05\end{array}$

$.01_{0}$ .022

51.0

Samples are $1 \frac{1}{4}$ in $(3.1 \mathrm{~cm})$ in diameter and (1.9. ch) thick, and are issued in the annealed condition.

The provisional value listed for an the present best estimate of the true value based on the results of the cooreratizalical program. The provisional value is not expected to deviate from the true value by more than \pm 1 in the last significant figure reported; for subscript figurss, the deviation is not expected to be more than \pm 5 in the subscript figure.

The material for the standards was prepared in a vacuum induction furnace at The Carpenter Steef Compars Reading, Pennsylvania, and supplied to NBS in the final form following a schanfe of fabrication designed to produce material of the highest possible homogeneity.

Homogeneity testing was performed at NBS by D. M. Bouchette, S. D. Rasberry, and J. L. Weber, Jr., and was found to be satisfactory for the elements certified.

Cooperating with NBS in the analytical program were the following: Armco Steel Corporation, Research and Technology, Middletown, Ohio; Falconbridge Nickel Mines, Limited, Metallurgical Laboratories, Thornhill, Ontario, Canada; The Carpenter Steel Company, Metallurgical Department, Reading, Pennsylvania; and Westinghouse Electric Corporation, Research and Development Center, Pittsburgh, Pennsylvania.

The overall direction and coordination of the technical measurements leading to certification were performed under the chairmanship of B. F. Scribner.

The technical and support aspects involved in the preparation, certification, and issuance of these Standard Reference Materials were coordinated through the Office of Standard Reference Materials by R. E. Michaelis.

February 18, 1969

Washington, D.C. 20234
W. Wayne Meinke, Chief Office of Standard Reference Materials 



\section{Uertifirate}

\section{Standard Reference Material 1800 \\ Microstandard Ion-Exchange Beads \\ Calcium Loaded \\ $\left(10^{-11}\right.$ to $10^{-9}$ grams)}

This Standard Reference Material is intended as a source of minute, known quantities of calcium. The calcium is attached to ion-exchange beads that are 5 to 25 microns $(\mu \mathrm{m})$ in diameter. The matrix is composed of a homogeneously sulfonated network of a cross-linked copolymer of styrene with 8 mole percent $m$-divinylbenzene. The calcium is electrostatically attached to the sulfonate groups. The calcium ions can be displaced by addition of an aqueous electrolyte solution.

Any single bead contains an amount, $m$, of calcium, sulfur, carbon, hydrogen, oxygen (and some water) according to the equation: $m_{\mathrm{Ca}}=\rho_{\mathrm{Ca}} V$, where $V=$ $\pi d^{3} / 6$ is the volume of the bead, and $m_{\mathrm{Ca}}$ and $\rho_{\mathrm{Ca}}$ are the mass and partial density, respectively, for calcium. The partial density of calcium in a typical dry bead is certified as : $\rho_{\mathrm{Ca}}^{\circ}=0.135 . \pm 0.010 \mathrm{~g} / \mathrm{cm}^{3}$. The superscript $\left(^{\circ}\right)$ is used to denote reference to a dry resin bead. The value of $\rho^{\circ}$ and its error (standard deviation) is computed from neutron activation analysis and frem electron micro. probe analysis of forty individual beads. The microprobe metsurements also agree with the expected constancy in the calcium to sylfurnsatio.

Analysis of gross quantities of this material genstial densies of the subscripted matrix elements $\rho_{\mathrm{S}}^{\circ}=0.21_{5}, \rho_{\mathrm{C}}^{\circ} 0 . A_{0}^{\circ}=0.06$. The bulk density of the dry material ranges from 1.49 (minum) to 1.50 (maximum) $\mathrm{g} / \mathrm{cm}^{3}$.

The preceding measurements therer material after vacum drying at $120^{\circ} \mathrm{C}$ for 16 hours. If exes for to weeks or more to ordinary atmospheres with relative humidities range 20 to 40 percent, the partial densities will be reduced according to the amount of sorbed water. Then, the partial density of each of the elements bead must be adjusted by multiplying by the factor 0.87 . In the case of erlcium, the corrected partial density is: $\rho_{\mathrm{Ca}}(20-40 \% \mathrm{RH})$ $=0.117 \pm 0.09 \mathrm{~g} / \mathrm{cm}^{3}$.

Washington, D. C. 20234 March 17, 1969
W. Wayne Meinke, Chief

Office of Standard Reference Materials

CAUTION: Inadvertent contamination by water, i.e., condensation, is sufficient to cause the loss of calcium by ion exchange hydrolysis. It is therefore essential that this microstandard be kept at less than 50 percent relative humidity. 
Measurements leading to the certification of this Standard Reference Material were carried out by D. A. Becker, L. A. Currie, H. D. Dixon, R. A. Durst, K. F. J. Heinrich, E. C. Kuehner, R. L. Myklebust, R. A. Paulson, T. C. Rains, and G. Schmuckler of the Analytical Chemistry Division.

The overall direction and coordination of the preparation and technical measurements leading to the certification of this material were performed under the chairmanship of D. H. Freeman.

The technical and support aspects involved in the preparation, certification and issuance of this Standard Reference Material were coordinated through the Office of Standard Reference Materials by T. W. Mears.

\section{USE OF MICROSTANDARD}

The present microstandard was prepared by casting a dispersion of dry, calcium-form, ion-exchange beads onto a clean glass slide. The beads are naturally attracted to the glass surface. The same attraction occurs when the beads are touched gently with a probe, and this permits them to be moved from the slide to another place.

DIAMETER MEASUREMENT: Under microscopic examination it will be observed that the majority of the beads in this standard are spherical. The nonspherical beads are readily identified and rejected on the basis of their appearance. Bead diameter measurements are then practicable to an estimated total uncertainty of \pm 0.1 micron $(\mu \mathrm{m})$. Such measurements are not difficult, but they do require proper microscopic measuring apparatus and illumination technique (such as Köhler illumination with the use of an interference filter at $\approx 560-\mathrm{nm}$ ). These procedures are described in the literature (D. H. Freeman, "Advances in Ion Exchange," Volume 1, Marcel Dekker, Inc., New York, 1966, chapter 5).

STORAGE: The microstandard beads must be protected against exposure to excessively humid atmosphere and, for practical purposes, it should be assumed that the standard is destroyed if exposed to humidities exceeding 50 percent relative humidity. Storage over a mild desiccant is recommended. Alternatively, the beads may be vacuum dried at $120^{\circ} \mathrm{C}$ for approximately $16 \mathrm{hr}$ in order to duplicate the dry state to which the composition measurements refer. After drying, the beads can be kept in the dry state by storing them over fresh phosphorous pentoxide, or they can be immersed in a dry hydrocarbon fluid. There is some loss in accuracy (but a gain in convenience) by working in atmospheres of controlled humidity. For example, isopiestic equilibration will occur after approximately two to four weeks of storage over an aqueous calcium chloride solution in the range from 0.2 to 0.4 water activity (approximately 7.2 moles $\mathrm{CaCl}_{2}$ per $\mathrm{kg}$ of $\mathrm{H}_{2} \mathrm{O}$ for $30 \%$ relative humidity).

These standards can be used in a variety of ways. A single bead can be treated with electrolyte to release the ion-bound calcium. Or, a bead can be observed destructively as in the laser microprobe where the sample is vaporized and then analyzed by emission spectroscopy. Single beads can be viewed by an instrument such as the electron microprobe which is capable of identifying and measuring relative amounts of the calcium or sulfur atoms contained by the beads or by comparative samples. 


\section{PERIODICALS}

JOURNAL OF RESEARCH reports National Bureau of Standards research and development in physics, mathematics, chemistry, and engineering. Comprehensive scientific papers give complete details of the work, including laboratory data, experimental procedures, and theoretical and mathematical analyses. Illustrated with photographs, drawings, and charts.

Published in three sections, available separately:

\section{Physics and Chemistry}

Papers of interest primarily to scientists working in these fields. This section covers a broad range of physical and chemical research, with major emphasis on standards of physical measurement, fundamental constants, and properties of matter. Issued six times a year. Annual subscription: Domestic, $\$ 9.50$; foreign, $\$ 11.75^{*}$.

\section{Mathematical Sciences}

Studies and compilations designed mainly for the mathematician and theoretical physicist. Topics in mathematical statistics, theory of experiment design, numerical analysis, theoretical physics and chemistry, logical design and programming of computers and computer systems. Short numerical tables. Issued quarterly. Annual subscription: Domestic, $\$ 5.00$; foreign, $\$ 6.25^{*}$.

\section{Engineering and Instrumentation}

Reporting results of interest chiefly to the engineer and the applied scientist. This section includes many of the new developments in instrumentation resulting from the Bureau's work in physical measurement, data processing, and development of test methods. It will also cover some of the work in acoustics, applied mechanics, building research, and cryogenic engineering. Issued quarterly. Annual subscription: Domestic, $\$ 5.00$; foreign, $\$ 6.25^{*}$.

\section{TECHNICAL NEWS BULLETIN}

The best single source of information concerning the Bureau's research, developmental, cooperative and publication activities, this monthly publication is designed for the industry-oriented individual whose daily work involves intimate contact with science and technology-for engineers, chemists, physicists, research managers, product-development managers, and company executives. Annual subscription: Domestic, $\$ 3.00$; foreign, $\$ 4.00^{*}$.

\section{NONPERIODICALS}

Applied Mathematics Series. Mathematical tables, manuals, and studies.

Building Science Series. Research results, test methods, and performance criteria of building materials, components, systems, and structures.

Handbooks. Recommended codes of engineering and industrial practice (including safety codes) developed in cooperation with interested industries, professional organizations, and regulatory bodies.

Special Publications. Proceedings of NBS conferences, bibliographies, annual reports, wall charts, pamphlets, etc.

Monographs. Major contributions to the technical literature on various subjects related to the Bureau's scientific and technical activities.

National Standard Reference Data Series. NSRDS provides quantitive data on the physical and chemical properties of materials, compiled from the world's literature and critically evaluated.

Product Standards. Provide requirements for sizes, types, quality and methods for testing various industrial products. These standards are developed cooperatively with interested Government and industry groups and provide the basis for common understanding of product characteristics for both buyers and sellers. Their use is voluntary.

Technical Notes. This series consists of communications and reports (covering both other agency and NBS-sponsored work) of limited or transitory interest.

Federal Information Processing Standards Publications. This series is the official publication within the Federal Government for information on standards adopted and promulgated under the Public Law 89-306, and Bureau of the Budget Circular A-86 entitled, Standardization of Data Elements and Codes in Data Systems.

\section{CLEARINGHOUSE}

The Clearinghouse for Federal Scientific and Technical Information, operated by NBS, supplies unclassified information related to Government-generated science and technology in defense, space, atomic energy, and other national programs. For further information on Clearinghouse services, write:

Clearinghouse

U.S. Department of Commerce

Springfield, Virginia 22151

- Difference in price is due to extra cost of Loreign malling.

Order NBS publications from:

Superintendent of Documents

Government Printing Office

Washington, D.C. 20402 
U.S. DEPARTMENT OF COMMERCE

WASHINGTON, D.C. 20230

OFFICIAL BUSINESS 